\title{
Auditors' Use of Formal Advice from Internal Firm Subject Matter Experts: The Impact of Advice Quality and Advice Awareness on Auditors' Judgments
}

\author{
Nicole Staats Wright
}

Dissertation submitted to the faculty of the Virginia Polytechnic Institute and State University in partial fulfillment of the requirements for the degree of

\author{
Doctor of Philosophy \\ in \\ General Business, \\ Accounting
Sudip Bhattacharjee (Chair)
Roseanne J. Foti
J. Gregory Jenkins
Debra A. Salbador
June 18, 2014
Blacksburg, Virginia \\ Velina K. Popova
}

Keywords: Subject Matter Experts, Advice-taking, Awareness, Advice Quality, Audit Planning

Copyright 2014, Nicole Staats Wright 
Auditors' Use of Formal Advice from Internal Firm Subject Matter Experts: The Impact of Advice Quality and Advice Awareness on Auditors' Judgments

\title{
Nicole Staats Wright
}

\begin{abstract}
During an audit, if an audit team does not have sufficient knowledge when auditing a complex issue they often call upon subject matter experts to provide advice. While these experts are the knowledge experts in their area, the quality of the advice depends upon their ability to fully understand and incorporate client specific facts. PCAOB inspection reports suggest that audit teams are neglecting to perform the required work to assess the quality of experts' recommendations. Additionally, the decision to use subject matter experts can be made during planning or when a complex issue surfaces during the audit. As such, auditors may or may not be a priori aware that an expert's use is planned before auditing a complex issue. In this dissertation, I examine how receiving advice of different levels of quality in terms of whether it incorporated all relevant client facts (lower or higher), and a priori awareness of the use of a subject matter expert (aware or unaware), can impact auditors' use of the advice and the resulting effort and judgment accuracy. I conducted a computerized experiment where professional auditors read a case study and made an initial judgment around a complex issue, received advice, and then made a final judgment. Based on advice-taking literature, I predict and find support that auditors who are a priori unaware of the use of a subject matter expert will employ lower effort in understanding the client facts and thus be less discerning and more accepting of the advice received. Being a priori unaware and receiving low quality advice can lead to lower judgment accuracy than receiving high quality advice with a priori unawareness. Auditors who are a priori aware are expected to, and found to employ greater effort, thus reducing the accuracy differences between receiving high and low quality advice. These findings can help improve the professions'
\end{abstract}


understanding of auditors' advice taking behavior and the conditions under which expert advice is accepted without performing the required quality assessment. 


\section{DEDICATION}

This dissertation is dedicated to my husband, Matt, and my children, Oscar and Alaina. Without Matt's support, encouragement, and sense of humor I would not have been able to complete this endeavor. Having a partner who is willing to sacrifice so much for me to pursue my dreams is an amazing blessing. My children provided an excellent source of distraction and a feeling of confidence that I can handle pretty much anything life wants to throw at me. I love you all for taking this journey with me.

I would also like to thank my family for their love and support. To my parents, Anita and Michael, for always encouraging me to give my best and providing so much support. I would never have been able to focus on my work without knowing that my children were being lovingly cared for and that I always had a supportive shoulder to lean on from my mother. My father traveled far for numerous visits and was always up for a catch-up phone call, which provided me with insights and an excellent sounding board. I love both of you very much. To my brothers, Chris and Matt, thank you for encouraging me and for always inspiring me. Finally, to my grandmother, Marion, thank you for instilling in me a sense of personal drive and hard work. You amaze me everyday. I love you all. 


\section{ACKNOWLEDGEMENTS}

I would like to acknowledge and express my sincere gratitude to the members of my dissertation committee - Dr. Sudip Bhattacharjee, Dr. Roseanne Foti, Dr. J. Gregory Jenkins, Dr. Velina Popova, and Dr. Debra Salbador. Thank you for your guidance, support, patience, and enthusiasm throughout this process. This dissertation has benefited greatly from your feedback and encouragement. I would also like to thank Dr. Robert Brown for his generous assistance in finding participants for my study. I extend a special thank you to my chair, Sudip Bhattacharjee, for the countless hours spent mentoring and teaching me throughout the doctoral program.

Thank you to the Accounting and Information Systems Department for the financial and administrative support provided at each stage of the program. Thank you to Dr. Jack Maher and Dr. Bryan Cloyd for the training that prepared me to complete this endeavor. I would also like to express my appreciation to Kathy Caldwell, Phyllis Neece, and Arnita Perfater for their patient support during my four years in the doctoral program. I also acknowledge the financial support that was provided by generous donors through the Ernest J. Pavlock Scholarship in Accounting and Information Systems, Clifford A. Cutchins III Scholarship in Accounting and Information Systems, and the John E. Peterson, Jr. \& Mary Jane C. Peterson Ph.D. Fellowship.

I would like to thank each of my fellow Ph.D. students for their valuable feedback on this study and for making my time in Blacksburg more enjoyable. A special thanks to Gabe Saucedo for being a great friend, listener, and partner in crime. I am also grateful for the time spent with Alan Stancil, Joanna Garcia, and Kathy Enget in countless classes, seminars, and projects. I feel very fortunate to have gone through this journey with each of you. Additionally, I would like to acknowledge several other students who added to my experience in Blacksburg: Kerry Inger, Ryan Leece, Todd White, Owen Brown, Eric Negangard, Jon Pyzoha, Mike Ozlanski, Brandon 
Ater, Christine Gimbar, John Lauck, Joe Rakestraw, Anne-Marie Caporale, Mark Sheldon, and Ian Twardus. Finally, I would like to thank the auditors and firms who donated their time and talent to this project. 


\section{Table of Contents}

\section{CHAPTER 1}

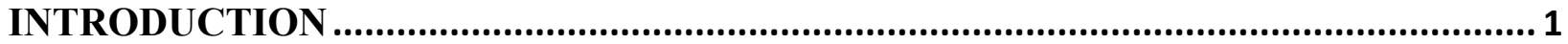

\section{CHAPTER 2}

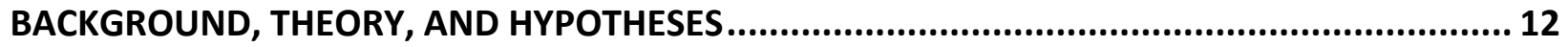

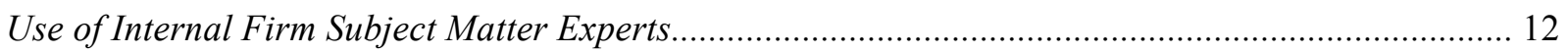

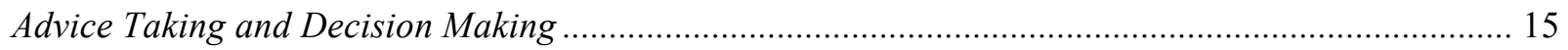

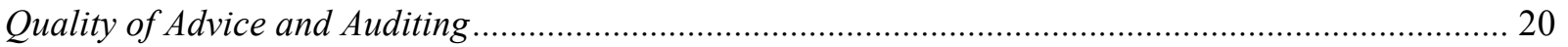

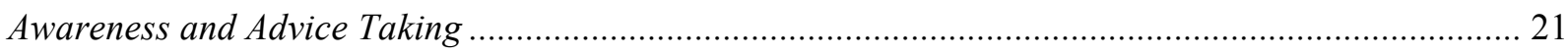

Quality of Advice and Awareness and the Impact on Audit Judgments........................................... 26

\section{CHAPTER 3}

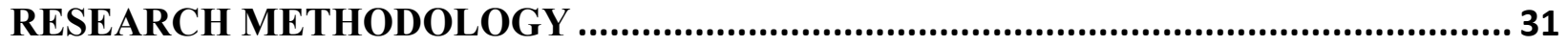

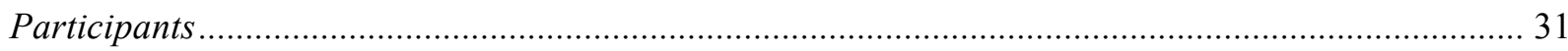

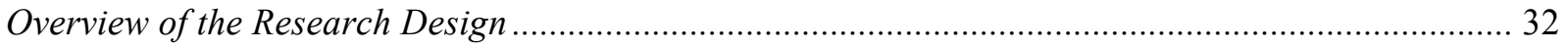

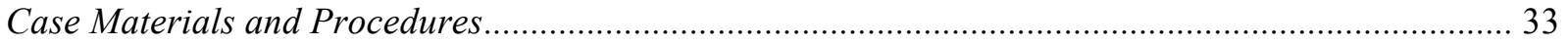

Post-experimental Questions, Manipulation Checks, and Demographics ....................................... 37

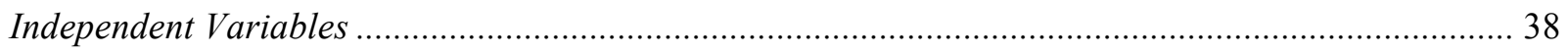

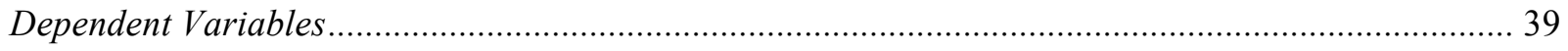

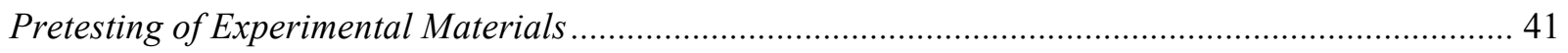

\section{CHAPTER 4}

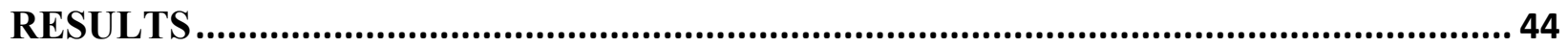

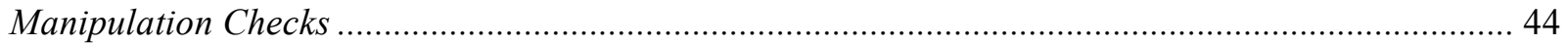

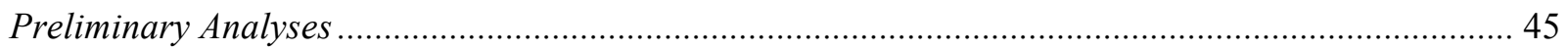

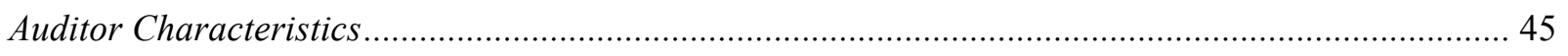

The Impact of Awareness on Auditor Pre-Advice Assessment....................................................... 48

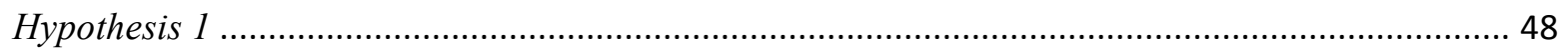

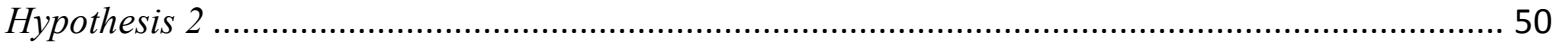

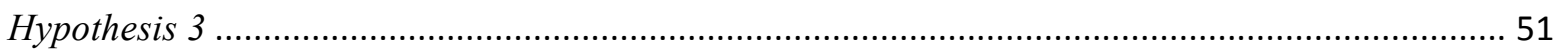

Summary of the Effect of Awareness on the Pre-Advice Assessment ............................................. 52

The Impact of Awareness and Advice Quality on Auditor Post-Advice Assessments .......................... 53

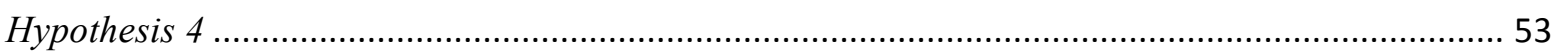

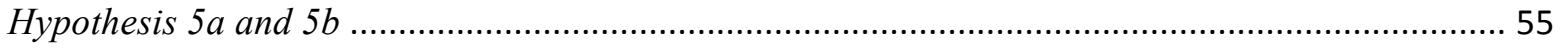

Summary of the Effect of Awareness and Advice Quality on the Post-Advice Assessment ............... 57

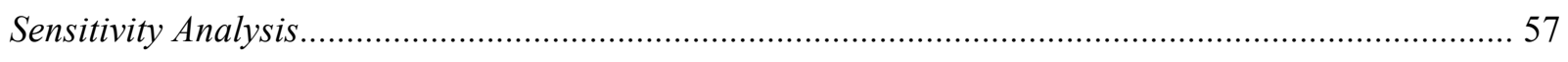

Exclusion of Auditors Who Failed the Manipulation Check Question ......................................... 58

Exclusion of Auditors Who Did Not Agree that Auditors at Their Rank Would Perform the Duties

Required in the Case ............................................................................................................... 59

\section{CHAPTER 5}


CONCLUSION, CONTRIBUTIONS, LIMITATIONS AND FUTURE RESEARCH........................... 61

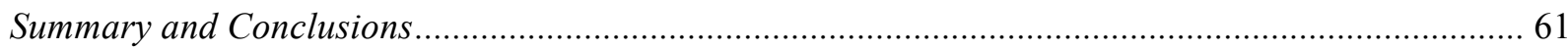

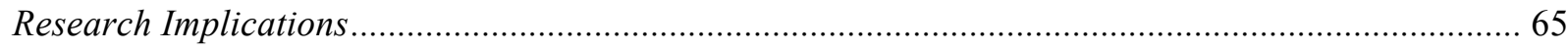

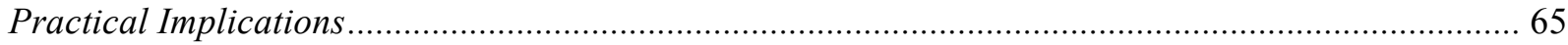

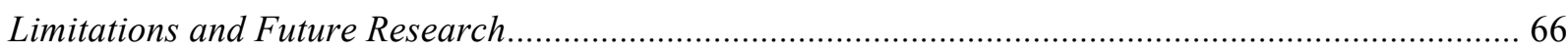

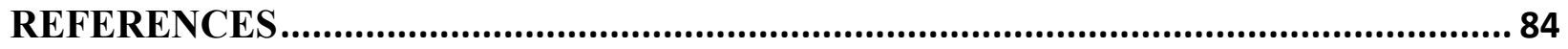

APPENDIX A - Advice Quality Manipulations ........................................................... 90

APPENDIX B - Sample Experimental Materials ....................................................... 98

APPENDIX C - IRB Approval Letter ....................................................................... 117 


\section{LIST OF FIGURES}

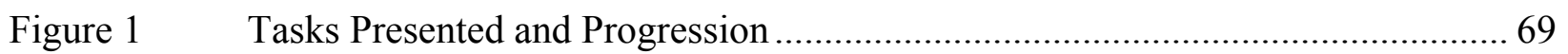

Figure 2 Predicted Effects of Awareness and Quality of Advice.................................... 70

Figure 3 Interaction Between Awareness and Advice Quality on Accuracy .................... 71 


\section{LIST OF TABLES}

Table 1 Descriptive Statistics of Post-Experimental Responses by Condition................ 73

Table 2 Results for Hypothesis 1 Descriptive Statistics and ANCOVA Results Impact of Awareness on Level of Effort - Time Spent on the Pre-Advice Task................. 74

Table 3 Results for Hypothesis 1 Descriptive Statistics and ANCOVA Results Impact of Awareness on Level of Effort - Time Spent on the Total Case ........................ 75

Table 4 Results for Hypothesis 2 Descriptive Statistics and ANCOVA Results Impact of Awareness on Confidence...................................................................... 76

Table 5 Pearson Correlation Matrix of Variables ....................................................... 77

Table 6 Results for Hypothesis 3 Descriptive Statistics and ANCOVA Results Impact of Awareness on Acceptance of Management's Position ..................................... 79

Table 7 Results for Hypothesis 4 Descriptive Statistics and ANCOVA Results Impact of Awareness and Advice Quality on Weight of Advice ..................................... 80

Table 8 Results for Hypothesis 5a Descriptive Statistics and ANCOVA Results Impact of Awareness and Higher Quality Advice on Accuracy .................................... 81

Table 9 Results for Hypothesis 5b Descriptive Statistics and ANCOVA Results Impact of Awareness and Lower Quality Advice on Accuracy ................................... 82

Table $10 \quad$ Summary of Hypothesis Testing............................................................... 83 


\section{CHAPTER 1}

\section{INTRODUCTION}

In order to ensure consistency and reduce risk, audit firms are requiring more consultation with internal firm subject matter experts for complex transactions (e.g. transactions involving fair value accounting, derivatives and other financial instruments, impairments, and revenue recognition) [PCAOB 2007; Bedard et al. 2008; Jenkins et al. 2008; Solomon 2008]. ${ }^{1}$ The availability of internal technical groups enable accounting firms to be considerate of budgetary constraints and ensure that advice provided to core audit teams is consistent. ${ }^{2}$ The advice that these subject matter experts provide to the core audit teams is incorporated into the audit evidence and is used to make a decision regarding the accounting treatment of an issue. This advice is based on information provided by management as well as potential discussions with the core audit team. Hence, the increased use of subject matter experts has the potential to impact auditor judgment accuracy and ultimately audit quality. Although these resources are available, audit teams must first decide if and when a situation calls for use of a subject matter expert and whether to incorporate the advice provided by that subject matter expert. While professional guidance is provided regarding when to utilize a subject matter expert and how to assess the quality of advice provided by subject matter experts (PCAOB 2007; AICPA 1994, 2006), the conditions under which the use of subject matter experts may be beneficial or

\footnotetext{
${ }^{1}$ Audit teams receive advice from different types of experts. The first set of experts is specialists. The use of specialists by audit teams is governed by AU-C 620 Using the Work of a Specialist, which defines a specialist as an individual who has an expertise in a field outside of accounting or auditing (AICPA 1994). In addition to specialists, firms often use technical experts within the field of accounting or auditing. I define these individuals as "subject matter experts." Subject matter experts are routinely used by audit teams for financial statement audits. Given the call for more consultations by firms' policies and regulators when the engagement team may be lacking in appropriate knowledge (e.g. Solomon 2008), the use of subject matter experts would be common. In this study I focus on advice received from subject matter experts.

${ }^{2}$ I define "core audit team" as the members of the engagement team who are performing the majority of the fieldwork and are in contact with the client.
} 
detrimental to audit judgment has not been examined. Specifically, even though subject matter experts are knowledge experts in their area, if they do not use all appropriate client facts when assessing the issue, the quality of the advice provided to the audit team may be of poor quality. Consequently, if the auditors do not assess the quality of advice provided by the subject matter expert, the final decision made by the auditors may be inaccurate or inappropriate.

In addition to quality considerations, if auditors become aware that a subject matter expert will provide assistance to the team it can influence how auditors utilize advice and arrive at their final decision. Prior to auditing complex transactions, auditors performing the audit work on a particular issue may or may not be aware that a subject matter expert will be asked to provide advice related to the specific issue. Audit teams may decide at any time during the course of evaluating complex transactions if a situation calls for use of a subject matter expert and whether to incorporate the advice provided by that subject matter expert. Even when auditors are aware that a subject matter expert will be utilized, they will first need to make a preliminary pre-advice decision and then make a final decision after receiving advice. As such, auditors will feel that they and the subject matter expert are working on the issue together. This could be used to alter auditors' effort level, preliminary assessment, and their willingness to accept advice. Research shows that a mandatory and binding requirement to consult with a fraud consultant not only affects an auditor's willingness to consult with the expert, but also impacts the assessment of the fraud (Gold et al. 2012). This dissertation investigates the ability auditors have to assess formal advice quality based on client specific facts and how characteristics of the audit process such as, whether auditors are aware they will receive advice, impacts the use of formal advice and the resulting audit judgments. 
Recent accounting research has shown that both formal and informal advice can impact audit judgment. Informal advice may be through discussions held between an engagement team member and the subject matter expert or through informal means such as email. Formal advice often takes the shape of written documentation that can be maintained in the audit file and serve to support judgments made by the core audit team. $\mathrm{Ng}$ and Shankar (2010) examined whether auditors' decisions on accepting a client's justification for its preferred accounting method is contingent on the presence of explicit advice from the audit firm's technical department. The results show that auditors use explicit advice from subject matter experts when making decisions. Shankar and $\mathrm{Ng}$ (2008) examined whether and how the use of advice is jointly affected by the performance evaluation focus of the auditor's supervisor and the client's accounting preferences. Auditors incorporated advice provided from a colleague that is outside the core audit team when a client's accounting preference is to use an acceptable method versus the most appropriate method. Kadous et al. (2013) investigated whether auditors' willingness to use informal contrary advice from their closest professional associate is a joint function of their social bond with their advisor and advice justifiability. They found that non-industry specialists relied more on trust heuristics than industry specialists when incorporating informal contrary advice into decisions regardless of the level of justifiability provided by the advisor. Therefore, extant accounting research indicates that auditors use advice from firm subject matter experts and consider social factors when considering informal advice. Professional standards specifically require that auditors judge the quality of advice received from subject matter experts (AICPA 1994, 2006). Moreover, audit process factors such as whether auditors are aware that subject matter experts are going to be used in a task prior to starting the task may influence advice taking behavior. 
Therefore, investigating the impact of these factors on the use of formal advice can extend existing advice taking literature including accounting literature.

Subject matter experts' advice can vary in its quality depending on how involved the subject matter expert is with the audit and if they have direct contact with management. In certain instances, subject matter experts may assume general facts and circumstances regarding an issue and provide lower quality advice due to not considering all relevant facts. Therefore, the core audit team, who has more knowledge regarding the client and the issue at hand, must ensure that the information utilized by the subject matter expert is accurate and reasonable to the specific facts to ensure the best solution to the issue. While auditing standards require that auditors assess the quality of the advice from subject matter experts (AICPA 1994, 2006), recent PCAOB inspection reports show that audit teams are not adhering to the guidance set forth regarding the use of specialists. ${ }^{3}$ For several consecutive years, the PCAOB inspection reports indicate that even if audit teams receive and incorporate advice from specialists they often do not perform the required work around the specialists' conclusions to ensure that the advice is appropriate and accurate (Church and Shefchik 2012; Rouse and Weirich 2006).

However, the advice taking literature indicates that advisees are often unable to discern between the quality of superior and inferior advice (e.g. Gino et al. 2012; Bonaccio and Dalal 2006). This research also suggests that task factors can impact the level of effort that advisees put into a task and may cause an overreliance on the advice, even when the advice may not be appropriate (Gino et al. 2012). Research notes that although advice generally helps to improve

\footnotetext{
${ }^{3}$ Although the PCAOB inspection reports specifically use the term "specialists," the issues noted by the PCAOB include such areas as fair value valuations, accounting for derivatives, and valuating inventory. Each of these areas falls under accounting and/or auditing. Thus, I feel that the general findings of the PCAOB reports are a lack of quality assessment of formal advice provided by experts and are applicable to this study. In order to be consistent with the PCAOB reports, I will use the term "specialists" as used per the reports when referring to the PCAOB reports.
} 
advisees' accuracy, advisees tend to overweigh their own opinion when compared to their advisor (Bonaccio and Dalal 2006). In addition, research has shown that if individuals are aware they will be working with others, they will put forth a lower level of effort (Henningsen et al. 2000). Individuals have also been shown to exert less effort if they believe that their input will have minimal impact on the final decision (Karau and Williams 1993), for example if they are working with an expert to make a judgment. On the other hand, auditors have been shown to plan for and adapt to known upcoming issues (Tan and Low 2011). This may be construed as planning to put forth greater effort in order to audit the issue. Lower levels of effort have been shown to reduce confidence in judgments (Paese and Sniezek 1991). Finally, lower confidence in pre-advice decisions has been shown to increase the likelihood of acceptance of advice, regardless of quality (Gino et al. 2012). Thus, research needs to examine the ability of auditors to identify any variation in the quality of advice based on client specific facts received from subject matter experts, in light of the potential impacts awareness of the use of subject matter experts may have on this process.

Awareness of the use of a subject matter expert prior to receiving advice is important for two reasons. First, research indicates that if auditors are aware of an event or constraint they can plan for it and adapt to it (Low and Tan 2011). Therefore, if auditors plan on using subject matter experts they would also plan to perform the required procedures to assess the quality of a subject matter expert's work. However, based on PCAOB inspection findings, it appears that this is not the case (Church and Shefchik 2012). Second, research shows that auditors put forth more cognitive effort if paired in heterogeneous teams as compared with working in homogeneous teams (Seol 2006). That is, if auditors know they are going to work with a subject matter expert on an issue, the auditor may put forth more effort toward resolving that issue than if they were 
unaware a subject matter expert was go be utilized. On the other hand, research in other disciplines have found evidence that individuals who think they are working alone outperform individuals who believe that they are working within a group (e.g. Henningsen et al. 2000; Weldon et al. 2000; Weldon and Gargano 1988). Finally, auditors' fraud decisions have been shown to be influenced by whether there is a mandatory requirement to use an internal fraud consultant (Gold et al. 2012). Thus, it is an empirical question whether, if they are made aware that a subject matter expert will be used by the audit team, will they put forth more or less effort to arrive at an initial judgment prior to receiving the subject matter expert's advice? Also, once that advice is received, will they look to share the responsibility of the decision with the subject matter expert and neglect assessing the quality of the advice?

I predict that auditors who are unaware that a subject matter expert will be used will exert a lower level of effort toward their initial (pre-advice) audit assessment when compared to auditors who are a priori aware. This lower level of effort is expected to impact the confidence unaware auditors have in their initial audit assessment, where lower level of effort leads to lower confidence (Paese and Sniezek 1991). In addition, due to the lower level of effort employed, I expect those auditors who are unaware of the use of a subject matter expert will be more accepting of management's position. Also, research has shown that if advisees are low in confidence for a specified task, the advisees are more accepting of advice (Gino et al. 2012). As lower confidence has been shown to increase the weight individuals place on advice, I expect those auditors a priori unaware to place more weight on advice received and be more accepting of advice. Therefore, I predict that auditors who are a priori unaware are more likely to accept advice regardless of the quality of advice. This can potentially lead to accepting advice that is not fully incorporating client specific facts. As such, I expect the a priori unaware auditors' 
acceptance of low quality advice will lead to inaccurate decisions. This will lead to a priori unaware auditors making less accurate audit recommendations. On the other hand, I predict that auditors who are made aware that a subject matter expert will eventually be used, will exert a higher level of effort toward their initial (pre-advice) audit assessment when compared to those auditors that are unaware. As such, this level of effort is expected to increase the confidence a priori aware auditors have in their pre-advice audit assessment, leading these auditors to be less accepting of management's position. The higher confidence level is expected to impact the weight a priori aware auditors place on advice, where they will place less weight on the advice and be less accepting of the advice. As such, I predict a priori aware auditors will be less accepting of advice, particularly advice that does not fully incorporate client specific facts. Since these auditors are expected to employ a greater level of effort in pre-advice assessment, they are expected to confirm their pre-advice assessment with the advice provided and are likely to not accept advice that does not confirm their previous assessment. In other words, I expect this group to put forth greater effort in their pre-advice assessment since they will have a greater ability to discern the advice accuracy. Therefore, I expect a priori aware auditors to arrive at more accurate audit recommendations to the audit team, regardless of the quality of subject matter expert advice they receive.

The research questions were examined using a $2 \times 2$ between-subjects computerized experiment that varied awareness of subject matter expert usage prior to performing the initial task (aware, unaware) and the quality of advice received (lower, higher) during a revenue recognition task. A two-stage audit scenario was utilized where auditors assessed management's position around a complex issue, received advice from an internal subject matter expert, and then made a revenue recognition recommendation to their audit team. This format is consistent with 
the methodology used in advice taking literature (e.g. Ng and Shankar 2010; Bonaccio and Dalal 2006; Kadous et al. 2013). I recruited 77 senior auditors from large public accounting firms, since auditors at this rank would be the first to assess a complex issue and would be the point of contact with a subject matter expert group.

The awareness variable was manipulated through the description of the task where participants were told, prior to determining their initial assessment of management's position, that a subject matter expert is assisting the audit team regarding the issue presented in the case. Quality of advice was manipulated through the advice provided to the participants from the subject matter expert. Lower quality advice provided participants with a mostly accurate answer except for specific client and issue facts being omitted from consideration by the subject matter expert. Higher quality advice provided participants an accurate answer that includes the specific client and issue facts correctly. Both types of advice were explicit in their recommendation of the accounting treatment.

Dependent variables were measured at two stages: pre-advice and post-advice. At the initial (pre-advice) stage, auditors provided their initial assessment of management's position. I also measured level of effort employed and the auditors' level of confidence in their initial assessment of management's position. After the advice was provided (post-advice stage) auditors provided their recommendation to their audit team (final judgment). Consistent with the advice taking research (e.g., Kadous et al. 2013; Tost et al. 2012; Gino et al. 2012), the change in judgment from the initial to the final judgment measures how much weight was placed on the subject matter expert's advice when arriving at the final judgment. The final judgment provided the information used to measure the accuracy variable, where the auditors' revenue recognition recommendations will be compared to the correct answer. The case included manipulation 
checks during the initial stage and post-experimental questions and demographic questions after the post-advice stage. Refer to Figure 1 for an outline of the case progression.

The results indicate that being a priori unaware that a subject matter expert will be utilized prior to working on a complex issue will reduce the level of effort employed by auditors when working through the issue. Although the reduction in effort did not impact the auditors' self-reported confidence, it did impact how accepting the auditors were of management's position. The a priori unaware auditors were less conservative in their pre-advice judgment and, as such, were more accepting of management's position. As predicted, the a priori unaware auditors were more accepting of advice, regardless of the quality of advice received. Therefore, the a priori unaware auditors who received the lower quality advice arrived at the least accurate final judgments. On the other hand, the a priori aware auditors employed a greater level of effort during the initial task when compared to the a priori unaware auditors. Also, the a priori aware auditors were more conservative in their pre-advice judgment and as such, less accepting of management's position. Due to the level of effort employed by a priori aware auditors, they performed better than the a priori unaware auditors at discerning the quality of advice and as such, placed less weight on the advice received. This resulted in the a priori aware auditors being more accurate, particularly when they received the lower quality advice as compared to those a priori unaware and receiving the same lower quality advice. Overall, these results indicate that both the quality of the advice received and auditors' a priori awareness of whether they are going to eventually receive advice impact their behavior when receiving advice from subject matter experts. With respect to awareness, auditors who are a priori aware expend more effort on the task at the pre-advice stage and on the entire task relative to auditors who are a priori unaware. This indicates that awareness may create a sense of joint responsibility towards the task that 
impacts auditors overall effort both at the pre-advice and post- advice stages. The higher level of effort at the pre-advice stage may allow auditors to scrutinize the client data more rigorously. Consequently, auditors who are a priori aware take a pre-advice position that is more conservative when compared to auditors who are a priori unaware. In addition, the results show that the quality of the advice from the subject matter experts impact auditors advice taking behavior. When auditors receive higher quality advice, they recognize the quality of the advice and incorporate this advice regardless of whether they were a priori aware or unaware that the advice was going to be provided. However, an interesting pattern of results emerges when auditors receive lower quality advice. Auditors who are a priori unaware tend to gravitate towards the lower quality advice. However, auditors who were priori aware were more discerning of the advice and took a final position that was closer to the higher quality advice rather than the lower quality advice they actually received. Therefore, the benefits of being a priori aware persists even after auditors in all groups received the advice.

This study adds to the advice taking literature by examining unexplored aspects of the use of formal advice received from internal firm subject matter experts and the impact of awareness. Furthermore, it provides an understanding of the impact that prior awareness of the use of subject matter experts can have on auditors' assessment of the quality of formal advice and the subsequent acceptance of formal advice. To my knowledge, no study has looked at how auditors assess the quality of formal advice. As such, this study makes a significant contribution to this literature. This study also provides insight into the joint impact of awareness and the quality of formal advice on an auditor's ability to assess advice and its impact on their recommendations to the audit team. Furthermore, by examining the role of advice taking on final decision accuracy, I specifically address a shortcoming identified in prior advice taking literature (Bonaccio and 
Dalal 2006). Finally, I am bringing together the role of group decision making, through the awareness variable, and the advice taking literature. Prior advice taking literature has cited this area worthwhile for exploration (Bonaccio and Dalal 2006).

The results of this study should be of interest to both audit regulators and practitioners by improving the understanding that the knowledge of planned audit procedures can have on auditors' assessments of advice from subject matter experts and the resulting decision accuracy. As recent $\mathrm{PCAOB}$ inspections reports suggest, auditors are neglecting to perform the required assessment of advice (Church and Shefchik 2012). Understanding why this may be occurring can potentially lead to changes in auditing standards and firm policies and practices. The impact advice awareness may have on auditors' level of effort and acceptance of lower quality advice can be of particular importance to auditors. Since this potential drawback can occur due to the unplanned use of subject matter experts, bringing attention to this issue can allow firms to implement or change firm policies. In addition, training can be provided to audit staff to make them aware of the potential issue.

This study can open additional research avenues. As more subject matter experts are being used by audit teams, understanding their interactions and communications can be important in understanding how to improve audit quality. In addition, recognizing that subject matter experts may not provide superior advice consistently can lead to additional areas for research. Finally, the idea of examining awareness has been mainly focused on the audit review process. As firms continue to put forth more effort towards planning audits, understanding the consequences of items such as the awareness of the use of subject matter experts can help improve audit efficiency and effectiveness. 


\section{CHAPTER 2}

\section{BACKGROUND, THEORY, AND HYPOTHESES}

\section{Use of Internal Firm Subject Matter Experts}

As business activities and transactions become more and more complex, audit teams are finding that they may not have the necessary knowledge in order to plan and perform an audit that is effective. Due to this, there has been a call for audit teams to seek out professionals that possess the technical knowledge the core audit team may be lacking (PCAOB 2007; Rouse and Weirich 2006; Solomon 2008). These professionals may be specialists as defined by authoritative guidance as having skills and knowledge outside accounting and/or auditing (AICPA 1994), or subject matter experts that have expertise pertaining to technical accounting and/or auditing knowledge, subject matter experts are often under the consultation umbrella of audit firms. They typically provide recommendations regarding technical accounting and/or auditing. For example, subject matter experts may assist audit teams with ensuring the appropriate accounting for complex revenue recognition issues is utilized or that fair value standards have been applied appropriately by clients.

Subject matter experts can join audit teams at any point during the engagement. If an engagement team is aware of a complex issue during the planning phase, the audit partner may choose to seek out a subject matter expert at that time and include them during planning of the audit of the complex issue. This helps to ensure that engagement team members are aware of the use of the subject matter expert and assists them in obtaining the necessary data or information for the subject matter expert from the client. It can also be a common occurrence for the engagement team to become aware of a complex issue during the course of the audit. A subject matter expert may be included as part of that audit team prior to working on the complex issue, 
or may be included after the audit team has already begun work over the issue. Regardless of when a subject matter expert assists an engagement team, they will provide a recommendation or advice regarding the issue to the engagement team. While this advice may be informal or formal, subject matter experts' advice provided to core audit teams is more likely to come in the form of formal advice in order to be in compliance with audit documentation requirements.

Regardless of the core audit team utilizing a specialist or a subject matter expert, there is authoritative guidance outlining the expectations of a quality assessment to be performed over the advice by the core audit team (AICPA 2006, 1994). This assessment includes gaining an understanding of the facts incorporated by the advising professional and if their recommendation makes sense with respect to the client, the client's specific situation, and the client's industry. This is particularly important when auditing complex issues as client specific facts can be very crucial when assessing the appropriateness of any accounting treatment. Therefore, the core audit team must ensure that subject matter experts are utilizing the correct and complete set of client facts in light of the fact that the core audit team is typically more familiar with client facts related to the issue. The core audit team is typically more familiar with the client's specific facts regarding an issue. In effect, the core audit team is uniquely qualified to assess the subject matter expert's understanding and implementation of the facts. Although the subject matter expert is considered to have more technical expertise, if they are applying incomplete or inaccurate facts, their judgment and recommendation may be impaired. For example, assume a situation where an audit team chooses to seek assistance from a subject matter expert regarding a client's revenue recognition of a sale of a product that includes a software component. The issue is that the client provides updates to a software product sold to customers. A particularly key client specific fact is how the updates will be delivered to customers. For the sake of illustration, assume that the 
revenue recognition expert excludes the fact that the software updates will be delivered over a specified amount of time, the expert will likely reach the conclusion that the value of the software updates should be recognized immediately instead of ratably over time. Missing this key client specific fact can result in a material misstatement by causing more revenue to be recognized during the current year rather than spreading out the revenue over multiple periods. For example, if the updates were to begin during the final quarter of the year and continue for twelve months, only three months of revenue should be recognized during the current year, leaving the remaining nine months to be recognized in the subsequent year. If the core audit team did not abide by the authoritative guidance requiring as assessment of the revenue recognition expert's advice, they may accept the advice and ultimately allow the financial statements to contain a material misstatement. Essentially, auditing standards indicate that the core audit team should evaluate the quality of the advice provided by the professional, prior to incorporating it in their assessment of the firm's financial statements (AICPA 2006, 1994). The final decision regarding the appropriate accounting is the responsibility of the core audit team. As such, they are required to assess all supporting evidence utilized to make their decisions, including the advice provided by subject matter experts.

Although these requirements to assess subject matter expert advice are set forth in the authoritative guidance, there is concern that auditors are not complying with it. The PCAOB has noted instances in consecutive years of inspection reports that auditors are not performing the required work over information provided by others (Church and Shefchik 2012). ${ }^{4}$ As subject matter experts provide recommendations or advice to engagement teams, but the core audit

\footnotetext{
${ }^{4}$ Church and Shefchik (2012) identify deficiencies per PCAOB reports that relate to auditors not performing adequate audit work when the audit team placed reliance on others. As per the description provided by Church and Shefchik (2012), "others" can include specialists or subject matter experts. These PCAOB findings indicate an overall lack of assessment of quality of formal advice by audit teams.
} 
teams not assessing the quality of advice raises some concerns. For instance, if important facts are misunderstood by the subject matter experts or the subject matter experts are unaware of key pieces of information, they may arrive at an inappropriate conclusion. If the core audit team elects to accept this advice without assessing its quality, the audit team may arrive at a lower quality decision and may ultimately issue an inappropriate opinion.

\section{Advice Taking and Decision Making}

Many decisions are not made by one person. The results of a financial statement audit can be looked upon as a team effort that includes the core audit team and other experts. Throughout an audit, the engagement team may seek advice from others outside the core audit team who have technical expertise. Consistent with advice taking literature, I define advice as any relevant ideas and recommendations that are offered to a decision maker (Bonaccio and Dalal 2006). Furthermore, I define formal advice as a documented recommendation provided to the decision maker. This study is focusing on subject matter experts providing explicit formal advice to the core audit team, who are the ultimate decision makers regarding the assessment of the audited financial statements.

The advice taking and advice giving literature has been growing substantially in recent years, particularly in the psychology arena (see Bonaccio and Dalal 2006 for a review). The main focus has been on advice taking, or utilization, although there have been some limited research of advice giving (Bonaccio and Dalal 2006). The central findings thus far in the literature are that decision makers seek out advice and utilize advice in order to share responsibility for the outcome of the decision and to improve the probability that their decisions will be accurate or be the best decisions (Yaniv 2004; Yaniv and Milyavsky 2007; Bonaccio and Dalal 2006). In fact, research has shown that there are indeed accuracy benefits that can be gained when advice from 
multiple sources is integrated (Yaniv and Milyavsky 2007). As such, it would appear that utilizing advice should lead to better decision quality. However, one of the most robust findings in the advice taking literature is that of "egocentric advice discounting" (e.g., Yaniv and Kleinberger 2000; Tost et al. 2012). Discounting is when advice is not utilized or only minimally incorporated by the advisee when arriving at their final decision. Most advice researchers have noted that advisees (participants who receive the advice and make the final judgment) in their experiments did not follow recommendations provided by their advisors nearly as much as they should have, thus reducing judgment quality. Research has found that although advice generally helps to improve advisees' accuracy, advisees tend to overweigh their own opinion when compared to their advisor (Bonaccio and Dalal 2006). This discounting occurs because advisees have access to their own internal justifications for how they arrived at their decisions and to the strength of the supporting evidence for that decision (Yaniv and Kleinberger 2000; Yaniv 2004). Since advisees did not have access to their advisors' reasoning, they have less evidence justifying the advisors' decisions.

Kruger (2003) argues that discounting may occur due to an egocentrism bias. This occurs when the advisees prefer their own opinions because they believe them to be more superior to those of others. Egocentrism can also be linked to advisee's pre-advice confidence level. Research has shown that the more confident an advisee is in their pre-advice judgment, the less weight they place on advice, ultimately discounting the advice provided (Tost et al. 2012).

Although findings for the egocentrism bias explanation have been robust in the literature (Bonaccio and Dalal 2006), there has also been findings that advice is perceived as more helpful and less intrusive when provided by an expert source (Goldsmith and Fitch 1997) and that expert advice is more influential than novice advice (Jungermann and Fischer 2005). Dalal and 
Bonaccio (2010) find that if advisors are perceived to have more knowledge than the advisee, advisees prefer explicit advice where the advisor recommends a particular course of action to the advisee. Schrah et al. (2006) also find that participants more readily accept advice from perceived experts as the complexity of the task increases. In addition to these findings regarding expertise, advice taking has also been linked to quality of advice. Not surprisingly, advisees discount inaccurate advice more than accurate advice (Yaniv and Kleinberger 2000; Yaniv and Milyavsky 2007).

Research has examined advice taking in various tasks. These tasks include asking participants to estimate the date of a U.S. historical event (Gino 2008), estimate the weight of a person depicted in a photograph (Gino et al. 2012; Tost et al. 2012), solve a complex mathematical problem (Gino et al. 2012), and estimate the amount of money held by a jar filled with coins depicted in a photograph (Gino et al. 2012). However, one should note that formal advice, in the sense of subject matter expert advice provided to audit teams, has not been studied in this manner. General advice taking research does not have advisees assess the quality of the advice prior to choosing to accept or decline the advice. Instead, advisees are provided with feedback of advisors' accuracy prior to receiving advice or advisees make multiple decisions and are provided with the results of those decisions so they are able to decipher which advisor provides more accurate advice (Bonaccio and Dalal 2006). This design is different than how auditors are required to assess quality of advice prior to accepting and adopting it into their final decisions (AICPA 2006, 1994). The key question that can arise when using advisors who are experts is — do advisees accept poor quality advice just because it is from a perceived expert and neglect to assess the quality of the advice? 
As the final decision is an important aspect of accounting and auditing, understanding the impact of advice taking and accuracy is a key contribution of this dissertation. In this respect, research has been limited in the realm of advice and accuracy of final decisions (Bonaccio and Dalal 2006). This research has noted that in general, using advice has been found to increase decision accuracy. Yaniv (2004) finds that exposing participants to advice from a single advisor improved accuracy for estimating dates of historical events. Sniezek et al. (2004) finds that if an advisee is paired with an expert advisor, the final judgment made by the advisee is more accurate when compared to final decisions of advisee paired with a novice advisor. Often the more advisors available to an advisee the more accurate the advisee's final decision (e.g. Yaniv and Milyavsky 2007; Yaniv 1997, 2004; Sorkin et al. 2001). For example, Yaniv (2004) finds that advisees who are provided advice from multiple advisors improve their decision accuracy of the price of a backpack with particular features. Feedback provided to an advisee has been linked to advisees' accuracy. Research has shown that providing feedback on advisees' own accuracy across trials improves their decision accuracy (Harvey and Fischer 1997). Also, advisees can learn to rely on outlying advisors if they receive feedback that these advisors are accurate (Harries et al. 2004). Decision accuracy is also influenced by task-related experience (e.g. Hollenbeck et al. 1995; Phillips 1999). Finally, accuracy of final decisions made by advisees is also impacted by the precision with which the advice is expressed, where the more precise the advice is, the more accurate the final decision. More precise advice can be expressed utilizing exact numbers rather than using ambiguous statements (Bonaccio and Dalal 2006).

Auditing literature has begun to explore the impact of advice taking and advice giving research on the audit process. The first instances of examining auditors and advice began by investigating the impact of consultation practices of audit firms. Salterio and Steven (1997) 
researched how consultation offices operate in Canadian audit firms. Subject matter experts often reside with the consultation offices within audit firms. Salterio and Steven (1997) found that across various audit firms that resources and expertise of consultation personnel can vary greatly. This may lead to varying levels of quality of recommendations provided by consultations offices to audit teams.

More recently, research has shown that both formal and informal advice can impact audit judgment. Similar to research on the role of consulting offices, Ng and Shankar (2010) examined whether auditors' decisions on accepting a client's justification for the client's preferred accounting method is contingent on the presence of explicit advice from the audit firm's technical department. The results show that auditors use explicit advice from technical advisors when making decisions. Shankar and $\mathrm{Ng}$ (2008) examined whether and how the use of advice is jointly affected by the performance evaluation focus of the auditor's supervisor and the client's accounting preferences. Auditors incorporated advice provided from a knowledgeable colleague that is outside the core audit team when a client's accounting preference is to use the acceptable methods versus the most appropriate method. These results suggest that social pressure to avoid disagreements with the client led to auditors accepting advice that was in agreement with client preferences. Kadous et al. (2013) investigated whether auditors' willingness to use informal contrary advice from their closest professional associate is a joint function of their social bond with their advisor and advice justifiability. They found that non-industry specialists relied more on trust heuristics than industry specialists when incorporating informal contrary advice into decisions regardless of the level of justifiability provided by the advisor. This study provides evidence that advice taking behavior of auditors may depend on task complexity as the non- 
industry auditors may have found the task more complex when compared to the industry expert, and in turn was more accepting of advice.

Taken together, this research shows that auditors use advice from internal firm advisors and consider social factors when considering informal advice. However, advice taking literature in psychology indicates that advisees are not always able to discern between the quality of superior and inferior quality advice (e.g. Bonaccio and Dalal 2006; Gino et al. 2012). In addition, research has shown that task factors can impact the level of effort that advisees put into a task that may cause an overreliance on the advice, even when the advice may not be appropriate (Gino et al. 2012). Therefore, elements of the audit process such as whether auditors are aware that subject matter experts are going to be utilized prior to starting the task, can influence advice taking and ability to discern quality need to be examined.

\section{Quality of Advice and Auditing}

Advice is only good if it leads to better decisions. This is particularly true in the realm of auditing and accounting. If auditors receive advice that is of inferior quality and they utilize this advice in their judgments and decisions, this can lead to inappropriate or inaccurate decisions. As a result, professional standards are in place to ensure that auditors assess the quality of advice provided to them by someone outside the core audit team (AICPA 2006, 1994). These standards apply regardless of formal or informal advice, or whether advice is provided from an expert or non-expert.

When looking at subject matter experts, the general expectation is that in most instances they would only provide superior quality advice due to their expertise. However, subject matter experts must rely on the core audit team to ensure that they have utilized all the key specific client facts and circumstances. As the application of accounting guidance can be very situation 
dependent, ensuring the use of the accurate client specific facts is of key importance to ensure that the most appropriate and accurate answer is reached. If specific client facts are not considered or misunderstood, the advice provided by the subject matter expert could vary, resulting in a low quality recommendation.

As the core audit team has close contact with the client, and has a greater understanding of the client and its business, they are best suited to ensure that the subject matter expert included all the necessary and key specific client facts. To effectively take advice, the core audit team must take two steps. First, the core audit team must familiarize themselves with the issue and the specific facts related to the client. If the core audit team members simply rely on the subject matter expert, they will not be able to ascertain whether all key client facts have been identified and utilized in the advice. Second, the core audit team needs to assess the quality of the advice received. If such an assessment is not performed by the core audit team, they may not recognize that inappropriate judgments or misapplication of guidance has been made by the subject matter expert due to utilizing information that is incomplete or inaccurate. Consequently, if the core audit team just accepts poor quality advice due to the omission or misunderstanding of client specific facts provided by a subject matter expert, it may result in poor decisions made by the audit team.

\section{Awareness and Advice Taking}

The impact of awareness on decision making may be understood under the framework of the group decision making literature. In this respect, Kerr and Tindale (2004) liken the "judge advisor system" (i.e., advice taking) to group decision making because multiple people may provide advice to a decision maker, but the final decision rests with a single person. This is very similar to the operation of a core audit team working with outside technical advisors. Thus, in 
some respects when auditors are aware that they will be provided advice from an expert prior to their initial judgment, the auditor and advisor can be considered a small group. As such, awareness of the use of a subject matter expert prior to receiving advice is an important variable when trying to understand advice-taking behavior by auditors. Wilks (2002) finds that earlier awareness of supervisors' views influences subordinates' judgments. This indicates that awareness can impact how an auditor performs decision-making processes. For example, if auditors plan on using a subject matter expert they would also plan to perform the required procedures to assess the quality of a subject matter expert's work. In fact, auditors are accountable for ensuring all evidence utilized during the audit is reasonable and of good quality. However, based on PCAOB inspection findings, it appears that this is not the case (Church and Shefchik 2012). Also, auditors' fraud decisions have been shown to be influenced by whether there is a mandatory requirement to use an internal fraud consultant (Gold et al. 2012).

Prior psychology research indicates that if individuals believe or are aware that they are working within a group setting, they will put forth less effort than if they believe they are working alone (Henningsen et al. 2000). Although this motivation loss is more evident in large groups, it still happens in small groups (Karau and Williams 1993). Research shows that if an individual's effort or contribution cannot be identified from the group, the individual will put forth less effort. Lower effort has been identified to occur if individuals believe their input will have little impact on the resulting group product due to other group members providing the necessary performance criterion (Karau and Williams 1993). Karau and Williams (1993) find that individuals devoted less effort when they expected their co-workers to perform well as opposed to expecting co-workers to perform poorly. 
How an individual views the advisor may impact the level of effort applied by the advisee if they are aware they will receive advice prior to making their initial judgment. If the advisee views the advisor as an expert and more knowledgeable of the subject area, the advisee may feel that any effort they put forth would be minimally helpful when making the final decision. The advisee may assume that the optimal answer will be provided by the advisor and as such, put forth minimal cognitive effort. Therefore, if an individual is aware that they will receive advice prior to making their initial judgment, they may put forth less cognitive effort for the initial judgment when compared to an individual who is unaware that they will receive advice. Putting forth less effort may lead individuals to be more accepting of advice because the advisee will not be committed to their initial judgment due to the lack of effort (Mitchell 1973). This reduction of motivation has been well documented in group decision making literature (e.g. Kerr and Tindale 2004; Karau and Williams 1993).

Although this reduction of effort has been well researched in decision making research, it is not the only reaction individuals have displayed when working in groups. The collective effort model, as described by Karau and Williams (1993) provides an alternative to this reduction of effort. The model proposes that an individual may increase their level of effort if they believe that the potential outcomes of the group task is valuable to them, even if the individual believes that individually their contribution may be less than others in the group (Karau and Williams, 1993). This effect is called social facilitation, meaning that the presence of others implies potential evaluation of an individual's contribution (Karau and Williams, 1993). If an individual is motivated to perform well on the task, then they want others to know they performed well on the task. Research shows that individuals who find the experimental task worthy of their effort do not employ less effort when working in groups, when compared to those that do not find the 
task important (Smith et al., 2001). In addition, individuals in a high motivational condition were less likely to exert a lower level of effort in a group setting when compared to those in a low motivational condition (Hart et al., 2004). This impact has also been shown in the advice-taking literature. When participants are given the option of when (i.e., during the initial judgment phase or after) they are able to receive advice during a complex decision problem, most participants opt to conduct a fairly substantial information search on their own prior to obtaining the advice (Sniezek and Buckley, 1995; Schrah et al., 2006). Thus, if an individual is aware of the option of receiving advice, they are likely to put forth effort to arrive at their initial judgment especially when the task is important and they are highly motivated.

Motivation and task importance are particularly salient in the auditing environment due to the requirements of auditing standards, firm performance evaluation systems, and auditors' professional skepticism. As such, it is reasonable to assess that auditors would view a complex audit issue as worthy of their effort, and therefore want to perform well on the task. This should lead the auditor to employ greater effort when they are aware they will be working with a subject matter expert, even though that expert may be more knowledgeable than them regarding the subject matter. In addition, auditors may perceive that the subject matter expert may have some input into their performance evaluation. Accounting literature has shown that awareness does impact level of effort employed by auditors. Low and Tan (2011) note that auditors made less estimate errors when they were made aware of time constraints early in the task when compared to those who were told of the time constraint late in the task. In addition, they find that auditors who were told early of the time constraint spent more effective total test time on the audit area than those auditors who were told of the time constraint later. These results suggest that awareness of the time constraint improved auditor effectiveness and effort employed when 
compared to auditors who were unaware of the pending time constraint. In addition, Tan (1995) finds that if auditors are aware that a review will occur they put forth more effort in their decision-making processes. Auditors recalled more inconsistent facts in their justification of a firm's financial viability when they were aware that a potential review of their work was possible versus those that were unaware of a possible pending review. Seol (2006) finds that auditors put forth more cognitive effort if paired in teams that were heterogeneous as compared with homogeneous teams. Based on prior research and the auditing environment, it is likely auditors would be motivated and identify the value of audit tasks and would, therefore, enhance their effort if they are aware of the use of a subject matter expert.

As auditors typically work in teams, this finding may be due to a feeling of social responsibility to the team and individual auditors wanting to contribute to team success, particularly if working with another auditor of a different level or with specialized expertise. As the accounting research provides findings that when auditors are made aware of events or constraints, they react by putting forth more effort than those that are unaware, this shows that auditors are highly motivated regarding auditing tasks. As such, consistent with the collective effort model, this motivation should lead auditors who are aware they will be working with a subject matter expert to put forth greater effort in order to understand the issue prior to receiving information from the subject matter expert as compared to those auditors who are unaware. As such, I expect auditors who are unaware that a subject matter expert will be utilized will put forth less cognitive effort to make an initial decision prior to receiving the advice as they do not know that additional assistance will be provided at a later time. In contrast, I expect auditors who are aware that a subject matter expert will be utilized will put forth more cognitive effort to make an 
initial decision, as they know they may potentially work with the subject matter expert and will want to be prepared. Therefore I will test the following hypothesis:

H1: Auditors who are unaware that a subject matter expert will provide advice will put forth less effort when arriving at their initial decision when compared to auditors who are aware that a subject matter expert will be utilized.

The level of effort employed by individuals has been shown to impact their confidence in their decisions. Paese and Sniezek (1991) find that the less effort employed by individuals, the less confident they feel about their decisions related to the task. Therefore, if an individual is aware that they will receive advice and, as such, they put forth less effort towards their preadvice decision, they may have less confidence in this decision. Therefore, I expect the auditors unaware they will receive advice from a subject matter expert prior to making their initial audit assessment to have less confidence in their pre-advice decision. Comparably, as it is expected that those auditors who are aware of the use of a subject matter expert and will put forth greater effort into their initial decision they will have more confidence in that decision. As such, I will test the following hypothesis:

H2: Auditors who are unaware that a subject matter expert will provide advice will be less confident in their pre-advice audit assessment when compared to auditors who are aware that a subject matter expert will provide advice.

\section{Quality of Advice and Awareness and the Impact on Audit Judgments}

Subject matter experts are typically utilized for complex or difficult tasks. These tasks require individuals to expend effort in order to understand the issue in addition to the client's position. Research has shown that a lower level of effort exerted by individuals to understand an issue leads to less comprehension of the issue (e.g., Wills et al. 2006). If auditors who are unaware that a subject matter expert will provide advice in the future are expected to put forth a lower level of effort during the initial task, and as such, they are likely to have a lower 
understanding of the client specific facts and of the issue at hand. Due to the complexity of the issue, these auditors may find the issue to be more ambiguous when compared to auditors who were aware they will receive advice from a subject matter expert and are likely to put forth more effort to understand the issue. Research has shown that if a client preference is known and the task is ambiguous, accountants' judgments align with management's position (e.g., Cloyd and Spilker 1999; Kadous et al. 2003). Cloyd and Spilker (1999) use an ambiguous tax issue and find that tax accountants bias their search to identify confirming evidence that is supportive of the client's preference. Kadous et al. (2003) find that when using an ambiguous issue, auditors who are asked to assess the best accounting method increase their directional goal to accept the client's position even though there are more appropriate accounting methods available. I expect that the lower effort of the auditors who are unaware they will receive advice from the subject matter expert will increase their perception of the ambiguity of the task. The increased perception of ambiguity will allow them to determine an initial (pre-advice) decision closer to management's assessment (i.e. be more accepting of management's preference). On the other hand, as the auditors who are aware that a subject matter expert will be utilized are expected to put forth more effort in reaching their initial decision, I expect that these auditors will be less likely to accept management's position. The additional effort put forth by this group will allow them to be comparably more discerning of management's interpretation of the accounting guidance and therefore arrive at a more conservative initial decision. Therefore I will test the following hypothesis:

H3: Auditors who are unaware that a subject matter expert will provide advice will have an initial audit assessment that is closer to management's assessment when compared to auditors who are aware that a subject matter expert will provide advice. 
Due to the less effort put forth by auditors who are unaware of the use of a subject matter expert when making their initial audit assessment, the less likely they will be able to discern lower quality advice provided by a subject matter expert. Specifically, if an auditor does not perform their due diligence in gaining a clear understanding of the issue and the client specific facts, it will be difficult for the auditor to identify if a subject matter expert misunderstood or utilized an incomplete set of client specific facts. As such, it will be difficult for these auditors to find a reason not to accept advice from internal firm subject matter experts. In addition, research provides evidence that lower effort results in less confidence in judgments (Paese and Sniezek 1991), and lower confidence increases the likelihood of acceptance of advice (Gino et al. 2012). With respect to having less confidence in a decision, this may lead individuals to be more accepting of advice, regardless of quality (Gino et al. 2012). This can be the case, particularly when dealing with expert advisors, such as subject matter experts. Research indicates that lack of confidence by an advisee can lead the advisee to be more accepting of advice (e.g. Cooper 1991; Gino et al. 2012). Since auditors who are unaware that a subject matter expert will be used, are expected to put forth less effort and have a lower confidence, I expect these auditors to be more accepting of advice as evidence in the weight placed on advice calculation. In contrast, those auditors who were aware of the use of a subject matter expert prior to their initial decision are expected to have put forth more effort in gaining an understanding of the issue in order to arrive at their initial decision. As such, this group will be able to better discern the quality of the advice provided by the subject matter expert. Their assessment of the advice would consist of comparing their understanding of the client specific facts with the assumptions and facts relied upon by the subject matter expert. If they do not agree, I expect auditors in this group to be less 
likely to use the advice provided by the subject matter expert. Therefore, I will test the following hypothesis:

H4: Auditors who are unaware that a subject matter expert will provide advice will be more accepting of advice when compared to auditors who are aware that a subject matter expert will be utilized.

At the end of the day, judgments made by auditors need to be materiality accurate. By employing the assistance of subject matter experts, audit teams are striving to incorporate the most appropriate and most accurate decision. In fact, research has found that accepting advice typically equates to more accurate decisions (e.g. Yaniv 2004; Sniezek et al. 2004; Yaniv and Milyavsky 2007). However, if the advice provided is of lower quality, then decisions relying on the advice would be less accurate or inappropriate. As stated earlier, auditors who are unaware that a subject matter expert will provide advice prior to making an initial audit assessment, will put forth less effort and be less confident in their initial decision. Thus, auditors who are unaware may potentially be less able to discern the accuracy of the advice and, as such, be more accepting of low quality advice. Auditors who are aware of the use of a subject matter expert prior to their initial decision may put forth a greater amount of effort into that initial decision and will be more confident, and therefore, more discerning of quality differences in advice. This would allow auditors who are aware during the initial decision, to accurately recognize the lower quality advice and choose not to accept it. Instead they are expected to employ their original assessment, which based on a higher level of effort employed is expected to be more accurate. As an audit is a group effort, I explore the accuracy of auditors' recommendations they would provide to their audit team. I expect that auditors that are more likely to accept lower quality advice will arrive at less accurate audit recommendations. This leads to an interaction such that, I expect that if an auditor is provided with high quality advice, regardless of timing of awareness, the auditor's 
audit recommendation will be accurate. However, if an auditor is provided with low quality advice, the accuracy of their audit recommendation will be dependent on the timing of their awareness of the use of a subject matter expert. Those auditors who were aware will have a more accurate audit recommendation, but those auditors who were unaware will have less accurate audit recommendation when both groups receive low quality advice. Based on this theory I will test the following hypothesis:

H5: Advice awareness will interact with quality of advice received such that:

a. There will be no difference in accuracy of the audit recommendation between auditors who are aware that a subject matter expert will provide advice prior to the initial judgment and receive high quality advice and auditors who are unaware and receive high quality advice.

b. Auditors who are unaware that a subject matter expert will provide advice prior to the initial judgment and receive low quality advice will have less accurate audit recommendations when compared to auditors who are aware and receive low quality advice. 


\section{CHAPTER 3}

\section{RESEARCH METHODOLOGY}

This chapter presents the research methodology used to examine the hypotheses, beginning with a description of the participants who completed the experiment. The next section describes the research design, case materials, and experimental procedures. The final section summarizes the operationalization of the independent variables and the measures used for the dependent variables of interest.

\section{Participants}

Seventy-seven professional auditors were recruited from Big-4 accounting firms and other large public accounting firms to participate in the study. ${ }^{5}$ The auditors were primarily the rank of audit senior (92.2\%), 52\% female and $66 \%$ worked for a Big-4 accounting firm. Audit seniors are the appropriate pool of participants because auditors at this rank would be the first to assess a complex issue and would be the point of contact with a subject matter expert group. Prior research has indicated that auditors at the senior level are likely to be involved in unstructured tasks that would be required when auditing a complex issue (Abdolmohammadi 1999). All of the participants completed an electronically delivered packet comprised of the experimental materials. Of the 77 participants, 47 completed the case during an in-house firm

\footnotetext{
${ }^{5}$ A total of 96 participants completed the case study. Of these total participants, 4 were excluded due to inappropriate responses. An additional 15 participants were excluded, as they reported zero to the question, "How many of your audit engagements have employed the use of internal firm subject matter experts during the most recent financial statement audit?" Prior advice-taking research has noted the importance of experience with taking advice in advice related studies. Schrah et al. (2006) find that advice is often met with uncertainty and mistrust due to questions of the advisor's expertise. Lack of experience may enhance these feelings. Redd (2002) finds that experience with past advice taking experience can impact weight placed on advice and ultimately decision accuracy. Accounting research has provided similar evidence, particularly research regarding consultations (Gold et. al. 2012). Gold et al. (2012) finds that prior experience with fraud consultations directly impacts auditors' likelihood of seeking and accepting fraud consultations. Therefore, following prior research, I excluded the participants who expressed no recent experience being on an engagement that utilized a subject matter expert.
} 
training attended by the researcher, while 30 participants completed the online instrument on their own.

\section{Overview of the Research Design}

I conducted an experiment with a $2 \times 2$ between-subjects experimental design and simple random assignment (Whitley 2002) to assess the impact of awareness of the use of a subject matter expert and the quality of the subject matter expert's advice on auditors' acceptance of the advice and the accuracy of auditors' revenue recognition recommendations. The participants were asked to take the role of an in-charge auditor for their firm on the integrated audit of a hypothetical audit client of which they were provided with the background information on the client and the industry. The participants then began the advice taking experiment following a two stage approach, where first they were provided information on the revenue recognition issue and then asked to provide their initial assessment of management's position. The first stage included the awareness manipulation (aware, unaware). After providing their initial assessment of management's position the auditor provided justification of their decision. Participants were then asked the awareness manipulation check question. This was followed by confidence assessment questions and a post experiment question to understand the likelihood of using a subject matter expert. The measures of level of effort were captured through the computer software used to deliver the experiment. The second stage began by providing the participants with a memo from the subject matter experts, which included explicit advice from the subject matter expert group. The second manipulated variable was quality (lower, higher) of the advice provided to the participants. Participants were then asked to provide their final revenue recognition recommendation including justification of their decision and how, if at all, they utilized the advice provided. Next, participants were asked to respond to post-experimental questions to 
understand their assessment of the quality of the advice and questions seeking to understand the participant's level of advice taking propensity. Finally, participants responded to demographic questions in order to complete the case.

\section{Case Materials and Procedures}

Participants began the study by reading a welcome page informing them that the purpose of the study is to examine auditors' decision making regarding revenue recognition. They were then told that they are to assume the in-charge role of an audit engagement that is nearing completion and there is one outstanding issue that requires their attention. Next, participants were presented with background information about the company, Tintype, Inc., which included a company description and summary financial statements. The company was described as a public company that manufactures cameras and other digital electronics for both personal and industry

use. The financial statement summary included the current unaudited balances and the preceding two years of audited balances.

The participants were then presented with the revenue recognition issue that they were asked to provide an assessment of management's position in the form of stating the amount of revenue that should be recognized for the year. The issue related to a new product that is manufactured and sold by the client during the current fiscal year. Unlike any of their other products, the product is a multiple element sale that includes a hardware piece, software package, and an optional maintenance plan. As such, this is a new revenue recognition method for the client which necessitates the use of a subject matter expert. The participants were expected to assess the appropriate revenue recognition guidance to use, the appropriate accounting units, and finally, the appropriate revenue recognition related to each accounting unit. Before discussion of the facts of the issue was presented to the participants, the awareness of the use of a subject 
matter expert was manipulated. Participants in the aware group were specifically told, "As this revenue recognition issue was identified during the planning phase of the audit, the engagement partner has elected to contact an internal firm revenue recognition subject matter expert for assistance." For participants in the unaware group, the presentation was silent to the use of a subject matter expert for this specific case. To mimic audit practice, participants were provided with a specified time limit to complete the task.

Along with the details of the issue, the participants were presented with management's position of revenue to be recognized. Management supported their view by providing their opinion on several key issues, including supporting citations of professional guidance. The issues related to the appropriate applicable guidance, the specified accounting units, and how much revenue they have recognized as of year-end. Management's position in the case is to view the product hardware and software package as a single accounting unit. They also identify the related maintenance plan as an additional accounting unit. Management's position is that they have performed all the required services in relation to the identified accounting units and therefore have recognized the total amount of revenue possible as of year-end.

After reviewing the issue, participants were then asked to provide their assessment of management's position by stating the amount of revenue that should be recognized as of yearend (initial assessment) based on company background, specific issue facts, and the applicable guidance. In addition, participants were asked to provide justification of their assessment of management's position. The effort employed by participants was measured by the Qualtrics software. The initial assessment of management's position provided by the participants in addition to the level of effort exerted by the participants to arrive at this judgment was used to test hypotheses $\mathrm{H} 1$ and H3. Participants were then asked questions related to confidence. 
Responses to these statements were used to test hypothesis H2. To complete this portion of the task, auditors were asked a manipulation question related to awareness.

As is typical of advice taking research, after providing their initial assessment of management's position, participants were then provided with the advice. Prior to receiving advice, participants were told that a subject matter expert provided advice. For the awareness group, they were told, "As previously noted, due to the complexity of the issue your engagement partner has decided to engage an internal firm revenue recognition subject matter expert to provide assistance to the team." The unaware group was told, "Due to the complexity of the issue your engagement partner has decided to engage an internal firm revenue recognition subject matter expert to provide assistance to the team." The participants were also told that as per AU-C 300 , they are expected to assess the information provided by the subject matter experts. In addition, participants were told "You should utilize your own judgment based on all the information provided to make your assessment regarding the revenue recognition issue." This statement was included so that participants were aware that they were not required to use the advice provided to them by the subject matter expert. Participants were also told that the subject matter expert was provided with the same information they received regarding the issue and management's position.

The advice was then provided to participants in the form of a memo from Chris Moore, the Revenue Recognition Subject Matter Expert Team manager. Receiving a memo is a typical method of providing formal advice from a specialized group to an engagement team. In the introduction section of the memo, participants were specifically told, "It is the audit team's responsibility to assess our understanding of management's facts and position." This statement was to again remind the participant of the responsibility of the auditor to assess the quality of the 
information provided by the subject matter expert. The memo first outlined the client specific facts as understood by the subject matter expert. This is where the quality variable was manipulated between participants. The lower quality advice was manipulated by the subject matter expert omitting important facts related to the software package. Based on accounting guidance and the specific client facts, the software package should be identified as a separate accounting unit from the hardware. Per the client specific facts and the accounting guidance, the revenue generated from the hardware can be recognized immediately, but the revenue from both the software package and the maintenance plan should be recognized over the 24 months of service. The lower quality advice omitted the facts that would lead one to identify the software package as an independent accounting unit and that the revenue should be recognized over the 24 month service period. The memo continued on to discuss their analysis of the issue, their understanding of management's position on a number of items, and finally, if they agreed with management's positions. The lower quality advice agreed with management's position on the separate accounting units and the position that the revenue for the hardware and software package can be recognized immediately. The advice disagreed with management regarding the maintenance plan and recommended that the revenue from the maintenance plans be recognized over the 24 month period. Although the lower quality advice omitted the facts regarding the software length of service, the explicit recommended amount of revenue that should be recognized is lower than management's position.

The higher quality advice incorporated all the client specific facts and as such, applied the accounting guidance appropriately, and identified three units of accounting (the hardware, the software package, and the maintenance plan). The higher quality advice agreed with management that the hardware revenue can be recognized immediately, but the software package 
revenue should be recognized over the 24 month service period. Consistent with the low quality advice, the higher quality advice disagreed with management regarding the maintenance plan and recommended that the revenue from the maintenance plans be recognized over the 24 month period. The explicit recommendation of revenue that should be recognized provided by the higher quality advice was lower than both management's position and the lower quality advice recommendation.

After receiving the advice, participants were reminded what management has recognized in addition to their initial assessment of management's position prior to receiving the advice. Participants again had access to the company background, facts of the issue, management's position, and the applicable revenue recognition guidance. Participants wre then asked to provide their recommendation of the amount of revenue that should be recognized as of year-end (final judgment) that they would provide to their audit team. This dependent variable was used to test hypothesis H5. The comparison between the initial assessment of management's position and the revenue recognition recommendation was used to test $\mathrm{H} 4$. Participants were also asked to provide justification for their decision and also how, if at all, they utilized the advice provided by the subject matter expert. Finally, participants were asked how they rated the quality of the advice provided to them through multiple questions, questions related to advice taking propensity, as well as, demographic questions to complete the instrument.

\section{Post-experimental Questions, Manipulation Checks, and Demographics}

The participants were asked to complete several questions after the initial task and after receiving advice. After the initial assessment of management's position, participants were asked if the case materials indicated that they will be receiving advice from a revenue recognition subject matter expert. Responses were used to assess the awareness manipulation. Participants 
were also asked questions regarding their confidence in their decision. The final question in this stage asked participants how likely they would use a subject matter expert for the issue discussed in the case. Responses to this question allowed me to assess if the participants felt the issue was sufficiently complex enough to utilize a subject matter expert and thus, give support for the case being realistic. After making the revenue recognition recommendation to the audit team, participants were asked to assess the quality of the advice provided by the subject matter expert. Specifically, they were asked if what, if any, addition information they would like to provide the subject matter expert and what follow-up questions would they like to ask the subject matter expert. The responses received allow me to assess the impact awareness has on an auditor's assessment of quality of advice. Next, participants were asked to respond to self-monitoring questions in order to ensure that participants' feelings regarding accepting advice in general was not impacting their acceptance (or not) of formal advice from an internal firm subject matter expert (Shankar and Ng 2008). Finally, participants were asked several demographic questions such as rank, experience dealing with revenue recognition, experience dealing with subject matter experts, and experience evaluating the advice provided by the subject matter expert to assess if all the appropriate client specific facts were utilized. See Appendix B for a sample of a full experimental case. Refer to Figure 1 for an outline of the task progression, including the introduction of the independent variables.

\section{Independent Variables}

As detailed earlier, I consider the effect of two independent variables, awareness of the use of a subject matter expert and quality of advice, on advice taking judgment. Two levels of awareness (aware and unaware) are manipulated through statements within the description of the task. 
The quality variable was provided to participants through advice received from a subject matter expert. The advice memo received from the subject matter expert group was used to manipulate the two quality conditions (high or low). Please see Appendix A for a copy of the quality of advice manipulations.

\section{Dependent Variables}

I assessed the effects of awareness and quality of advice on dependent variables measured during each stage of the experiment. During the initial (pre-advice) task, the participant's initial assessment of management's position, level of effort, and the confidence in the initial assessment was measured. After reviewing the issue and management's position, participants were asked to assess management's position (the initial assessment) by "entering how much revenue should be recognized for the sales of the Safeco Eye Laser and the related components." Level of effort is of key importance as it indicates the effort utilized to understand the issue and possible alternative decisions. Auditors are required to assess audit evidence, including recommendations provided by subject matter experts (AICPA 2006, 1994). If auditors are lacking in their level of effort when assessing the issue, the client specific facts, and the applicable guidance, they may find it difficult to assess the quality of subject matter expert advice. Level of effort was measured in two ways; first by the amount of time spent on completing the pre-advice task, and second, the amount of time spent completing the full case. These were measured by the Qualtrics software. Confidence in the auditor's initial decision can impact if the auditor is receptive of advice. Lack of confidence may lead to auditors to be more accepting of advice, particularly if that advice is seen as being from an expert. On the other hand, being overly confident may lead one to exhibit traits of egocentrism and be less willing to accept advice. In order to assess if awareness impacts confidence, I measured confidence after the 
auditors enter their initial assessment of management's position. Consistent with prior research (Gino et al. 2012), the participants rated their confidence on a 7-point scale (disagree to agree) based on the following statements: I think my revenue recognition estimate is accurate, I am very certain about the accuracy of my revenue recognition judgment, I am sure I am performing well on this revenue recognition task, and I felt that I had adequate time to complete the required task (Gino et al. 2012). The confidence variable for each participant was calculated as the average rating of these statements. The agreement with management's position variable was used to assess how close the pre-advice assessment is to the provided management's position. This was calculated as the difference between the amount of revenue recognized by management (management's position) and the participant's initial assessment.

During the second stage (post-advice), two dependent variables were measured: weight placed on advice and the accuracy of the final decision. After receiving the advice memo from the subject matter expert, participants were asked to provide their recommendation to the audit team of the amount of revenue that should be recognized. This judgment provided the information to assess the final two dependent variables. Weight placed on advice (WOA) is a common dependent variable seen in the advice taking literature (Bonaccio and Dalal 2006). This variable measures the impact the advice provided to a participant had on their final judgment when compared to their initial (pre-advice) judgment, as well as, the participant's receptivity to advice. WOA is calculated as follows:

$$
W O A=\frac{\mid \text { final estimate }- \text { initial estimate } \mid}{\mid \text { advice }- \text { initial estimate } \mid}
$$

WOA is an important variable to auditors because although auditors may receive recommendations from other professionals who may have more technical expertise, auditing standards still require that auditors assess the advice provided (AICPA 1994, 2006). If auditors 
just accept advice without assessing the quality and that quality is inferior, the final decision made by the auditor may not be appropriate or accurate.

Accuracy of the final decision interplays with the fact that auditors are expected to arrive at the correct decision if one exists. This requires having a full understanding of the issue and applying the applicable accounting guidance appropriately. If an auditor does not arrive at the accurate decision the overall audit quality of the engagement may be decreased. Accuracy was measured by assessing the difference between a participant's revenue recognition recommendation and the correct amount of revenue that should be recognized based on client specific facts and applicable guidance.

\section{Pretesting of Experimental Materials}

The experimental materials went through three rounds of pretesting, each with a distinct purpose. First, the instrument was pretested with 12 Accounting Ph.D. students with, on average, 2.6 years of former public accounting experiences to ensure the task was realistic, the instructions were clear, and the duration to complete was reasonable. Minor changes to the task instructions and materials were made based on the feedback received.

Second, the case study was separately pretested by a focus group to assess if the task is realistic and if the accuracy variable to be used during analysis is correct. The materials were provided to a focus group consisting of two partners, three senior managers, and one manager from a Big 4 accounting firm. The following questions were asked in order to assess if the case study progression is realistic; "In your experience, do you believe that it is reasonable to have an audit team first assess management's position prior to receiving advice from a subject matter expert" and "Do you believe that it is reasonable that the audit team will, upon receiving advice from the subject matter expert, assess the advice." Each participant in the focus group responded 
"yes" to these questions. The focus group was then asked; "In your experience, do you believe it is reasonable that an auditor at the senior level would be the staff in charge of first assessing management's position, and then upon receiving advice from a subject matter expert, evaluating it to assess if the subject matter expert utilized all the appropriate client specific facts?" This was done to ascertain if senior level auditors were a reasonable target for participants. Each person in the focus group responded "yes" to this question. In order to directly ask if the case is reasonable, the focus group participants were asked the following; "Based on your review of the case materials, do you agree that the case realistically captures the use of subject matter experts during an audit," and "Based on your review of the case materials, do you agree that the case presents a probable initial position that management might take on this type of revenue recognition." Using a 7-point scale where 1 is "I fully disagree" and 7 is "I full agree," the average response was 6.8 and 7, respectively. Finally, in order to assess the reasonableness of subject matter experts providing lower quality advice as demonstrated in the case materials, the focus group was asked, "Based on your experience, do you agree that, in some instances, subject matter experts may provide lower quality advice if they fail to consider specific client facts." Using a 7-point scale where 1 is "I fully disagree" and 7 is "I fully agree," the average response was 6.5. Taken together, this establishes that it is reasonable for an audit team to assess management's position even if a subject matter expert was going to be utilized, that seniors are realistic participants for this task, that subject matter experts may provide lower quality advice through the admittance of client specific facts during their assessment, and that the case overall is realistic.

In order to assess the accuracy variable to be utilized, the focus group was provided with the high quality subject matter advice. Focus group participants were then asked, "Given the case 
materials and client specific facts, do you believe that the higher quality advice arrives at the accurate answer?" After a discussion and a minor change to the case materials, all participants of the focus group agreed with the accuracy variable. This verifies the accuracy of the high quality advice in the instrument and provides an accuracy criterion to be used to measure the accuracy of participants' responses.

The final pretest was performed via the review of the instrument by one Big 4 accounting firm and one large national accounting firm in order to assess if the research question is of interest to the accounting firm, how realistic the case study is presented, and if the accounting firm would provide participants for the study. The review team for the Big 4 accounting firm consisted of two partners and one partner for the large national accounting firm. No substantial changes were recommended by the reviewers and each firm agreed to provide participants. Refer to Appendix B for a sample of a full experimental case. 


\section{CHAPTER 4}

\section{RESULTS}

This chapter presents the data analyses conducted for the study and the results of the hypothesis testing. Recall that participants were randomly assigned to one of four cases by crossing a priori awareness (aware or unaware) of the use of a subject matter expert and advice quality (lower or higher) provided by the subject matter expert: Aware-Lower Quality, AwareHigher Quality, Unaware-Lower Quality, and Unaware-Higher Quality.

\section{Manipulation Checks}

Before examining the effectiveness of the manipulated variables, I conducted an analysis to ensure the participants paid adequate attention to the case materials. After providing responses to the pre-advice dependent measures, all of the participants were then asked if the engagement partner elected to utilize a revenue recognition subject matter expert for the issue. The participants in the aware group were specifically told that the engagement partner decided to utilize a revenue recognition subject matter expert, while the case materials were silent to the use of a subject matter expert for those in the unaware group. Therefore, the response to this question indicates whether the participants paid sufficient attention to the case facts. Of the 77 participants, 48 auditors were able to correct identify if a subject matter expert was going to be utilized or not.

As an additional analysis to examine if the 29 auditors who failed this check question were different from the 48 auditors who did not, I conducted an independent samples t-test to compare the total time spent on the pre-advice task between the 48 auditors who correctly responded to the manipulation check question and the 29 auditors who failed to do so. Untabulated results provide that the difference in total time spent on the first task did not significantly differ between 
those auditors who passed the manipulation check question and those that did not $(\mathrm{t}=1.35$, $\mathrm{p}=0.1810$, two-tailed). Based on these results, and because a review of the responses to the other questions did not show significant differences between these groups, data analysis was performed on the full sample. Refer to sensitivity testing performed for further analysis performed using only the auditors who passed the manipulation check question.

\section{Preliminary Analyses}

I analyzed the results using a $2 \times 2$ analysis of variance (ANOVA) model to test the effects of awareness and advice quality on each of my dependent variables. My preliminary analysis considers whether the data meets the three basic assumptions of the ANOVA model: independent observations, normal distribution of the dependent variables, and homogeneity of variance. The first requirement, independent observations, is addressed in the experimental design my randomly assigning the participants to each of the four experimental conditions. A Shapiro-Wilk test for normality was performed on the data for the primary dependent measures (i.e. level of effort, confidence, acceptance of management's position, weight placed on advice, and accuracy). There were some violations of this assumption for the primary variables. Research has found that ANOVA is a robust analysis and not highly sensitive to violations of normality (Glass et al., 1972; Lix et al., 1996). As such, I conducted my analysis using ANOVA, or ANCOVA where applicable, and utilized non-parametric analysis to supplement testing. Finally, no data violated the homogeneity of variance assumption.

\section{Auditor Characteristics}

Table 1 presents descriptive statistics by experimental condition for demographic and post experimental questions. I performed a one-way ANOVA on each of these measures (i.e. professional experience, experience dealing with revenue recognition, use of subject matter 
experts on engagements, if auditors at their rank would perform the case required duties, and acceptance of advice propensity) to test for differences by condition using the experimental treatment as a single four-level variable.

\section{Experience}

Overall, the participants have an average of 39.82 months of professional audit experience. The one-way ANOVA results reported in Table 2 indicate that there is not a significant difference in the level of experience across the four experimental groups $(F=0.33, p=0.8021$, two tailed). As such, the level of experience of the auditors is not significantly different by condition.

\section{Experience with Revenue Recognition}

To gain additional insight of the participants' experience with revenue recognition participants were asked how often they deal with assessing revenue recognition policies employed by clients. The average response was 3.99 based on a 1-7 Likert scale where 1 was "Never" and 7 was "All the Time." This response indicates that the participants have some familiarity with working with revenue recognition, but would not be considered experts in that audit area. Further, results of a one-way ANOVA to test for differences by condition are not significant $(\mathrm{F}=0.79, \mathrm{p}=0.5031$, two-tailed $)$, indicating that experience with revenue recognition does not differ by experimental condition.

\section{Experience with Use of Internal Firm Subject Matter Experts}

The participants were also asked how many of their audit engagements employed the use of internal firm subject matter experts during the most recent financial statement audit. The average response of 2.38 engagements indicates that use of internal firm subject matter experts is occurring and that participants at this rank are aware of that use. Results of a one-way ANOVA 
are not significant ( $\mathrm{F}=0.44, \mathrm{p}=0.7232$, two-tailed), indicating that experience with the use of internal firm subject matter experts does not differ by experimental condition.

\section{Performance of Case Requirements for Audit Senior Rank}

When asked if an auditor at their rank would be responsible for evaluating the advice provided by the subject matter expert to assess if all the appropriate client specific facts were utilized, 55\% of participants responded affirmatively. These results agree with the results of the pretesting of the case materials with the focus group and support that it is reasonable for auditors at the senior auditor rank to perform the tasks outlined in the case materials. Results of a oneway ANOVA are not significant $(\mathrm{F}=0.34, \mathrm{p}=0.7976$, two-tailed), indicating that there is no difference by experimental condition.

\section{Acceptance of Advice Propensity}

Finally, auditors were asked three questions in order to assess their propensity to accept advice. Responses to the following questions; "I believe that seeking advice during an engagement suggests a lack of technical expertise," "I believe that seeking advice conveys a lack of confidence," and "I believe that seeking advice negatively affects performance evaluations at the end of the audit engagement" were based on a Likert scale ( $1=$ "I fully disagree" and 7= "I fully agree") and then averaged together to arrive at an acceptance of advice propensity score. The participants has an average acceptance of advice propensity score of 1.75 , indicating that, on average, auditors do not believe that accepting advice would negatively impact their reputation. Results of a one-way ANOVA are not significant ( $\mathrm{F}=1.06, \mathrm{p}=0.3729$, two-tailed), indicating that there is no difference by experimental condition. 


\section{The Impact of Awareness on Auditor Pre-Advice Assessment}

Recall that the experiment is designed as a two-stage experiment, where during the first stage the awareness of the use of a subject matter expert is manipulated. During this stage, participants are provided with details regarding a revenue recognition issue, provided with management's position, and then asked to provide their assessment (pre-advice assessment) of management's position. This assessment along with measures of participants' level of effort and confidence in their assessment will be utilized to test $\mathrm{H} 1, \mathrm{H} 2$, and H3. I performed an Analysis of Covariance (ANCOVA) for each hypothesis test using the auditors' self-reported experience dealing with revenue recognition policies as the covariate for each analysis. Advice-taking research has shown that specific task experience is an important influencing factor of decision accuracy (e.g., Hollenbeck et al. 1998, Phillips, 1999). In addition, research has shown that lack of task experience has precluded individuals from forming a pre-advice opinion (e.g., Budescu and Rantilla, 2000). Harvey and Fischer (1997) find that lack of task-related experience impacts advice discounting. Finally, accounting literature has also reported task-level experience impacting auditors' willingness to seek consultation from a fraud expert (Gold et al., 2012). Therefore, as the experimental case is a complex revenue recognition task, the experience each auditor has with revenue recognition is likely to impact their performance on the task and their willingness to accept advice. As such, this variable will be utilized as a covariate for each test of hypothesis.

\section{Hypothesis 1}

Recall that Hypothesis 1 states that as compared to auditors who are aware, auditors who are unaware that a subject matter expert will be utilized are expected to exert a lower level of effort in order to arrive at the pre-advice assessment of management's position. To test this hypothesis, 
I measured the time spent by participants to complete the pre-advice task and to complete the full case in order to assess level of effort employed. Prior research has used similar methods to assess effort employed by auditors (e.g., Hannan et al., 2013, Ford and Pasewark, 2012). Using these calculated dependent variables, I used an ANCOVA model with awareness (aware or unaware) as the independent variable and experience with revenue recognition as a covariate ${ }^{6}$. Table 2 and 3 present the descriptive statistics of the dependent measures across the two conditions (Panel A) and the results of the ANCOVA model (Panel B) for the time spent on the pre-advice task and on the full case, respectively ${ }^{7}$.

The mean time spent to complete the pre-advice task by the a priori aware group was 25.63 minutes (Table 2). Compared to the mean time for the a priori unaware group of 20.74 minutes, which results in a difference that is significant $(F=2.56, p=0.0527$ one-tailed $)$. The mean time spent completing the full case by the a priori aware group and a priori unaware group was 33.62 and 27.59 minutes, respectively (Table 3). The difference between the two groups is significant $(\mathrm{F}=3.52, \mathrm{p}=0.0322$ one-tailed $)$

As expected, the results for each variable show that the aware group spent more time working, or employed a greater level of effort, on the pre-advice task and the entire case. These results support my predictions related to the impact of awareness on level of effort employed by auditors. Untabulated results of the non-parametric Kruskal-Wallis test provide similar results (time spent on pre-advice task; $\mathrm{p}=0.0895$, one-tailed, and time spent on the full case; $\mathrm{p}=$ 0.0741, one-tailed). These results support H1.

\footnotetext{
${ }^{6}$ ANCOVA models for each hypothesis were analyzed using the following covariates; total experience, reported number of engagements that utilized a subject matter expert, acceptance of advice propensity, if auditors agreed that auditors at their level would perform the duties required by the case and Big 4 auditor. None of these tests provided substantial differences in the presented results.

${ }^{7}$ As I base my analyses on ANCOVA, I report adjusted means for analysis purposes, unless otherwise stated.
} 


\section{Hypothesis 2}

Hypothesis 2 predicts that auditors who are unaware of the use of a subject matter expert will have lower confidence in their pre-advice decision when compared to the auditors a priori aware. I calculated participants' confidence based on the average score from four confidence questions: "I think my revenue recognition estimate is accurate," "I am very certain about the accuracy of my revenue recognition judgment," "I am sure I am performing well on this revenue recognition task," and "I felt that I had adequate time to complete the required task." ${ }^{, 8,9}$ Recall that these confidence questions were based on a 7-point Likert scale, anchored by "I fully disagree" and "I fully agree." Table 4 provides the descriptive statistics (Panel A) and results of the ANCOVA analysis (Panel B). The means indicate that confidence ratings of the participants in the aware group (4.99) were not significantly different than the participants in the unaware group (5.01) during the pre-advice decision $(\mathrm{F}=0.01, \mathrm{p}=0.4563$ one-tailed). The Kruskal-Wallis test provides similar results $(\mathrm{p}=0.3823$, one-tailed). $\mathrm{H} 2$ is not supported. Based on a review of the correlation between the confidence variable and the experience with revenue recognition variable, it is evident that confidence may have been driven more by the auditors' prior experience with revenue recognition than whether they were a priori aware or unaware of the use of a subject matter expert ( $\mathrm{p}=0.005$, two-tailed). As confidence in task performance is often linked to prior similar task experience or domain knowledge, which is often obtained from task experience, this correlation is not surprising. Refer to Table 5 for the correlation table.

\footnotetext{
${ }^{8}$ In addition to the average confidence score, I also perform ANOVA analysis for each confidence question. No single question provided significant results (all p-values $>0.10$ ).

${ }^{9}$ As the final question in the confidence question series may also measure pressure auditors feel due to the expressly stated time constraints, I used the results of this question as a covariate for the other hypothesis testing. None of these analyses provided results due to the fourth confidence question.
} 


\section{Hypothesis 3}

Recall Hypothesis 3 states that those auditors who are unaware of the use of a subject matter expert will have a pre-advice assessment that is closer to management's position than those auditors who are a priori aware. Table 6 provides the descriptive statistics (Panel A) and results of the analysis of this hypothesis (Panel B).

Prior to performing the analysis of Hypothesis 3, I first analyzed if there was a difference between the judgment made by each awareness group (aware, unaware) of the revenue that should be recognized and management's position. The unadjusted mean revenue recognition amount judgment was $\$ 10,857,694$ and $\$ 12,150,508$ for the aware and unaware groups, respectively. I conducted an independent samples t-test to compare each group's mean judgment to management's position of $\$ 15,017,940$. Untabulated results provide that each group's mean is statistically different (aware group, $\mathrm{t}=6.79, \mathrm{p}<0.0001$, two-tailed; unaware group, $\mathrm{t}=12.88, \mathrm{p}$ $<0.0001$, two-tailed) than management's position. The means also show that each group provided pre-advice judgments that were more conservative than management's position.

In order to perform testing of Hypothesis 3, I computed the difference between the amount stated as management's position in the case materials and the participant's pre-advice decision (acceptance of management's position). As management's position is the least conservative option, the difference between the participant's pre-advice assessment and management's position reflects how conservative the pre-advice assessment can be viewed. The descriptive statistics show that the aware group was more conservative in their pre-advice decision $(\$ 4,169,535)$ when compared to the unaware group $(\$ 2,860,087)$, which is a significant difference $(\mathrm{F}=4.70, \mathrm{p}=0.0167$ one-tailed). As such, auditors who were unaware of the use of a 
subject matter expert provided pre-advice decisions that were closer to management's position. The Kruskal-Wallis test provides similar results. H3 is supported.

\section{Summary of the Effect of Awareness on the Pre-Advice Assessment}

Based on the results, it appears that awareness impacts the level of effort participants put forth during the pre-advice task and for the full case. The mean times spent on the pre-advice task and on the full case shows that more time was spent by those in the a priori aware group than those in the a priori unaware group. These results provide support that if an auditor is unaware that a subject matter expert will be utilized before they begin working on an issue, the auditor will not put forth the same level of effort than if the use of a subject matter expert was known.

Although prior psychology research using undergraduate students as participants suggested that lower level of effort reduces confidence, results from this study do not support this prediction. Auditors are different from undergraduate students in that they have domain knowledge surrounding auditing tasks. Accounting research has shown auditors report a higher than average self confidence when scales, such as Likert scales, are used (e.g., Moeckel and Plumlee, 1989, Whitecotton, 1996). These results are consistent with prior research and indicate that auditors are confident of their performance on tasks. Therefore, differences in confidence levels may be difficult to attain given that auditors generally show a high level of confidence in their abilities.

Finally, awareness appears to have an impact on auditors' acceptance of management's position. Acceptance of management's position results between the a priori unaware and a priori aware groups suggest that if an auditor is unaware of the use of a subject matter expert prior to 
working on the issue, they will initially be more accepting of management's position. Refer to Table 10 for a summary of hypothesis testing results.

\section{The Impact of Awareness and Advice Quality on Auditor Post-Advice Assessments}

The second stage of the experiment begins with the introduction that a subject matter expert will be utilized (or reminded to those participants in the aware group) and participants are then presented with the subject matter expert's advice. Recall that the quality of the advice is manipulated by the lower quality advice being based on assumptions that do not include a few client specific facts leading to inaccurate advice. The higher quality advice includes all the client specific facts and as such, the subject matter expert provides accurate advice. Participants are then asked to provide their recommendation to their audit team (post-advice assessment) based on all the previously provided information as well as the subject matter advice received. This assessment will be utilized to test $\mathrm{H} 4, \mathrm{H} 5 \mathrm{a}$, and H5b. ANCOVA analysis was performed for each hypothesis, again using experience with revenue recognition as the covariate variable for each analysis.

\section{Hypothesis 4}

Hypothesis 4 predicts that auditors who are a priori unaware of the use of a subject matter expert will be more accepting of advice provided by a subject matter expert during the postadvice phase of the experiment when compared to auditors who were aware that a subject matter expert was to be utilized during the pre-advice phase. Recall that the weight placed on advice (WOA) is calculated as follows:

$$
W O A=\frac{\mid \text { final estimate }- \text { initial estimate } \mid}{\mid \text { advice }- \text { initial estimate } \mid}
$$

Using this equation, I calculated a WOA score for each participant utilizing the pre- and postassessment of revenue recognition provided by participants and the corresponding advice 
provided to their experimental condition. The WOA score falls in the range of 0 to 1 , where 0 indicates that the participant did not utilize the advice during their post-advice assessment and 1 indicates that participant fully relied on the advice when making the post-advice assessment. Following prior research, when a participant's pre-advice assessment was equal to the advice they received (i.e., the denominator is equal to zero), the participant was excluded (Gino 2008). Refer to Table 7 for descriptive statistics (Panel A), results of the ANCOVA analysis (Panel B), and tests of contrasts (Panel C). In addition to the experience with revenue recognition covariate, I also included the auditors' self-reported number of engagements that utilized a subject matter expert as a covariate in the analysis. This variable can be viewed as a proxy for experience with receiving advice from a subject matter expert. Prior advice-taking research has found that prior experience of receiving advice as impacting advice acceptance and discounting of advice when using WOA as a dependent measure (Redd, 2002). Schrah et al. (2006) finds that lack of experience of advice taking provides for a difference in trustworthiness of advisors. Finally, Koestner et al. (1999) finds that individual differences in advice-taking experience impacts weight placed on advice and overall advice discounting. Therefore, I used both task experience and advice taking experience as covariates when testing weight placed on advice.

Using the independent variables of awareness (aware, unaware) and advice quality (lower, higher) and the dependent variable of WOA score, I analyzed the main effects and the interaction of awareness and advice quality on WOA. The mean weight of advice score for auditors who received lower quality advice was 0.6562 and 0.5446 , for the unaware and aware conditions, respectively. As expected those who were unaware placed more weight on advice provided by the subject matter expert than those that were a priori aware. In the higher quality condition, the mean weight of advice score was 0.6839 and 0.3998 for the unaware and aware 
conditions, respectively. The aware variable is statistically significant $(\mathrm{F}=2.83, \mathrm{p}=0.0495$, onetailed) and neither the interaction of awareness nor the advice quality variables are significant $(\mathrm{F}$ $=0.39, \mathrm{p}=0.5363$, two-tailed and $\mathrm{F}=0.12, \mathrm{p}=0.7319$, two-tailed, respectively), as predicted. Contrast testing reveals that the difference between the unaware and aware groups within the lower quality advice condition is not significant $(\mathrm{t}=0.50, \mathrm{p}=0.3083$, one-tailed $)$, whereas the difference between the unaware and aware groups within the higher quality advice condition is significant $(\mathrm{t}=1.71, \mathrm{p}=0.0464$, one-tailed $)$.

Overall, the results provide that awareness is a significant driver of the weight auditors place on advice received from a subject matter expert. H4 is supported as awareness is impacting WOA as predicted.

\section{Hypothesis $5 a$ and $5 b$}

The final analysis investigates the accuracy of the audit recommendation (final judgment) made by participants. Before formally testing the hypothesis, I first examined how accurate each experimental condition was with their final recommendation of revenue recognition. I compared each condition's mean to the accurate amount of revenue that should be recognized by management, $\$ 10,660,545$, using independent t-tests. The unadjusted mean final recommendation of the Aware-Higher Quality Advice condition was \$10,414,321. Untabulated results provide that this mean is not statistically different than the accurate answer $(\mathrm{t}=0.32, \mathrm{p}=$ 0.7553, two-tailed). The unadjusted mean final recommendation of the Unaware-Higher Quality Advice condition was $\$ 11,020,547$, which was also not statistically different from the accurate answer $(\mathrm{t}=1.33, \mathrm{p}=0.1973$, two-tailed $)$. As each of these conditions received the higher quality advice and were expected to be accurate with their final recommendation, these results are in agreement with H5a. The unadjusted mean final recommendation of the Aware-Lower Quality 
Advice condition was $\$ 11,468,781$. This is also not statistically different from the accurate answer $(\mathrm{t}=1.04, \mathrm{p}=0.1575$, one-tailed $)$. The unadjusted mean final recommendation of the Unaware-Lower Quality Advice condition was \$12,593,250, which was statistically different from the accurate answer $(\mathrm{t}=1.33, \mathrm{p}<0.0001$, one-tailed $)$. These results indicate that when auditors receive higher quality advice, they recognize the quality of the advice and incorporate this advice regardless of whether they were a priori aware or unaware that the advice was going to be provided. In addition, the results show that auditors who are a priori unaware tend to gravitate towards the lower quality advice. However, auditors who were priori aware were more discerning of the advice and took a final position that was closer to the higher quality advice rather than the lower quality advice they actually received. Therefore, the benefits of being a priori aware persists even after auditors in all groups received the advice.

Next I conducted formal testing of the hypotheses. I calculated the accuracy variable by subtracting the accurate answer of the amount of revenue that should be recognized from the final recommendation amount provided by participants. The larger the difference between these numbers the less accurate the audit recommendation made by the participants. Recall that Hypothesis 5a states that no difference in accuracy is expected between the a priori unaware and aware groups when both are provided with higher quality advice. However, as stated in Hypothesis 5b, I expect that those a priori aware auditors who receive lower quality advice will be more accurate than a priori unaware auditors who receive the same lower quality advice. Table 8 provides the results between the unaware and aware groups that both received higher quality advice. The mean accuracy was $\$ 357,789$ and $-\$ 243,520$ for the a priori unaware and aware groups, respectively. As expected, these groups did not significantly differ in the accuracy of their audit recommendation ( $\mathrm{F}=0.61, \mathrm{p}=0.4415$ two-tailed), providing support for $\mathrm{H} 5 \mathrm{a}$ as 
both the a priori unaware and aware groups were accurate when provided with the higher quality advice.

Table 9 displays the results between the unaware and aware groups when both received the lower quality advice. The mean accuracy was $\$ 1,951,472$ and $\$ 783,604$ for the a priori unaware and aware groups, respectively. As expected, the aware group was more conservative and as such, more accurate with their final response. Using ANCOVA analysis with accuracy as the independent variable and experience with revenue recognition as the covariate, the difference between these two groups is marginally significant $(\mathrm{F}=2.30, \mathrm{p}=0.0691$ one-tailed $)$. H5b is marginally supported. Refer to Figure 3 for a graphical display of the results of Hypotheses 5a and $5 \mathrm{~b}$.

Summary of the Effect of Awareness and Advice Quality on the Post-Advice Assessment Results indicate that a priori awareness of the use of a subject matter expert does impact the weight auditors place on advice received from a subject matter expert. In addition, those that received higher quality advice were more accurate in their final judgment, regardless of whether they were a priori aware or unaware of the use of a subject matter expert. However, an interesting pattern of results emerges when auditors receive lower quality advice. Auditors who are a priori unaware gravitated towards the lower quality advice. On the other hand, auditors who were priori aware were more discerning of the advice and took a final position that was closer to the higher quality advice rather than the lower quality advice they actually received. Therefore, the benefits of being a priori aware persisted even after auditors in all groups received the advice. Refer to Table 10 for a summary of hypothesis testing results.

\section{Sensitivity Analysis}

I performed sensitivity analysis in order to understand the potential impact of the following groups of auditors within the sample; those auditors who passed the manipulation 
check question and those auditors who agreed that an auditor at their rank would perform the duties required of the case. Each of these groups is a small sample size, which makes it difficult to make assessments regarding hypothesis testing. As such, I first analyzed if each group was consistently represented across the experimental conditions. Then I analyzed if the responses for the dependent variables were statistically different than the average responses provided by the alternative response sample (i.e., I compared the auditors who passed the manipulation check question with those that failed) ${ }^{10}$.

\section{Exclusion of Auditors Who Failed the Manipulation Check Question}

In order to assess if there were any differences between those auditors who passed the manipulation check question and those who failed to respond appropriately, I conducted the testing using only the 48 auditors who passed the manipulation check question. I first tested for a difference by condition using passing the manipulation check question as a dependent variable and the experimental treatment as a single four-level variable. The untabulated one-way ANOVA results indicate that there is not a significant difference in the number of those auditors who passed across the four experimental groups $(\mathrm{F}=2.35, \mathrm{p}=0.0791$, two tailed $)$.

Next, I tested the main individual dependent variables utilized for the hypothesis testing to gain an understanding if the passing auditors provided different responses from the auditors who failed. Within the a priori aware groups, both the mean time spent on the pre-advice task and the mean time spent on the full case were significantly different. The mean time spent on the pre-advice task for the failing sample and the passing sample was 16.67 and 28.55 minutes, respectively $(\mathrm{t}=3.51, \mathrm{p}=0.0018$, two-tailed $)$. The mean time spent on the full case for the failing sample and the passing sample was 23.12 and 37.11 minutes, respectively $(\mathrm{t}=3.75, \mathrm{p}=$ 0.0010, two-tailed). The acceptance of management's position variable was not statistically

\footnotetext{
${ }^{10}$ The sensitivity analysis was performed using unadjusted means.
} 
different between the a priori aware groups. The main dependent variables were not statistically different between the two a priori unaware groups.

The WOA and accuracy variables were not statistically different between the two groups for the Aware-Lower Quality, Unaware-Higher Quality, and Unaware-Lower Quality conditions. Within the Aware-Higher Quality condition, the WOA variable was not statistically different, however, the accuracy scores were significantly different. The mean accuracy score for the failing sample and the passing participants was $-\$ 1,705,962$ and $\$ 45,723$, respectively $(t=2.20$, $\mathrm{p}=0.0448$, two-tailed).

Although these results provide that the pre-advice task and full case times between the a priori aware groups as well as the accuracy scores for the Unaware-Higher Quality Advice condition are statistically different from the failing sample, this does not indicate that the failing group should be excluded from the full sample. Since 20 of the 29 failing participants (70\%) were in the a priori unaware condition, the wording of the question may have proved to be confusing. The case materials were silent to the use of a subject matter expert for this condition and, as such, the participants may have responded to what they believe an audit team's reaction would be or what they believed their firm's required use of a subject matter expert would be in a similar situation. Therefore, it appears reasonable to retain those auditors who failed the manipulation check question in the full testing sample.

Exclusion of Auditors Who Did Not Agree that Auditors at Their Rank Would Perform the Duties Required in the Case

In order to assess if there were any differences between those auditors who agreed that auditors at their rank would perform the duties as outlined in the case to those that disagreed, I conducted testing using only the 42 auditors who agreed with the statement. I first tested for a difference by condition using agreement as a dependent variable and the experimental treatment 
as a single four-level variable. The untabulated one-way ANOVA results indicate that there is not a significant difference in the number of those auditors who passed across the four experimental groups $(\mathrm{F}=0.34, \mathrm{p}=0.7976$, two tailed $)$.

Next, I tested the individual dependent variables utilized for the hypothesis testing to gain an understanding if the agreeing auditors provided different responses from the auditors that disagreed. The main dependent variables of pre-advice task time and full task time did not differ significantly within the a priori aware groups. However, the acceptance of management's position variable did differ significantly. The mean acceptance of management's position for the disagree sample and the agreeing sample was $\$ 4,334,068$ and $\$ 4,357,395$, respectively $(\mathrm{t}=8.18$, $\mathrm{p}<0.0001$, two-tailed). None of the main dependent variables differed significantly between the a priori unaware groups. The WOA and accuracy variables were not statistically different between the two groups for the Aware-Lower Quality, Aware-Higher Quality, Unaware-Higher Quality, and Unaware-Lower Quality conditions.

These results indicate that the agreeing auditors are overall similar to the disagree sample and are therefore not driving results. Although the acceptance with management's position scores between the aware groups are statistically different from the disagree sample, this does not indicate a robustness issue with results from the full sample. As the agreeing auditors are spread across all four conditions, this should alleviate any issues with these auditors driving results in one direction or another. 


\section{CHAPTER 5}

\section{CONCLUSION, CONTRIBUTIONS, LIMITATIONS AND FUTURE RESEARCH}

This final chapter reviews the results of the hypothesis testing presented in Chapter Four. It also includes a discussion of the contributions this study makes to extant literature and the implications for research and practice. The chapter concludes with a discussion of the limitations of the study and avenues for future research.

\section{Summary and Conclusions}

In this dissertation, I examine how a priori awareness of the use of an internal subject matter expert and the quality of advice received from the subject matter expert can influence the ability of auditors to discern the quality of the advice provided and, in turn, the accuracy of the auditors' final judgment. Although a subject matter expert is deemed an expert by an audit team, auditing standards require core audit teams to assess the information provided by these experts. PCAOB inspection reports for the past several years have identified deficiencies by audit firms regarding the assessment of information provided by specialists and experts utilized by core audit teams. The purpose of this study is to examine if audit environmental factors may be impacting if and how well auditors are assessing information provided by subject matter experts. Specifically, I examine if an auditor is aware that a subject matter expert will be utilized for a specific issue before the auditor performs any work surrounding that issue, will that influence the level of effort employed by that auditor when assessing the issue pre-advice, the acceptance of advice from the subject matter expert regardless of the quality of advice provided, and finally the accuracy of the final judgment made by the auditor. If advice is of lower quality, the final judgment made by the audit team may be inaccurate, and as such, can lead to a potential misstatement in the audited financial statements. This study shows that awareness impacts the 
pre-advice level of effort employed by auditors. In addition, this study provides evidence that awareness impacts the weight auditors place on advice received from subject matter experts, regardless of quality. This study also provides evidence that accuracy is impacted by a priori awareness and advice quality. My predictions are motivated by the advice taking literature, which states that use of a perceived expert, lower levels of effort, and lower confidence leads to more weight being placed on advice received when individuals are making a final judgment.

In an experiment involving 77 professional auditors, I examined how judgments regarding a complex revenue recognition issue were impacted if the auditor was made aware of the future use of an internal subject matter expert prior to making an initial judgment. I also examined auditors' ability to assess the quality of the advice received and finally, if the initial judgment was adjusted due to the assessment of the advice quality and the quality of advice received. Auditors were introduced to the revenue recognition issue after the awareness manipulation (where those a priori aware were told that an internal subject matter expert was to be used and case materials were silent to the use of an internal subject matter expert for those a priori unaware), provided with management's position, and then asked to provided their initial judgment of the amount of revenue that should be recognized. The first set of hypotheses was tested using the initial judgment provided.

I predicted, and found support, that those auditors a priori unaware would exert a lower level of effort arriving at their initial judgment when compared to those a priori aware. These results indicate that a priori awareness impacts level of effort. Since auditors are expected to assess the quality of information received from an expert, if auditors are not putting for effort in assessing the issue, they may be lowering their ability to discern the quality of information provided by an expert. I also expected, but did not find statistical support, that those a priori 
unaware would have lower confidence in their initial judgment when compared to those unaware. Finally, due to the expected lower level of effort and lower confidence levels, I predicted that those auditors a priori unaware would provide an initial judgment that was closer to management's position when compared to those a priori aware. Results indicate that this expectation was met. The results indicate that if auditors are a priori unaware of the use of a subject matter expert and are more likely to accept management's position, they may be likely to accept a subject matter expert's advice if it is in line with management's position without appropriately assessing the quality of the advice.

Next, the auditors were told of the use of a subject matter expert (or reminded), reminded of the auditing standards that require the assessment of information provided to them by subject matter experts, and then provided with the subject matter expert's advice in the form of a formal memo that was explicit regarding the amount of revenue that management should recognize. The advice was manipulated for quality through client specific facts not used by the lower quality advice. The auditors were then asked to provide their recommendation of revenue that should be recognized to the audit team. This judgment was used to test the final set of hypotheses.

I predicted that auditors a priori unaware would place more weight on the advice, regardless of advice quality when compared to those a priori aware. Results provide support for this hypothesis. These results indicate that if an auditor is a priori unaware, they may more willingly rely on advice provided by a subject matter expert, regardless of the quality of advice.

Regarding accuracy of the final recommendation, I predicted and find that auditors who received higher quality advice would have no difference in accuracy, regardless if they were a priori aware or unaware. As such, these results indicate that as long as the advice is of high quality, accuracy of auditors' decisions will not be impaired. Finally, for those who received 
lower quality advice, I expected and found that those in the a priori aware group to be more accurate when compared to those in the unaware group due to their greater ability to discern the quality of the advice. These results indicate that accuracy will be impacted if auditors are a priori unaware of the use of a subject matter expert, which lowers their ability to discern the quality of advice, and receive lower quality advice.

Overall, these results indicate that both the quality of the advice received and auditors' a priori awareness of whether they are going to eventually receive advice impact their behavior when receiving advice from subject matter experts. With respect to awareness, auditors who are a priori aware expend more effort on the task at the pre-advice stage and on the entire task relative to auditors who are a priori unaware. This indicates that awareness may create a sense of joint responsibility towards the task that impacts auditors overall effort both at the pre-advice and post- advice stages. The higher level of effort at the pre-advice stage may allow auditors scrutinize the client data more rigorously. Consequently, auditors who are a priori aware take a pre-advice position that is more conservative when compared to auditors who are a priori unaware. In addition, the results show that the quality of the advice from the subject matter experts impact auditors advice taking behavior. When auditors receive higher quality advice, they recognize the quality of the advice and incorporate this advice regardless of whether they were a priori aware or unaware that the advice was going to be provided. However, an interesting pattern of results emerges when auditors receive lower quality advice. Auditors who are a priori unaware tend to gravitate towards the lower quality advice. On the other hand, auditors who were a priori aware were more discerning of the advice and took a final position that was closer to the higher quality advice rather than the lower quality advice they actually received. 
Therefore, the benefits of being a priori aware persisted even after auditors in all groups received the advice.

\section{Research Implications}

This research extends the advice taking literature in auditing by examining three unexplored aspects of the use of formal advice received from internal firm subject matter experts. First, it provides an understanding of the impact that prior awareness of the use of subject matter experts can have on auditors' acceptance of formal advice. Second, it explores the impact of awareness on the assessment of the quality of formal advice. Third, it provides insight into the joint impact of awareness and the quality of formal advice on auditors' assessment of advice accuracy and resulting decisions. The study also contributes to psychology literature on advice taking by exploring if advice awareness can impact the use of subsequent advice. Furthermore, by examining the role of advice taking on final decision accuracy, I specifically address a shortcoming identified in prior advice taking literature in psychology (Bonaccio and Dalal 2006). Finally, as the audit team can be looked upon as a small group, I am bringing together the role of group decision making, through the awareness variable, and the advice taking literature. Prior advice taking literature in psychology has cited this area worthwhile for exploration (Bonaccio and Dalal 2006).

\section{Practical Implications}

The results of this study should be of interest to both audit regulators and practitioners by improving the understanding that the knowledge of planned audit procedures can have on auditors' assessment of advice from SMEs and the resulting decision accuracy. As recent PCAOB inspection reports suggest, auditors are neglecting to perform the required assessment of advice (Church and Shefchik 2012). Understanding why this may be occurring can potentially 
lead to changes in auditing standards and firm policies and practices. Of particular importance, is the impact awareness may have on auditors' level of effort and acceptance of lower quality advice. Making practitioners aware of this potential drawback that can occur due the a priori unknown use of subject matter experts should allow for practitioners to implement firm policies and provide training to audit staff educating them on this issue.

\section{Limitations and Future Research}

This study has some inherent limitations due to choices made in the experimental design and execution. The task pertains to a single issue: revenue recognition of multiple elements. The results may not generalize to all types of accounting issues. As revenue recognition is regarded as high risk (AICPA 2002), it is reasonable that a subject matter expert would be involved when dealing with a revenue recognition issue. Also, the internal firm formal advice is received from a designated subject matter expert, as such, the results may not generalize to other types of formal advice. However, because subject matter experts are common within audit firms, it would not be uncommon for audit teams to receive formal advice from a subject matter expert on an issue. It is also important to note that the participants in the study make a preliminary assessment and audit recommendation of the amount of revenue recognition to be recognized by year-end. Although the preliminary audit assessment and recommendation are routinely done by in-charge auditors, the final audit judgment is typically performed by the core team headed by an engagement partner and manager. This study does not address how the variables studied would be impacted when an engagement manager or partner is involved in the audit process, but provides a path leading to this potential future research. In addition, the participants in this study were unable to request additional information to aid them in their assessments. 
This study can open additional research avenues. As more subject matter experts are being used by audit teams, understanding their interactions and communications can be important in understanding how to improve audit quality. In addition, recognizing that subject matter experts may not provide superior advice consistently can lead to additional areas for research. Finally, the idea of examining awareness had been mainly focused on in the audit review process literature. As firms continue to put forth more effort towards planning audits, understanding the consequences of items such as the awareness of the use of subject matter experts can help improve audit efficiency and effectiveness. 
FIGURES 
Figure 1. Tasks Presented and Progression

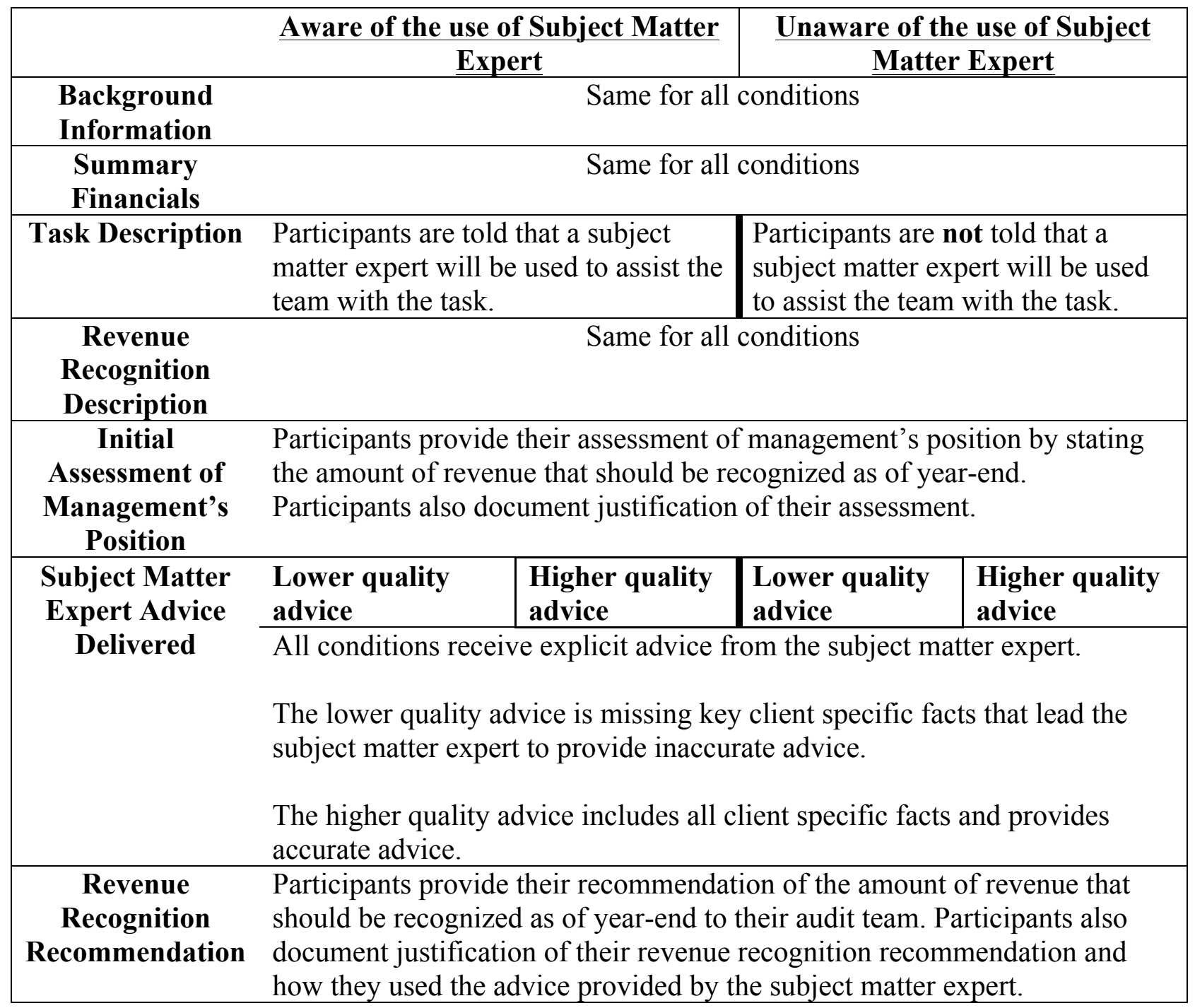


Figure 2. Predicted Effects of Awareness and Quality of Advice

Predicted Effects of Awareness and Quality of Advice on Accuracy of Revenue Recognition Recommendation (H5a and H5b)

Accurate

Accuracy of

Revenue

Recognition

Recommendation

Not Accurate
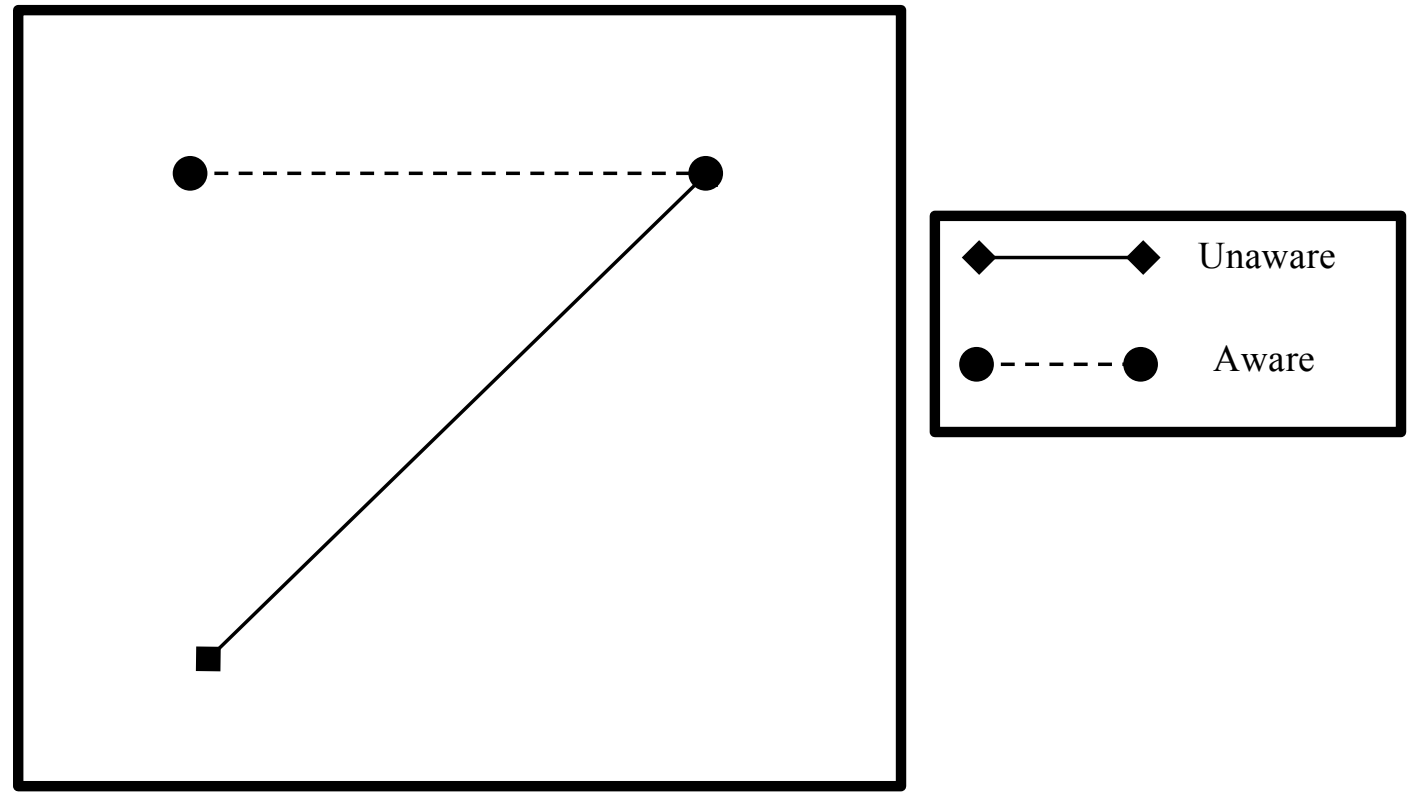

Low Quality

High Quality 
Figure 3. Interaction Between Awareness and Advice Quality on Accuracy

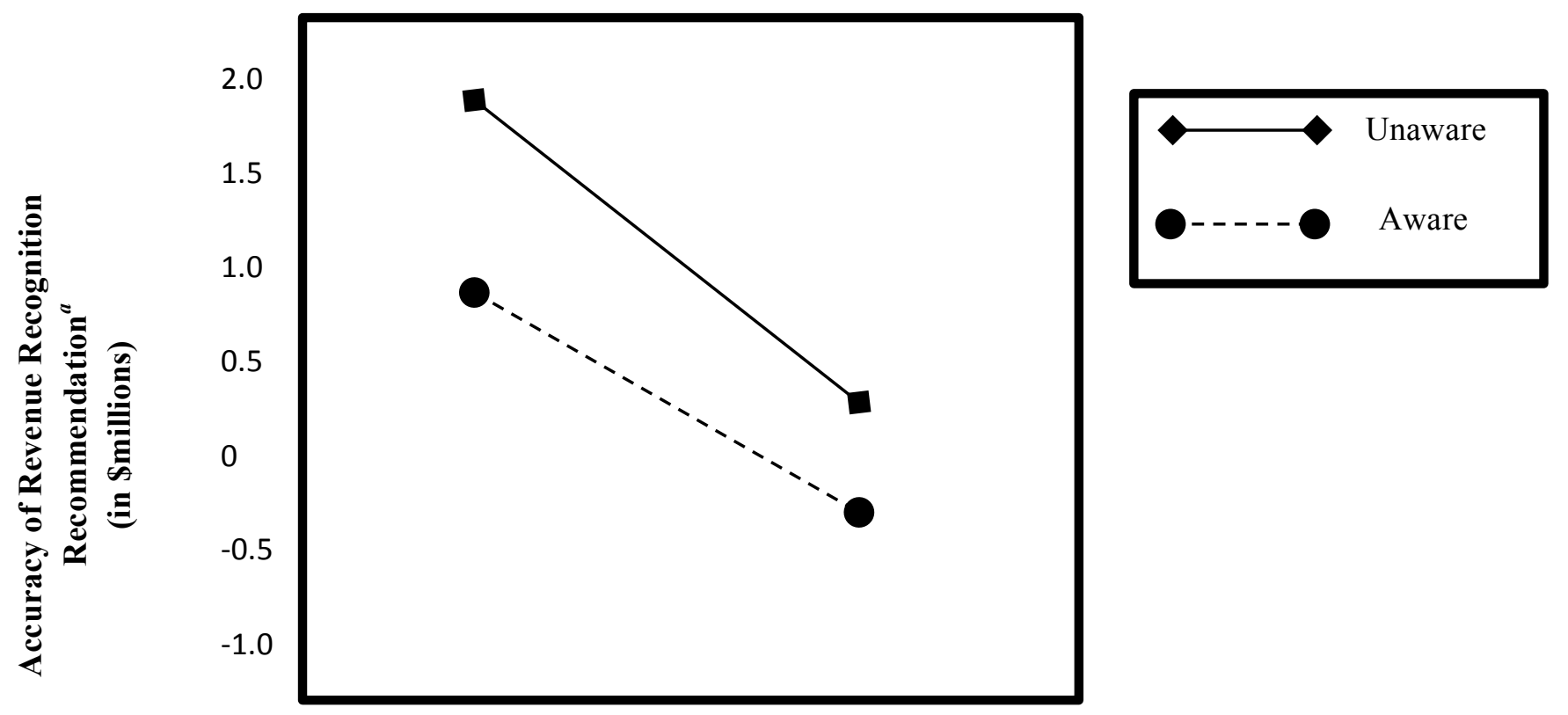

Lower Quality Higher Quality

\section{Notes:}

${ }^{a}$ Accuracy is calculated as the difference between the auditor's final judgment and the accurate amount of revenue to be recognized. Note that the smaller the accuracy score the more accurate the final judgment. 
TABLES 


\begin{tabular}{|c|c|c|c|c|c|c|}
\hline \multicolumn{7}{|c|}{$\begin{array}{c}\text { TABLE } 1 \\
\text { Descriptive Statistics of Post-Experimental Responses by Condition } \\
(\mathrm{n}=77)\end{array}$} \\
\hline \multicolumn{7}{|c|}{ Mean (Standard Deviation) } \\
\hline & $\begin{array}{l}\text { Aware } \\
\text { Lower } \\
\text { Quality } \\
(\mathbf{n}=\mathbf{1 6})\end{array}$ & $\begin{array}{l}\text { Aware } \\
\text { Higher } \\
\text { Quality } \\
(\mathbf{n}=\mathbf{1 8})\end{array}$ & $\begin{array}{l}\text { Unaware } \\
\text { Lower } \\
\text { Quality } \\
(\mathbf{n}=\mathbf{2 1})\end{array}$ & $\begin{array}{l}\text { Unaware } \\
\text { Higher } \\
\text { Quality } \\
(\mathbf{n}=\mathbf{2 2})\end{array}$ & F-statistic & p-value \\
\hline Professional Experience $^{\mathrm{a}}$ & 38.4 & 38.7 & 42.2 & 39.5 & 0.33 & 0.8021 \\
\hline $\begin{array}{l}\text { Experience Deal with } \\
\text { Revenue Recognition }\end{array}$ & 4.6 & 3.7 & 3.9 & 3.9 & 0.79 & 0.5031 \\
\hline $\begin{array}{l}\text { Use of Internal Firm } \\
\text { Subject Matter Experts } \\
\text { on Engagements }\end{array}$ & 2.1 & 2.2 & 2.6 & 2.5 & 0.44 & 0.7232 \\
\hline $\begin{array}{l}\text { If Auditors at Their Rank } \\
\text { Would Perform the Case } \\
\text { Required Duties }\end{array}$ & $50 \%$ & $50 \%$ & $52.4 \%$ & $63.6 \%$ & 0.34 & 0.7976 \\
\hline $\begin{array}{l}\text { Acceptance of Advice } \\
\text { Propensity }\end{array}$ & 1.8 & 1.7 & 1.5 & 2.0 & 1.06 & 0.3729 \\
\hline \multicolumn{7}{|l|}{ Notes: } \\
\hline \multicolumn{7}{|l|}{ All p-values are two-tailed } \\
\hline \multicolumn{7}{|c|}{${ }^{a}$ Months of work experience as an audit professional } \\
\hline \multicolumn{7}{|c|}{$\begin{array}{l}\text { "Auditors' self-rating for the question "How often do you deal with assessing revenue recognition policies employed by } \\
\text { clients?" ( } 1=\text { Never; } 7 \text { = All the Time })\end{array}$} \\
\hline \multicolumn{7}{|c|}{$\begin{array}{l}\text { "Auditors' response to the question "How many of your audit engagements have employed the use of internal firm subject } \\
\text { matter experts during the most recent financial statement audit?" }\end{array}$} \\
\hline \multicolumn{7}{|c|}{$\begin{array}{l}\text { Auditors' response to the question, "When auditing a company similar to the company in the case study, would an auditor } \\
\text { at your rank be responsible to evaluate the advice provided by the subject matter expert to assess if all the appropriate client } \\
\text { specific facts were utilized?" (\% of affirmative responses) }\end{array}$} \\
\hline \multicolumn{7}{|c|}{$\begin{array}{l}\text { "Average score of the three questions; "I believe that seeking advice during an engagement suggests a lack of technical } \\
\text { expertise," "I believe that seeking advice conveys a lack of confidence," and "I believe that seeking advice negatively } \\
\text { affects performance evaluations at the end of the audit engagement." ( } 1=\text { I fully disagree; } 7=\text { I fully agree })\end{array}$} \\
\hline
\end{tabular}




\begin{tabular}{|l|ccc|}
\hline \multicolumn{5}{|c|}{$\begin{array}{c}\text { TABLE 2 } \\
\text { Results for Hypothesis 1 }\end{array}$} \\
Descriptive Statistics and ANCOVA Results \\
Impact of Awareness on Level of Effort - Time Spent on the Pre-Advice Task
\end{tabular}

Panel B: ANCOVA Results for Dependent Variable - Time Spent on the Pre-Advice Task (in minutes)

Covariate - Experience with Revenue Recognition ${ }^{e}$

\begin{tabular}{lcccc} 
Source of Variation & $d f$ & Sum of Squares & F-Ratio & p-value \\
Awareness & 1 & 450.3360 & 2.69 & $0.0527^{a}$ \\
$\begin{array}{l}\text { Experience with Revenue } \\
\text { Recognition }\end{array}$ & 1 & 428.7652 & 2.56 & $0.1140^{b}$ \\
Error & 74 & 12402.8376 & & \\
\hline
\end{tabular}

\begin{tabular}{|l|}
\hline Notes: \\
\hline${ }^{a}$ p-values are one-tailed \\
\hline${ }^{b}$ p-values are two-tailed \\
\hline${ }^{c}$ Participants in the aware group were told before the pre-advice judgment task that an internal \\
subject matter expert will be used by the engagement team. Participants in the unaware group \\
were not told that an internal subject matter expert would be utilized during in the pre-advice \\
judgment task. \\
${ }^{d}$ All reported means are adjusted means from an ANCOVA with awareness as the independent \\
variable and experience with revenue recognition as the covariate. \\
\hline${ }^{e}$ Auditors' self-rating for the question "How often do you deal with assessing revenue \\
recognition policies employed by clients?" (1 = Never; $7=$ All the Time $)$ \\
\hline
\end{tabular}




\begin{tabular}{|c|c|c|c|c|c|}
\hline & $\begin{array}{r}\text { D } \\
\text { Awa }\end{array}$ & $\begin{array}{r}T \\
\text { esults } f \\
\text { Statisti } \\
\text { Level of }\end{array}$ & $\begin{array}{l}3 \\
\text { othesis } 1 \\
\text { ANCOVA } \\
\text { - Time S }\end{array}$ & the To & \\
\hline & & & & & \\
\hline Awareness $^{c}$ & $N$ & Means & Std. Dev. & Min. & $\operatorname{Max}$ \\
\hline Aware & 34 & 33.62 & 18.0815 & 5.69 & 102.67 \\
\hline Unaware & 43 & 27.59 & 9.9334 & 6.89 & 58.76 \\
\hline
\end{tabular}

Panel B: ANCOVA Results for Dependent Variable - Time Spent on Total Case (in minutes) Covariate - Experience with Revenue Recognition ${ }^{d}$

\begin{tabular}{lcccc} 
Source of Variation & $d f$ & Sum of Squares & F-Ratio & p-value \\
Awareness & 1 & 687.5750 & 3.52 & $0.0322^{a}$ \\
$\begin{array}{l}\text { Experience with Revenue } \\
\text { Recognition }\end{array}$ & 1 & 400.9889 & & \\
Error & 74 & 14450.8582 & 2.05 & $0.1561^{b}$ \\
\hline
\end{tabular}

\begin{tabular}{|l|}
\hline Notes: \\
\hline${ }^{a} \mathrm{p}$-values are one-tailed \\
\hline${ }^{b}$-values are two-tailed \\
\hline${ }^{c}$ Participants in the aware group were told before the pre-advice judgment task that an internal \\
subject matter expert will be used by the engagement team. Participants in the unaware group \\
were not told that an internal subject matter expert would be utilized during in the pre-advice \\
judgment task. \\
\hline${ }^{d}$ Auditors' self-rating for the question "How often do you deal with assessing revenue \\
recognition policies employed by clients?" ( $1=$ Never; $7=$ All the Time $)$ \\
\hline
\end{tabular}




\begin{tabular}{|c|c|c|c|c|c|}
\hline \multicolumn{6}{|c|}{$\begin{array}{c}\text { TABLE } 4 \\
\text { Results for Hypothesis } 2 \\
\text { Descriptive Statistics and ANCOVA Results } \\
\text { Impact of Awareness on Confidence }\end{array}$} \\
\hline \multicolumn{6}{|c|}{ Panel A: Descriptive Statistics for Dependent Variable - Confidence $^{a}$} \\
\hline Awareness ${ }^{b}$ & $\bar{N}$ & Means & Std. Dev. & Min. & $\operatorname{Max}$ \\
\hline Aware & 34 & 4.99 & 1.1822 & 2 & 7 \\
\hline Unaware & 43 & 5.01 & 0.9864 & 3 & 7 \\
\hline
\end{tabular}

Panel B: ANCOVA Results for Dependent Variable - Confidence Covariate - Experience with Revenue Recognition ${ }^{d}$

\begin{tabular}{lcccc|} 
Source of Variation & $d f$ & Sum of Squares & F-Ratio & $p$-value \\
Awareness & 1 & 0.0128 & 0.01 & $0.4563^{a}$ \\
$\begin{array}{l}\text { Experience with Revenue } \\
\text { Recognition }\end{array}$ & 1 & 8.9261 & & \\
Error & 74 & 78.0611 & 8.46 & $0.0048^{b}$ \\
\hline
\end{tabular}

\begin{tabular}{|l|}
\hline Notes: \\
\hline${ }^{a}$-values are one-tailed \\
\hline${ }^{b}$-values are two-tailed \\
${ }^{a}$ Average of Auditors' responses to the following questions, "I think my revenue recognition \\
estimate is accurate," "I am very certain about the accuracy of my revenue recognition \\
judgment," "I am sure I am performing well on this revenue recognition task," and "I felt that I \\
had adequate time to complete the required task." ( 1 = I fully disagree; 7 = I fully agree) \\
\hline${ }^{b}$ Participants in the aware group were told before the pre-advice judgment task that an internal \\
subject matter expert will be used by the engagement team. Participants in the unaware group \\
were not told that an internal subject matter expert would be utilized during in the pre-advice \\
judgment task.
\end{tabular}


TABLE 5

Pearson Correlation Matrix of Variables

\begin{tabular}{|c|c|c|c|c|c|c|c|c|c|c|c|c|c|c|c|}
\hline & $\begin{array}{l}\text { Prof } \\
\text { Exper }\end{array}$ & Big 4 & $\begin{array}{c}\text { Rev } \\
\text { Rec } \\
\text { Exper }\end{array}$ & $\begin{array}{l}\text { SME } \\
\text { Exper }\end{array}$ & $\begin{array}{c}\text { Rank } \\
\text { Perform } \\
\text { Duties }\end{array}$ & $\begin{array}{l}\text { Accept } \\
\text { Advice } \\
\text { Pro }\end{array}$ & Aware $^{a}$ & Advice $^{b}$ & $\begin{array}{c}\text { Pre- } \\
\text { advice } \\
\text { Time }\end{array}$ & $\begin{array}{l}\text { Total } \\
\text { Case } \\
\text { Time }\end{array}$ & Confidence & $\begin{array}{c}\text { Accept } \\
\text { Mgt } \\
\text { Position }\end{array}$ & WOA & Accuracy & $\begin{array}{l}\text { Advice } \\
\text { Quality }\end{array}$ \\
\hline \multirow{2}{*}{$\begin{array}{l}\text { Prof Exper } \\
\text { (p-value) }\end{array}$} & \multirow[t]{2}{*}{1} & 0.103 & $.338 * *$ & 0.255 & $-.352 * *$ & -0.081 & -0.085 & 0.259 & -0.136 & -0.135 & 0.001 & -0.01 & 0.121 & 0.022 & -0.044 \\
\hline & & 0.375 & 0.003 & 0.025 & 0.002 & 0.486 & 0.464 & 0.823 & 0.237 & 0.243 & 0.992 & 0.928 & 0.369 & 0.83 & 0.706 \\
\hline \multirow{2}{*}{ Big 4} & 0.103 & \multirow[t]{2}{*}{1} & $-.284 * *$ & $-.195 *$ & -0.175 & 0.086 & -0.029 & 0.046 & -0.138 & -0.184 & -0.01 & 0.066 & 0.04 & 0.01 & -0.168 \\
\hline & 0.375 & & 0.012 & 0.09 & 0.127 & 0.456 & 0.804 & 0.693 & 0.232 & 0.109 & 0.905 & 0.566 & 0.769 & 0.928 & 0.144 \\
\hline \multirow{2}{*}{$\begin{array}{l}\text { Rev Rec } \\
\text { Exper }\end{array}$} & $.338^{* *}$ & $-.284 * *$ & \multirow[t]{2}{*}{1} & 0.041 & -0.147 & -0.168 & 0.076 & 0.118 & 0.18 & -0.161 & $.320^{* *}$ & -0.022 & -0.125 & 0.043 & $.320^{* *}$ \\
\hline & 0.003 & 0.012 & & 0.722 & 0.202 & 0.145 & 0.51 & 0.307 & 0.118 & 0.163 & 0.005 & 0.848 & 0.355 & 0.708 & 0.005 \\
\hline \multirow[t]{2}{*}{ SME Exper } & 0.255 & $-.195 *$ & 0.041 & 1 & -0.124 & 0.069 & -0.129 & -0.005 & -0.071 & -0.106 & 0.054 & -0.052 & -0.018 & -0.035 & 0.048 \\
\hline & 0.025 & 0.09 & 0.722 & & 0.283 & 0.55 & 0.263 & 0.965 & 0.54 & 0.36 & 0.64 & 0.651 & 0.892 & 0.764 & 0.677 \\
\hline \multirow{2}{*}{$\begin{array}{c}\text { Rank } \\
\text { Perform } \\
\text { Duties }\end{array}$} & $.352 * *$ & -0.175 & -0.147 & -0.124 & \multirow[t]{2}{*}{1} & -0.013 & 0.081 & 0.09 & 0.043 & 0.008 & -0.043 & 0.057 & 0.167 & 0.095 & -0.062 \\
\hline & 0.002 & 0.127 & 0.202 & 0.283 & & 0.914 & 0.483 & 0.436 & 0.711 & 0.944 & 0.711 & 0.625 & 0.213 & 0.41 & 0.594 \\
\hline \multirow{2}{*}{$\begin{array}{c}\text { Accept } \\
\text { Advice Pro }\end{array}$} & -0.081 & 0.086 & -0.168 & 0.069 & -0.013 & \multirow[t]{2}{*}{1} & -0.002 & -0.164 & -0.089 & -0.108 & -0.141 & -0.082 & 0.117 & -0.013 & 0.082 \\
\hline & 0.486 & 0.456 & 0.145 & 0.55 & 0.914 & & 0.985 & 0.153 & 0.439 & 0.349 & 0.22 & 0.478 & 0.385 & 0.908 & 0.481 \\
\hline \multirow[t]{2}{*}{ Aware } & -0.085 & -0.029 & 0.076 & -0.129 & 0.081 & -0.002 & 1 & -0.041 & 0.17 & $.198^{*}$ & 0.012 & $-.242 * *$ & $-.231 *$ & -0.181 & 0.07 \\
\hline & 0.464 & 0.804 & 0.51 & 0.263 & 0.483 & 0.985 & & 0.725 & 0.14 & 0.085 & 0.915 & 0.034 & 0.083 & 0.114 & 0.545 \\
\hline \multirow[t]{2}{*}{ Advice } & 0.259 & 0.046 & 0.118 & -0.005 & 0.09 & -0.164 & -0.041 & 1 & -0.079 & -0.1 & $.287 * *$ & 0.029 & 0.076 & $.274 * *$ & $-.662 * *$ \\
\hline & 0.823 & 0.693 & 0.307 & 0.965 & 0.436 & 0.153 & 0.725 & & 0.494 & 0.383 & 0.011 & 0.8 & 0.575 & 0.016 & $<.000$ \\
\hline \multirow{2}{*}{$\begin{array}{l}\text { Pre-advice } \\
\text { Time }\end{array}$} & -0.136 & -0.138 & 0.18 & -0.071 & 0.043 & -0.089 & 0.17 & -0.079 & 1 & $.967 * *$ & -0.146 & 0.199 & 0.091 & 0.019 & 0.135 \\
\hline & 0.237 & 0.232 & 0.118 & 0.54 & 0.711 & 0.439 & 0.14 & 0.494 & & $<.000$ & 0.205 & 0.082 & 0.502 & 0.868 & 0.243 \\
\hline
\end{tabular}




\begin{tabular}{|c|c|c|c|c|c|c|c|c|c|c|c|c|c|c|c|}
\hline $\begin{array}{l}\text { Total Case } \\
\text { Time }\end{array}$ & $\begin{array}{r}-0.135 \\
0.243\end{array}$ & $\begin{array}{r}-0.184 \\
0.109\end{array}$ & $\begin{array}{r}-0.161 \\
0.163\end{array}$ & $\begin{array}{r}-0.106 \\
0.36\end{array}$ & $\begin{array}{l}0.008 \\
0.944\end{array}$ & $\begin{array}{r}-0.108 \\
0.349\end{array}$ & $\begin{array}{l}.198^{*} \\
0.085\end{array}$ & $\begin{array}{r}-0.1 \\
0.383\end{array}$ & $\begin{array}{l}.967 * * \\
<.000\end{array}$ & 1 & $\begin{array}{r}-0.121 \\
0.296\end{array}$ & $\begin{array}{l}0.203 \\
0.076\end{array}$ & $\begin{array}{l}0.001 \\
0.996\end{array}$ & $\begin{array}{l}0.005 \\
0.964\end{array}$ & $\begin{array}{l}0.161 \\
0.163\end{array}$ \\
\hline \multirow{2}{*}{ Confidence } & 0.001 & -0.01 & $.320^{* *}$ & 0.054 & -0.043 & -0.141 & 0.012 & $.287 * *$ & -0.146 & -0.121 & 1 & 0.092 & -0.166 & -0.076 & $-.202^{*}$ \\
\hline & 0.992 & 0.905 & 0.005 & 0.64 & 0.711 & 0.22 & 0.915 & 0.011 & 0.205 & 0.296 & & 0.425 & 0.217 & 0.509 & 0.079 \\
\hline \multirow{2}{*}{$\begin{array}{l}\text { Accept Mgt } \\
\text { Position }\end{array}$} & -0.01 & 0.066 & -0.022 & -0.052 & 0.057 & -0.082 & $-.242 * *$ & 0.029 & 0.199 & 0.203 & 0.092 & 1 & -0.328 & $-.764 * *$ & 0.06 \\
\hline & 0.928 & 0.566 & 0.848 & 0.651 & 0.625 & 0.478 & 0.034 & 0.8 & 0.082 & 0.076 & 0.425 & & 0.013 & $<.000$ & 0.605 \\
\hline \multirow[t]{2}{*}{ WOA } & 0.121 & 0.04 & -0.125 & -0.018 & 0.167 & 0.117 & $-.231 *$ & 0.076 & 0.091 & 0.001 & -0.166 & -0.328 & 1 & $.255^{*}$ & -0.166 \\
\hline & 0.369 & 0.769 & 0.355 & 0.892 & 0.213 & 0.385 & 0.083 & 0.575 & 0.502 & 0.996 & 0.217 & 0.013 & & 0.055 & 0.217 \\
\hline \multirow[t]{2}{*}{ Accuracy } & 0.022 & 0.01 & 0.043 & -0.035 & 0.095 & -0.013 & -0.181 & $.274 * *$ & 0.019 & 0.005 & -0.076 & $-.764 * *$ & $.255^{*}$ & 1 & $-.336^{* *}$ \\
\hline & 0.83 & 0.928 & 0.708 & 0.764 & 0.41 & 0.908 & 0.114 & 0.016 & 0.868 & 0.964 & 0.509 & $<.000$ & 0.055 & & 0.001 \\
\hline \multirow{2}{*}{$\begin{array}{c}\text { Advice } \\
\text { Quality } \\
\text { Assessment }\end{array}$} & -0.044 & -0.168 & -0.035 & 0.048 & -0.062 & 0.082 & 0.07 & $-.662 * *$ & 0.135 & 0.161 & $-.202^{*}$ & 0.06 & -0.001 & $-.336^{* *}$ & 1 \\
\hline & 0.706 & 0.144 & 0.766 & 0.677 & 0.594 & 0.481 & 0.545 & $<.000$ & 0.243 & 0.163 & 0.079 & 0.605 & 0.992 & 0.001 & \\
\hline
\end{tabular}

\section{Notes:}

${ }^{*}$ Significant at the 0.10 level

* Significant at the 0.05 level

${ }^{a}$ Aware variable equals 1 for a priori aware and 0 for a priori unaware

${ }^{b}$ Advice variable equals 1 for lower quality advice and 0 for higher quality advice 


\begin{tabular}{|lccccc|}
\hline \multicolumn{5}{|c|}{$\begin{array}{c}\text { TABLE 6 } \\
\text { Results for Hypothesis 3 }\end{array}$} \\
\multicolumn{5}{|c|}{$\begin{array}{l}\text { Descriptive Statistics and ANCOVA Results } \\
\text { Impact of Awareness on Acceptance of Management's Position }\end{array}$} \\
\hline \multicolumn{4}{|c|}{ Panel A: Descriptive Statistics for Dependent Variable - Acceptance of Management's Position ${ }^{a}$} \\
\hline Awareness ${ }^{b}$ & $N$ & Means & Std. Dev. & Min. & Max \\
Aware & 34 & $\$ 4,169,535$ & 3572171.22 & 0 & $11,263,457$ \\
Unaware & 43 & $\$ 2,860,087$ & 1460394.79 & $1,370,250$ & $7,508,970$ \\
\hline
\end{tabular}

\begin{tabular}{|lcccc|}
\hline \multicolumn{4}{|l|}{$\begin{array}{l}\text { Panel B: ANCOVA Results for Dependent Variable - Acceptance of Management's Position } \\
\text { Covariate - Experience with Revenue Recognition }\end{array}$} \\
\hline $\begin{array}{l}\text { Source of Variation } \\
\text { Awareness }\end{array}$ & $d f$ & Sum of Squares & F-Ratio & p-value \\
$\begin{array}{l}\text { Experience with Revenue } \\
\text { Recognition }\end{array}$ & 1 & $3.2367 \mathrm{E} 13$ & 4.70 & $0.0167^{a}$ \\
Error & 1 & 267712623377 & 0.04 & $0.8443^{b}$ \\
\hline
\end{tabular}

\begin{tabular}{|l|}
\hline Notes: \\
\hline${ }^{a}$ p-values are one-tailed \\
${ }^{b}$ p-values are two-tailed \\
\hline${ }^{a}$ Agreement with management's position was calculated as the difference between the amount \\
recognized by management per the case materials and the pre-advice revenue recognition \\
judgment provided by participants. \\
\hline${ }^{b}$ Participants in the aware group were told before the pre-advice judgment task that an internal \\
subject matter expert will be used by the engagement team. Participants in the unaware group \\
were not told that an internal subject matter expert would be utilized during in the pre-advice \\
judgment task. \\
\hline
\end{tabular}




\begin{tabular}{|c|c|c|}
\hline & $\begin{array}{l}\text { TABLE } 7 \\
\text { Its for Hypothes } \\
\text { tistics and ANC } \\
\text { d Advice Quali }\end{array}$ & Advice \\
\hline Panel A: De & eans (Std. Dev & $f$ Advice ${ }^{c}$ \\
\hline & & \\
\hline Awareness $^{d}$ & Lower Quality & Higher Quality \\
\hline Aware & 0.5446 & 0.3998 \\
\hline & $(0.5043)$ & $(0.5002)$ \\
\hline & [9] & [16] \\
\hline Unaware & 0.6562 & 0.6839 \\
\hline & $(0.6924)$ & $(0.4651)$ \\
\hline & [12] & [20] \\
\hline
\end{tabular}

Panel B: ANCOVA Results for Dependent Variable - Weight of Advice

Covariates - Experience with Revenue Recognition and Experience with Subject Matter Experts

\begin{tabular}{lcccc|} 
Source of Variation & $d f$ & Sum of Squares & F-Ratio & $p$-value \\
Aware & 1 & 0.6834 & 2.83 & $0.0495^{a}$ \\
Advice Quality $^{e}$ & 1 & 0.0287 & 0.12 & $0.7319^{b}$ \\
$\begin{array}{l}\text { Aware * Advice Quality } \\
\text { Experience with Subject }\end{array}$ & 1 & 0.0938 & 0.39 & $0.5363^{b}$ \\
$\begin{array}{l}\text { Matter Experts } \\
\begin{array}{l}\text { Experience with Revenue } \\
\text { Recognition }\end{array}\end{array}$ & 1 & 0.2081 & 0.86 & $0.3580^{b}$ \\
Error & 1 & 0.0041 & 0.02 & $0.8973^{b}$ \\
\hline
\end{tabular}

\begin{tabular}{|lcc|}
\hline Panel C: $t$-Test Comparisons of Group within Condition & & \\
\hline Comparison & $t$-statistic & $p$-value \\
Aware vs. Unaware within Lower Quality Advice & 0.50 & $0.3083^{a}$ \\
Aware vs. Unaware within Higher Quality Advice & 1.71 & $0.0464^{a}$ \\
Lower Quality Advice vs. Higher Quality Advice within Aware & 0.70 & $0.4890^{b}$ \\
Lower Quality Advice vs. Higher Quality Advice within Unaware & 0.15 & $0.8785^{b}$ \\
\hline
\end{tabular}

\begin{tabular}{|l|}
\hline Notes: \\
\hline${ }^{a}$ p-values are one-tailed \\
\hline${ }^{b}$ p-values are two-tailed \\
${ }^{c}$ Weight of Advice is calculated as the absolute value of (final judgment - initial \\
judgment)/(advice - initial judgment). Participants who had an initial judgment equal to the \\
advice they received were excluded for this analysis. \\
${ }^{d}$ Participants in the aware group were told before the pre-advice judgment task that an internal \\
subject matter expert will be used by the engagement team. Participants in the unaware group \\
were not told that an internal subject matter expert would be utilized during in the pre-advice \\
judgment task. \\
\hline $\begin{array}{l}\text { e Advice quality is the type of advice (lower quality, higher quality) received from the internal } \\
\text { subject matter expert. }\end{array}$ \\
\hline
\end{tabular}




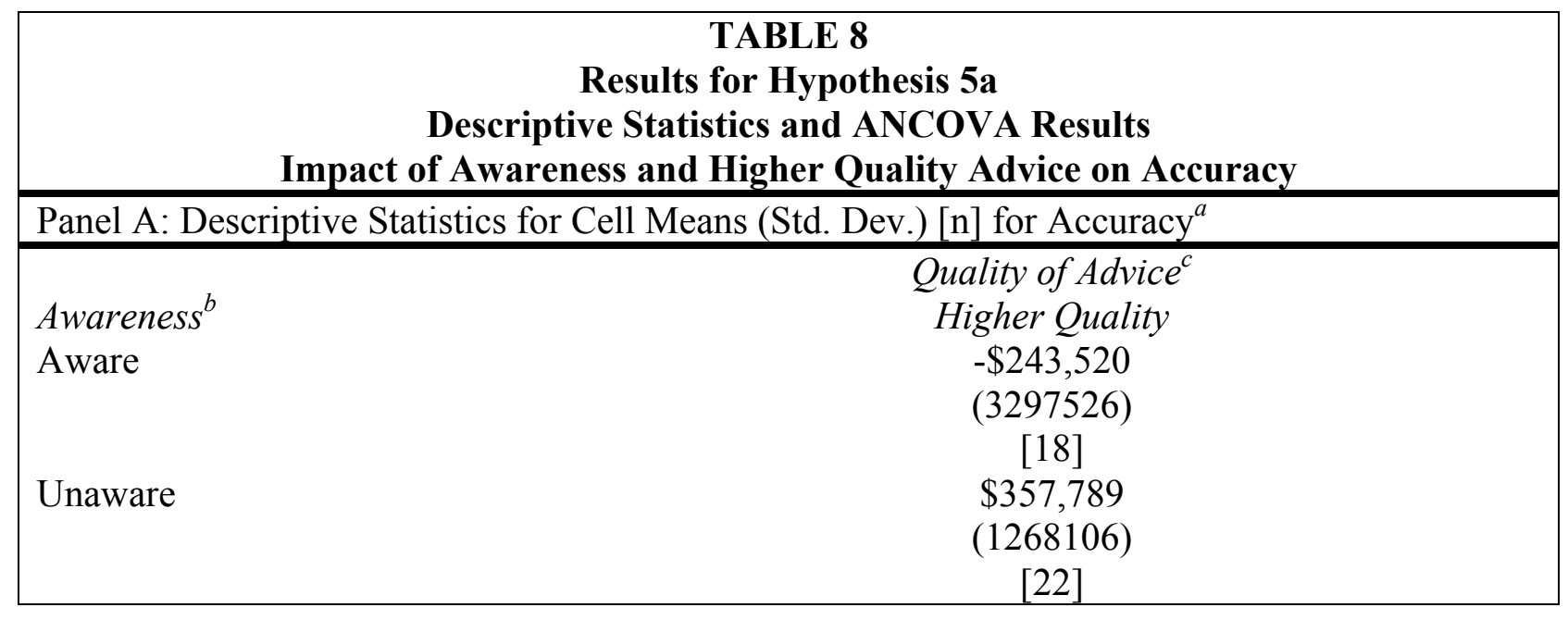

\begin{tabular}{|lcccc|}
\hline \multicolumn{4}{l}{ Panel B: ANCOVA Results for Dependent Variable - Accuracy } \\
\multicolumn{4}{l|}{ Covariate - Experience with Revenue Recognition } \\
\hline $\begin{array}{l}\text { Source of Variation } \\
\text { Awareness }\end{array}$ & $d f$ & Sum of Squares & F-Ratio & p-value \\
Experience with Revenue & 1 & $3.5743 \mathrm{E} 13$ & 0.61 & 0.4415 \\
Recognition & 1 & 226282978185 & 0.04 & 0.8459 \\
Error & 37 & $2.1846 \mathrm{E} 14$ & & \\
\hline
\end{tabular}

\begin{tabular}{|l|}
\hline Notes: \\
\hline All p-values are two-tailed \\
${ }^{a}$ Accuracy is calculated as the difference between the auditor's final judgment and the accurate \\
amount of revenue to be recognized. Note that the smaller the accuracy score the more accurate \\
the final judgment. \\
${ }^{b}$ Participants in the aware group were told before the pre-advice judgment task that an internal \\
subject matter expert will be used by the engagement team. Participants in the unaware group \\
were not told that an internal subject matter expert would be utilized during in the pre-advice \\
judgment task. \\
${ }^{c}$ Advice quality is the type of advice (lower quality, higher quality) received from the internal \\
subject matter expert.
\end{tabular}




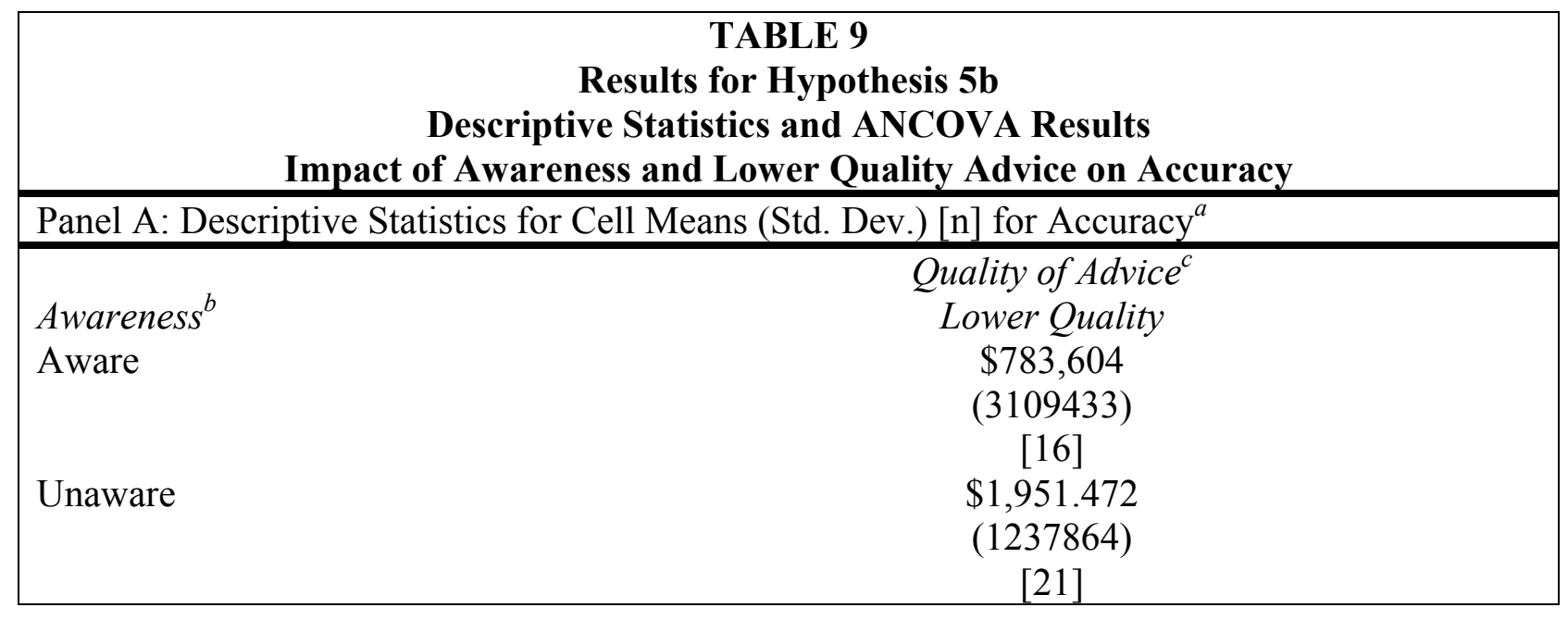

\begin{tabular}{|lcccc|}
\hline \multicolumn{4}{l}{ Panel B: ANCOVA Results for Dependent Variable - Accuracy } \\
\multicolumn{4}{l|}{ Covariate - Experience with Revenue Recognition } \\
\hline $\begin{array}{l}\text { Source of Variation } \\
\text { Awareness }\end{array}$ & $d f$ & Sum of Squares & F-Ratio & p-value \\
Experience with Revenue & 1 & $1.1882 \mathrm{E} 13$ & 2.30 & $0.0691^{a}$ \\
Recognition & 1 & 3734095812 & 0.00 & $0.9787^{b}$ \\
Error & 34 & $1.7527 \mathrm{E} 14$ & & \\
\hline
\end{tabular}

\begin{tabular}{|l|}
\hline Notes: \\
\hline${ }^{a}$ p-values are one-tailed \\
\hline${ }^{b}$ p-values are two-tailed \\
${ }^{a}$ Accuracy is calculated as the difference between the auditor's final judgment and the accurate \\
amount of revenue to be recognized. Note that the smaller the accuracy score the more accurate \\
the final judgment. \\
${ }^{b}$ Participants in the aware group were told before the pre-advice judgment task that an internal \\
subject matter expert will be used by the engagement team. Participants in the unaware group \\
were not told that an internal subject matter expert would be utilized during in the pre-advice \\
judgment task. \\
${ }^{c}$ Advice quality is the type of advice (lower quality, higher quality) received from the internal \\
subject matter expert.
\end{tabular}




\begin{tabular}{|c|c|c|c|}
\hline \multicolumn{4}{|c|}{$\begin{array}{c}\text { TABLE } 10 \\
\text { Summary of Hypothesis Testing }\end{array}$} \\
\hline Dependent Measure & Test & p-value & Supported \\
\hline Time Spent on Pre-advice Task & ANCOVA & $0.0527^{a}$ & Yes \\
\hline Time Spent on Full Case & ANCOVA & $0.0322^{a}$ & Yes \\
\hline Dependent Measure & Test & p-value & Supported \\
\hline Confidence $^{c}$ & ANCOVA & $0.4563^{a}$ & No \\
\hline Dependent Measure & Test & p-value & Supported \\
\hline $\begin{array}{l}\text { Acceptance of Management's } \\
\text { Position }^{d}\end{array}$ & ANCOVA & $0.0167^{a}$ & Yes \\
\hline Dependent Measure & Test & $p$-value & Supported \\
\hline $\mathrm{WOA}^{e}$ & ANCOVA & $0.0464^{a}$ & Yes \\
\hline Dependent Measure & Test & $p$-value & Supported \\
\hline Accuracy $^{f}-$ Higher Quality Advice & ANCOVA & $0.4415^{b}$ & Yes \\
\hline Dependent Measure & Test & $p$-value & Supported \\
\hline Accuracy - Lower Quality Advice & ANCOVA & $0.0691^{a}$ & Yes \\
\hline
\end{tabular}

\begin{tabular}{|c|}
\hline Notes: \\
\hline${ }^{a} \mathrm{p}$-values are one-tailed \\
\hline${ }^{b} \mathrm{p}$-values are two-tailed \\
\hline $\begin{array}{l}\text { "Average of Auditors' responses to the following questions, "I think my revenue recognition } \\
\text { estimate is accurate," "I am very certain about the accuracy of my revenue recognition } \\
\text { judgment," "I am sure I am performing well on this revenue recognition task," and "I felt that I } \\
\text { had adequate time to complete the required task." ( } 1=\text { I fully disagree; } 7 \text { = I fully agree })\end{array}$ \\
\hline $\begin{array}{l}{ }^{d} \text { Agreement with management's position was calculated as the difference between the amount } \\
\text { recognized by management per the case materials and the pre-advice revenue recognition } \\
\text { judgment provided by participants. }\end{array}$ \\
\hline $\begin{array}{l}{ }^{e} \text { Weight of Advice is calculated as the absolute value of (final judgment - initial } \\
\text { judgment)/(advice - initial judgment). Participants who had an initial judgment equal to the } \\
\text { advice they received were excluded for this analysis. }\end{array}$ \\
\hline $\begin{array}{l}{ }^{f} \text { Accuracy is calculated as the difference between the auditor's final judgment and the accurate } \\
\text { amount of revenue to be recognized. }\end{array}$ \\
\hline
\end{tabular}




\section{REFERENCES}

Abdolmohammadi, M. J. 1999. A Comprehensive Taxonomy of Audit Task Structure, Professional Rank and Decision Aids for Behavioral Research. Behavioral Research In Accounting 11:51-93.

AICPA. 1994. Statement of Auditing Standards No. 73: Using the Work of a Specialist. New York, NY: AICPA.

- 2002. Statement of Auditing Standards No. 99: Consideration of Fraud in a Finanical Statement Audit. New York, NY: AICPA.

- 2006. Statement of Auditing Standards No. 108: Planning and Supervision. New York, NY: AICPA.

Bedard, J. C., D. R. Deis, M. B. Curtis, and J. G. Jenkins. 2008. Risk Monitoring and Control in Audit Firms: A Research Synthesis. AUDITING: A Journal of Practice \& Theory 27 (1):33.

Bonaccio, S., and R. S. Dalal. 2006. Advice taking and decision-making: An integrative literature review, and implications for the organizational sciences. Organizational Behavior and Human Decision Processes 101 (2):127-151.

Braun, R. L. 2000. The effect of time pressure on auditor attention to qualitative aspects of misstatements indicative of potential fraudulent financial reporting. Accounting, Organizations and Society 25:17.

Budescu, D.V., and A.K. Rantilla. 2000. Confidence in Aggregation of Expert Opinions. Acta Psychologica 104: 371-398.

Church, B. K., and L. B. Shefchik. 2012. PCAOB Inspections and Large Accounting Firms. Accounting Horizons 26 (1):43-63.

Cloyd, C. B., and B. C. Spilker. 1999. The Influence of Client Preferences on Tax Professionals' Search for Judicial Precedents, Subsequent Judgments and Recommendations. The Accounting Review 74 (3):299-324.

Cooper, R. S. 1991. Information Processing in the Judge-advisor System of Group Decisionmaking. In Unpublished master's thesis: University of Illinois, Urbana-Champaign.

Dalal, R. S., and S. Bonaccio. 2010. What types of advice do decision-makers prefer? Organizational Behavior and Human Decision Processes 112 (1):11-23.

Ford, C.O., and W.R. Pasewark. 2012. The Effect of the Need for Cognition in Audit Sampling. Advances in Accounting Behavioral Research 15: 29-52. 
Gino, F. 2008. Do we listen to advice just because we paid for it? The impact of advice cost on its use. Organizational Behavior and Human Decision Processes 107 (2):234-245.

Gino, F., A. W. Brooks, and M. E. Schweitzer. 2012. Anxiety, advice, and the ability to discern: feeling anxious motivates individuals to seek and use advice. J Pers Soc Psychol 102 (3):497-512.

Glass, G.V., P.D. Peckham, and J.R. Sanders. 1972. Consequences of Failure to Meeet Assumptions Underlying Fixed Effects Analyses of Variance and Covariance. Review of Educational Research 42 (3):237-288.

Gold, A., W. R. Knechel, and P. Wallage. 2012. The Effect of the Strictness of Consultation Requirements on Fraud Consultation. The Accounting Review 87 (3):925-949.

Goldsmith, D. J., and K. Fitch. 1997. The Normative Context of Advice as Social Support. Human Commincation Research 23:23.

Hannan, R.L., G.P. McPhee, A.H. Newman, and I.D. Tafkov. 2013. The Effect of Relative Performance Information on Performance and Effort Allocation in a Multi-Task Environment. The Accounting Review 88 (2):553-575.

Harries, C., I. Yaniv, and N. Harvey. 2004. Combining advice: the weight of a dissenting opinion in the consensus. Journal of Behavioral Decision Making 17 (5):333-348.

Hart, J.W., S.J. Karau, M.F. Stasson, and N.A. Kerr. 2004. Achievement Motivation, Expected Coworker Performance, and Collective Task Motivation: Working Hard or Hardly Working. Journal of Applied Social Psychology 34 (5): 984-1000.

Harvey, N., and I. Fischer. 1997. Taking Advice: Accepting Help, Improving Judgment, and Sharing Responsibility. Organizational Behavior and Human Decision Processes 70 (2):117-134.

Henningsen, D. D., M. G. Cruz, and M. L. Miller. 2000. Role of Social Loafing in Predeliberation Decision Making. Group Dynamics: Theory, Research, and Practice 4 (2):168-176.

Hollenbeck, J.R., D.R. Ilgen, J.A. LePine, J.A. Colquitt, and J. Hedlund. 1998. Extending the Multitask Theory of Team Decision Making: Effects of Feedback and Experience in Hierarchical Teams. Academy of Management Journal 41:269-282.

Hollenbeck, J. R., D. R. Ilgen, D. J. Sego, J. Hedlund, D. A. Major, and J. Phillips. 1995. Multilevel Theory of Team Decision Making: Decision Performance in Teams Incorporating Distributed Expertise. Journal of Applied Psychology 80 (2):292-317.

Jenkins, J. G., D. R. Deis, J. C. Bedard, and M. B. Curtis. 2008. Accounting Firm Culture and Governance: A Research Synthesis. Behavioral Research In Accounting 20 (1):45-76. 
Jungermann, H., and K. Fischer. 2005. Using expertise and experience for giving and taking advice. In The Routines of Decision Making, edited by T. Betsch and S. Haberstroh. Mahwah, NJ: Lawrence Erlbaum, 157-173.

Kadous, K., S. J. Kennedy, and M. E. Peecher. 2003. The Effect of Quality Assessment and Directional Goal Commitment on Auditor's Acceptance of Client-Preferred Accounting Methods. The Accounting Review 78 (3):759-780.

Kadous, K., J. Leiby, and M. E. Peecher. 2013. How Do Auditors Weight Informal Contrary Advice? The Joint Influence of Advisor Social Bond and Advice Justifiability. The Accounting Review Forthcoming.

Karau, S. J., and K. D. Williams. 1993. Social Loafing: A Meta-Analytic Review and Theoretical Integration. J Pers Soc Psychol 64 (4):681-707.

Kerr, N. L., and R. S. Tindale. 2004. Group performance and decision making. Annu Rev Psychol 55:623-655.

Koestner, R., I. Gingras, R. Abutaa, G.F. Losier, L. DiDio, and M. Gagne. 1999. To Follow Expert Advice When Making a Decision: An Examination of Reactive Versus Reflective Autonomy. Journal of Personality 65:851-872.

Krueger, J. I. 2003. Return of the ego--Self-referent information as a filter for social prediction: Comment on Karniol (2003). Psychological Review 110 (3):585-590.

Lix, L.M., J.C. Keselman, and H.J. Keselman. 1996. Consequences of Assumption Violations Revisited: A Quantitative Review of Alternatives to the One-way Analysis of Variance F Test Review of Educational Research 66:579-619.

Low, K.Y., and H.T. Tan. 2011. Does Time Constraint Lead to Poorer Audit Performance? Effects of Forewarning of Impending Time Constraints and Instructions. AUDITING: $A$ Journal of Practice \& Theory 30 (4):173-190.

Mitchell, T. R. 1973. Motivation and Participation: An Integration. The Academy of Management Journal 16 (4):670-681.

Moeckel, C.L., and R.D. Plumlee. 1989. Auditors' Confidence in Recognition of Audit Evidence. The Accounting Review 64 (4):653-667.

Ng, T. B.-P., and P. G. Shankar. 2010. Effects of Technical Department's Advice Quality Assessment Standards, and Client Justifications on Auditors' Propensity to Accept ClientPreferred Accounting Methods. The Accounting Review 85 (5):1743-1763.

Paese, P. W., and J. A. Sniezek. 1991. Influences on the Appropriateness of Confidence in Judgment: Practice, Effort, Information, and Decision-Making. Organizational Behavior and Human Decision Processes 48:100-131. 
PCAOB. 2007. Staff Audit Practice Alert No. 2 Matters Related to Auditing Fair Value Measurements of Finanical Instruments and the Use of Specialists. Washington, D.C.: PCAOB.

Phillips, J. M. 1999. Antecedents of Leader Utilization of Staff Input in Decision-Making Teams. Organizational Behavior and Human Decision Processes 77 (3):215-243.

Redd, S.B. 2002. The Influence of Advisers on Foreign Policy Decsion Making. Journal of Conflict Resolution 46: 335-364.

Rouse, R. W., and T. R. Weirich. 2006. Auditors on the hot seat. Journal of Corporate Accounting \& Finance 17 (4):25-29.

Schrah, G. E., R. S. Dalal, and J. A. Sniezek. 2006. No Decision-maker is an Island: Integrating Expert Advice with Information Acquisition. Journal of Behavioral Decision Making 19 (1):43-60.

Seol, I. 2006. The Effect of Auditor Interaction on Decision Making in the Going-concern Task. Managerial Auditing Journal 21 (6):582-597.

Shankar, P. G., and T. B.-P. Ng. 2008. When does Advice Influence Auditors' Decisions? Moderating Effects of Performance Evaluation Focus and Client Attitude. Working paper.

Smith, B.N., N.A. Kerr, M.J. Markus, and M.F. Stasson. 2001. Individual Differences in Social Loafing: Need for Cognition as a Motivator in Collective Performance. Group Dynamics: Theory, Research, and Practice 5 (2):150-158.

Sniezek, J.A. and T. Buckley. 1995. Cueing and Cognitive Conflict in Judge-advisor Decision Making. Organizational Behavior and Human Decision Processes 62:159-174.

Sniezek, J. A., G. E. Schrah, and R. S. Dalal. 2004. Improving judgement with prepaid expert advice. Journal of Behavioral Decision Making 17 (3):173-190.

Solomon, I. 2008. Conversations with the Big 4 Accounting Firms' Chief Executives. Current Issues in Auditing 2:C13-C29.

Sorkin, R. D., C. J. Hays, and R. West. 2001. Signal-Detection Analysis of Group Decision Making. Psychological Review 108 (1):183-204.

Tan, H.T. 1995. Effects of Expectation, Prior Involvement, and Review Awareness on Memory for Audit Evidence and Judgment. Journal of Accounting Research 33 (1):113-137.

Tost, L. P., F. Gino, and R. P. Larrick. 2012. Power, competitiveness, and advice taking: Why the powerful don't listen. Organizational Behavior and Human Decision Processes 117:53-40. 
Weldon, E., and G. M. Gargano. 1988. Cognitive Loafing: The Effects of Accountability and Shared Responsibility on Cognitive Effort. Personality and Social Psychology Bulletin 14 (1):159-171.

Weldon, M. S., C. Blair, and P. D. Huebsch. 2000. Group Remembering: Does Social Loafing Underlie Collaborative Inhibition? Journal of Experimental Psychology: Learning, Memory, and Cognition 26 (6):1568-1578.

Whitecotton, S.M. 1996. The Effect of Expertise and Confidence on Decision Aid Reliance: A Causal Review. Behavioral Research in Accounting 8:194-216.

Whitley, B. 2002. Principles of research in behavioral science. 2nd ed. New York, NY: McGraw-Hill.

Wilks, T. J. 2002. Predecisional Distortion of Evidence as a Consequence of Real-Time Audit Review. The Accounting Review 77 (1):51-73.

Wills, T. W., S. Estow, S. A. Soraci, and J. Garcia. 2006. The aha effect in groups and other dynamic learning contexts. The Journal of General Psychology 133 (3):221-236.

Yaniv, I. 1997. Weighting and Trimming: Heuristics for Aggregating Judgments under Uncertainty. Organizational Behavior and Human Decision Processes 69 (3):237-250.

- 2004. Receiving other people's advice: Influence and benefit. Organizational Behavior and Human Decision Processes 93:1-14.

Yaniv, I., and E. Kleinberger. 2000. Advice Taking in Decision Making: Egocentric Discounting and Reputation Formation. Organizational Behavior and Human Decision Processes 83 (2):260-282.

Yaniv, I., and M. Milyavsky. 2007. Using advice from multiple sources to revise and improve judgments. Organizational Behavior and Human Decision Processes 107:104-124. 
APPENDICIES 


\section{APPENDIX A \\ Advice Quality Manipulations}

\section{High Quality}

\section{MEMO}

To: Tintype, Inc Engagement Team

From: Chris Moore, Revenue Recognition Subject Matter Expert Team manager

Subject: Safeco Eye Laser and related maintenance plans revenue recognition

Date: February 20, 20x3

This memo is to respond to the request made by the Tintype, Inc engagement team to review management's revenue recognition policies regarding the Safeco Eye Laser and related maintenance plans. It is the audit team's responsibility to assess our understanding of management's facts and position. Based on our discussions with the Tintype, Inc. engagement team we understand management's facts and position on the following:

- There are three components related to the Safeco Eye Laser. These components include (1) the Safeco Eye Laser hardware, (2) the software package, and (3) the separately sold maintenance plan. Specifically related to each component identified by management we noted:

- The laser hardware is delivered to the customer's specified site and is installed for the customer. The laser hardware is not sold as a stand-alone product without the embedded software. The stand-alone value per laser is $\$ 35,280$. There is no right of return for sales of the Safeco Eye Laser.

○ The software package was developed by Tintype and there are no substitute software programs that can be used by the laser manufactured or sold by competitors. Software updates are provided for the laser when and if new treatment applications are available. In order to ensure customers are receiving the newest updates for the software, Tintype pushes monthly updates to customers. Twenty-four months of updates are included as part of the initial software package when the laser is purchased. Additional months of updates can be purchased subsequent to the end of the two year period. The software is not licensed to the customer as each laser only works with the embedded software. There is no stand-alone value of the embedded software. The software package is not sold separately. The value of the software package is assessed at $\$ 11,760$.

- A two-year separately priced maintenance agreement can also be purchased for the equipment. This plan includes telephone support, repair or replacement of nonconforming parts, software updates, and bug fixes for the software. The 
maintenance plan sells for $\$ 10,500$ and can only be applied to a particular laser and has never been sold separately.

- Management believes that ASC 605-25 Revenue Recognition: Multiple-Element Arrangements applies to the Safeco Eye Laser sales transactions, due to there being multiple revenue generating activities related to the sales of the Safeco Eye Laser.

- As required by ASC 605-25, management identifies the following separate units of accounting:

- The laser hardware with the software package and

- The related maintenance plan.

- Management believes that the revenue related to the laser and the software package, as well as the maintenance plan should be recognized immediately. This has resulted in management recognizing \$15,017,940 of revenue for the sales of the Safeco Eye Laser as of December 31, 20x2.

\section{Analysis}

\section{1) Value of the Elements}

Based on our understanding management and the engagement team had previously come to an agreement on the stand-alone values of the laser hardware, the software package, and the maintenance plan. We will be utilizing the values as provided by management and outlined above.

\section{2) Revenue Recognition Guidance To Be Applied}

It is apparent to us that the embedded software does function together with the laser to provide the essential functionality of the laser. This assessment is due to:

a. Tintype has never sold, nor does it offer to sell, the Safeco Eye Laser without the embedded software and

b. The non-software components of the Safeco Eye Laser substantially contributes to the functionality of the product.

As per ASC 985-605-15-4A, guidance in ASC 985-605 does not apply to the following transactions and activities:

a. Arrangements for products or services containing software that is incidental to the products or services as a whole

e. Software components of tangible products that are sold, licensed, or leased with tangible products when the software components and non-software components of the tangible product function together to deliver the tangible product's essential functionality 
Based on the guidance, sales of the Safeco Eye Laser would not fall under ASC 985-605. Instead, the revenue recognition for the product sales and related maintenance plan falls under ASC 605-25, Revenue Recognition: Multiple-Element Arrangements. We agree with management's assessment in regards to the applicable guidance.

\section{3) Specified Units of Accounting}

Per ASC 605-25-2, "revenue arrangements with multiple deliverables shall be divided into separate units of accounting if the deliverables in the arrangement meet the criteria in paragraph 605-25-25-5." ASC 605-25-25-5 states:

"In an arrangement with multiple deliverables, the delivered item or items shall be considered a separate unit of accounting if both the following criteria are met:

a. The delivered item or items have value to the customer on a stand-alone basis.

b. If the arrangement includes a general right of return relative to the delivered item, delivery or performance of the undelivered item or items is considered probable and substantially in control of the vendor."

It is our position that, the delivered items have

(1) Value to the customer on a stand-alone basis and

(2) The performance of the undelivered items are considered probable and in control of Tintype, Inc.

Therefore, the criterion to divide deliverables into separate units of accounting has been met. Furthermore, it is our position that the software package is considered a separate unit of accounting from the laser hardware due to the ability of Tintype to assess a stand-alone value as well as the customers having the option to purchase additional months of updates. As such, the software package is considered to meet ASC 605-25-25-5 (a) as previously stated.

Based on the information, the units of accounting are:

(1) The laser hardware,

(2) The software package, including the updates that are provided on a monthly basis, and

(3) The maintenance support provided by the maintenance agreement.

In this regard, we disagree with management's position on the separate units of accounting. We advise that the revenue from each unit should be recognized separately based on what that unit of accounting is and when the revenue from that unit is earned.

\section{Revenue Recognition}


Based on this analysis, the transaction price in the arrangement would be allocated to each deliverable based on its relative stand-alone selling price, as per ASC 605-25, and recognized in accordance with the applicable guidance within ASC 605-25-1, which states that "revenue is not recognized until earned."

The portion of the transaction price allocated to the Safeco Eye Laser hardware should be recognized upon delivery to the customer. The portion of the transaction price allocated to the software package and maintenance should be recognized when the services are provided to the customer. As the embedded software has no value, the software package value relates to the updates that are provided over a two-year period. In this instance, we disagree with management's position that the maintenance plan revenue should be recognized immediately.

Based on the information provided by the Tintype engagement team we believe a total of $\$ 10,660,545$ revenue should be recognized as of December 31, 20x2 for the sales of the Safeco Eye Laser, software package, and the related maintenance plans. Refer to the schedule below for calculations.

\begin{tabular}{|l|c|c|c|c|}
\hline & $\begin{array}{c}\text { Safeco Eye } \\
\text { Laser }\end{array}$ & $\begin{array}{c}\text { Safeco Eye } \\
\text { Laser Software } \\
\text { Package }\end{array}$ & $\begin{array}{c}\text { Safeco Eye } \\
\text { Laser } \\
\text { Maintenance } \\
\text { Plan }\end{array}$ & Total \\
\hline $\begin{array}{l}\text { Total number } \\
\text { sold on July 1, } \\
\text { 20x2 }\end{array}$ & 261 & 261 & 261 & \\
\hline Value per unit & $\$ 35,280$ & $\$ 11,760$ & $\$ 10,500$ & \\
\hline $\begin{array}{l}\text { Number of } \\
\text { months service } \\
\text { is provided }\end{array}$ & $\mathrm{n} / \mathrm{a}$ & 24 & 24 & \\
\hline $\begin{array}{l}\text { Revenue per } \\
\text { unit sold to be } \\
\text { recognized per } \\
\text { month }\end{array}$ & $\mathrm{n} / \mathrm{a}$ & $\$ 490.00$ & $\$ 437.50$ & \\
\hline $\begin{array}{l}\text { Number of } \\
\text { months service } \\
\text { was used during } \\
\text { 20x2 }\end{array}$ & $\mathrm{n} / \mathrm{a}$ & 6 & 6 & \\
\hline $\begin{array}{l}\text { Total revenue } \\
\text { recognized as of } \\
\text { December 31, } \\
\text { 20x2 }\end{array}$ & $\$ 9,208,080$ & $\$ 767,340$ & $\$ 685,125$ & $\$ 10,660,545$ \\
\hline
\end{tabular}




\section{Low Quality}

MEMO

To: Tintype, Inc Engagement Team

From: Chris Moore, Revenue Recognition Subject Matter Expert Team manager

Subject: Safeco Eye Laser and related maintenance plans revenue recognition

Date: February 20, 20x3

This memo is to respond to the request made by the Tintype, Inc engagement team to review management's revenue recognition policies regarding the Safeco Eye Laser and related maintenance plans. It is the audit team's responsibility to assess our understanding of management's facts and position. Based on our discussions with the Tintype, Inc. engagement team we understand management's facts and position on the following:

- There are three components related to the Safeco Eye Laser. These components include (1) the Safeco Eye Laser hardware, (2) the software package, and (3) the separately sold maintenance plan. Specifically related to each component identified by management we noted:

- The laser hardware is delivered to the customer's specified site and is installed for the customer. The laser hardware is not sold as a stand-alone product without the embedded software. The stand-alone value per laser is $\$ 35,280$. There is no right of return for sales of the Safeco Eye Laser.

- The software package was developed by Tintype and there are no substitute software programs that can be used by the laser manufactured or sold by competitors. Software updates are provided for the laser when and if new treatment applications are available. The software is not licensed to the customer as each laser only works with the embedded software. The software package is not sold separately. The value is assessed at $\$ 11,760$.

- A two-year separately priced maintenance agreement can also be purchased for the equipment. This plan includes telephone support, repair or replacement of nonconforming parts, software updates, and bug fixes for the software. The maintenance plan sells for $\$ 10,500$ and can only be applied to a particular laser and has never been sold separately.

- Management believes that ASC 605-25 Revenue Recognition: Multiple-Element Arrangements applies to the Safeco Eye Laser sales transactions, due to there being multiple revenue generating activities related to the sales of the Safeco Eye Laser.

- As required by ASC 605-25, management identifies the following separate units of accounting:

- The laser hardware with the software package and 
- The related maintenance plan.

- Management believes that the revenue related to the laser and the software package, as well as the maintenance plan should be recognized immediately. This has resulted in management recognizing $\$ 15,017,940$ of revenue for the sales of the Safeco Eye Laser as of December 31, 20x2.

\section{Analysis}

\section{4) Value of the Elements}

Based on our understanding management and the engagement team had previously come to an agreement on the stand-alone values of the laser hardware, the software package, and the maintenance plan. We will be utilizing the values as provided by management and outlined above.

\section{5) Revenue Recognition Guidance To Be Applied}

It is apparent to us that the embedded software does function together with the laser to provide the essential functionality of the laser. This assessment is due to:

c. Tintype has never sold, nor does it offer to sell, the Safeco Eye Laser without the embedded software and

d. The non-software components of the Safeco Eye Laser substantially contributes to the functionality of the product.

As per ASC 985-605-15-4A, guidance in ASC 985-605 does not apply to the following transactions and activities:

b. Arrangements for products or services containing software that is incidental to the products or services as a whole

e. Software components of tangible products that are sold, licensed, or leased with tangible products when the software components and non-software components of the tangible product function together to deliver the tangible product's essential functionality

Based on the guidance, sales of the Safeco Eye Laser would not fall under ASC 985-605. Instead, the revenue recognition for the product sales and related maintenance plan falls under ASC 605-25, Revenue Recognition: Multiple-Element Arrangements. We agree with management's assessment in regards to the applicable guidance.

\section{6) Specified Units of Accounting}

Per ASC 605-25-2, "revenue arrangements with multiple deliverables shall be divided into separate units of accounting if the deliverables in the arrangement meet the criteria in paragraph 605-25-25-5." ASC 605-25-25-5 states: 
"In an arrangement with multiple deliverables, the delivered item or items shall be considered a separate unit of accounting if both the following criteria are met:

c. The delivered item or items have value to the customer on a stand-alone basis.

d. If the arrangement includes a general right of return relative to the delivered item, delivery or performance of the undelivered item or items is considered probable and substantially in control of the vendor."

It is our position that, the delivered items have

(1) Value to the customer on a stand-alone basis and

(2) The performance of the undelivered items are considered probable and in control of Tintype, Inc.

Therefore, the criterion to divide deliverables into separate units of accounting has been met. Furthermore, it is our position that the software package is considered as part of the laser hardware as the customers would not have use for the software package without the laser and as such, would not value the software package on a stand-alone basis.

Based on the information, the units of accounting are:

(4) The laser hardware and the software package and

(5) The maintenance support provided by the maintenance agreement.

In this regard, we agree with management's position on the separate units of accounting. We advise that the revenue from each unit should be recognized separately based on what that unit of accounting is and when the revenue from that unit is earned.

\section{Revenue Recognition}

Based on this analysis, the transaction price in the arrangement would be allocated to each deliverable based on its relative stand-alone selling price, as per ASC 605-25, and recognized in accordance with the applicable guidance within ASC 605-25-1, which states that "revenue is not recognized until earned."

The portion of the transaction price allocated to the Safeco Eye Laser hardware and software package should be recognized upon delivery to the customer. The portion of the transaction price allocated to the maintenance should be recognized when the services are provided to the customer. In this instance, we disagree with management's position that the maintenance plan revenue should be recognized immediately. 
Based on the information provided by the Tintype engagement team we believe a total of $\$ 12,962,565$ revenue should be recognized as of December 31,20x2 for the sales of the Safeco Eye Laser, software package, and the related maintenance plans. Refer to the schedule below for calculations.

\begin{tabular}{|l|c|c|c|}
\hline & Safeco Eye Laser & $\begin{array}{l}\text { Safeco Eye Laser } \\
\text { Software } \\
\text { Package }\end{array}$ & Total \\
\hline $\begin{array}{l}\text { Total number } \\
\text { sold on July 1, } \\
\text { 20x2 }\end{array}$ & 261 & 261 & \\
\hline Value per unit & $\$ 35,280$ & $\$ 11,760$ & \\
\hline $\begin{array}{l}\text { Total revenue } \\
\text { recognized as of } \\
\text { December 31, } \\
\text { 20x2 }\end{array}$ & $\$ 9,208,080$ & $\$ 3,069,360$ & $\$ 12,277,440$ \\
\hline
\end{tabular}

\begin{tabular}{|l|c|c|}
\hline & $\begin{array}{c}\text { Safeco Eye Laser } \\
\text { Maintenance Plan }\end{array}$ & Total \\
\hline $\begin{array}{l}\text { Total number sold on } \\
\text { July 1, 20x2 }\end{array}$ & 261 & \\
\hline Value per unit & $\$ 10,500$ & \\
\hline $\begin{array}{l}\text { Number of months } \\
\text { service is provided }\end{array}$ & 24 & \\
\hline $\begin{array}{l}\text { Revenue per unit sold to } \\
\text { be recognized per month }\end{array}$ & $\$ 437.50$ & \\
\hline $\begin{array}{l}\text { Number of months } \\
\text { service was used during } \\
\text { 20x2 }\end{array}$ & 6 & $\$ 685,125$ \\
\hline $\begin{array}{l}\text { Total revenue recognized } \\
\text { as of December 31, 20x2 }\end{array}$ & $\$ 685,125$ & $\$ 12,962,565$ \\
\hline $\begin{array}{l}\text { Grand total revenue } \\
\text { recognized as of } \\
\text { December 31, 20x2 }\end{array}$ & & \\
\hline
\end{tabular}




\section{APPENDIX B \\ Sample Experimental Materials}

\section{Aware/High Quality Condition}

Welcome!

I am a PhD student at Virginia Tech and this research case is part of my program of study for my doctorate. In this research study I plan to examine auditors' decision making during the audit process. As a former auditor, I realize your time is very valuable and I appreciate your willingness to participate.

This study is a case study that will ask you to assume the role of an in-charge auditor for your firm on the integrated audit of a hypothetical audit client with a December 31 year-end. You will be given information about the audit client and an issue surrounding revenue recognition of a new product developed and sold during the audit year. You will also be provided the applicable accounting guidance. Using the information given, you will be asked to provide your judgment related to the amount of revenue the client should recognize for sale of the new product.

This study should take approximately 35 minutes to complete. Please do not begin until you have time to complete the study without interruption. All data are being collected in a manner that ensures your complete anonymity. All firm and individual responses will only be analyzed in the aggregate.

Thank you for your assistance!

If at any time you have questions or concerns about the study, please contact:

Nicole Wright, CPA

Ph.D. Student in Residence

Virginia Tech

wrightns@vt.edu

Dr. David M. Moore

Institutional Review Board (IRB) Chair

Virginia Tech

(540) 231-4991

moored@vt.edu 


\section{Client Background Information}

Tintype, Inc. (Tintype) is a leading manufacturer of personal cameras and other electronics.

Tintype was founded as a personal camera manufacturer in 1982, in Birmingham, Alabama. The company went public in 1984 and has since expanded its manufacturing lines into other lines of electronics for both personal and industry use. Tintype has expanded its manufacturing plants from one located in Birmingham in 1982 to 13 across the United States.

Currently Tintype maintains three business units. The Office business unit manufactures printers for office use. The Consumer business unit manufactures a variety of digital cameras, camcorders, inkjet printers, image scanners, and multimedia projectors. The Medical business unit manufactures LCD lithography systems, organic LED panel manufacturing equipment, ophthalmic equipment, and digital radiography systems. Sales from these units are typically to the end user, which may include business, hospitals and doctor offices, or retail stores.

The global economy in 20x2 experienced increasing uncertainty in the second half of the year as the pace of recovery decelerated due to economic downturn in the United States and Europe, the economy as a whole continued to grow moderately, primarily driven by emerging economies.

With the advances in technology, the demand for all of Tintype's products continues to be stable or increased from the prior year. Although the recent economy downturn may have impacted personal purchasing power, the industry appears to be strong and sustainable. However, as increased technology requires demands on manufacturing and end customers have expectations of prices eventually decreasing, companies operating within this industry may need to employ outsourcing or find other ways to reduce manufacturing costs. In addition, heavy investment in $\mathrm{R} \& \mathrm{D}$ is required to maintain a viable presence in this industry. Although Tintype is a small player in the industry, Tintype has been able to maintain growth since its inception through extensive use of research and development. The advancement of technology and increased expectations from customers requires that Tintype continuously look forward to what the market will want and what new technologies can be incorporated in its products.

In addition to incorporating technology, Tintype is committed to maintaining its production in the United States. As such, the company is always looking for ways to reduce costs and be as efficient as possible in all aspects of its business. Tintype completed an operational audit several years ago and has since been able to maintain its costs even during the recent downward economic trends. Tintype has not experienced any major restructuring or layoffs.

Your firm has audited Tintype for several years. In each of these years, Tintype has received an unqualified opinion for both the financial statement and internal controls audits. The relationship between Tintype's management and the engagement team has been good during previous audits, as well as during the current year engagement.

\section{Please scroll to the next page to review summary balances of the company's financial statements.}


Selected financial results for 20x2 (unaudited) and the audited results for 20x1 and 20x0 are provided below:

\begin{tabular}{|c|c|c|c|}
\hline \multicolumn{4}{|c|}{$\begin{array}{c}\text { Tintype, Inc. } \\
\text { Income Statement } \\
\text { For the years ended December } 31,20 \times 2,20 \times 1 \text {, and } 20 \times 0 \\
\text { (in thousands) }\end{array}$} \\
\hline & $\begin{array}{c}20 \times 2 \\
\text { (unaudited) }\end{array}$ & $\begin{array}{c}20 \times 1 \\
\text { (audited) }\end{array}$ & $\begin{array}{c}20 \times 0 \\
\text { (audited) }\end{array}$ \\
\hline Net Sales & $\$ 313,646$ & $\$ 297,547$ & $\$ 282,847$ \\
\hline Cost of Sales & 225,937 & 210,679 & 200,937 \\
\hline $\begin{array}{l}\text { Selling, General and Administrative } \\
\text { Expenses }\end{array}$ & 70,267 & 70,139 & 66,573 \\
\hline Other Expense (Income) & 1,589 & $\underline{1,873}$ & 1,435 \\
\hline Net Income & $\underline{\$ 15,853}$ & $\underline{\underline{\$ 14,856}}$ & $\underline{\$ 13,902}$ \\
\hline Earnings Per Share (EPS) & $\$ 2.63$ & $\$ 2.61$ & $\$ 2.60$ \\
\hline
\end{tabular}

\section{Tintype, Inc.}

Balance Sheet

As of December 31, 20x2, 20x1, and 20x0

(in thousands)

Cash

Total Inventories

Property, Plant, and Equipment, Net

Total Assets

Current Liabilities

Long-term Debt

Total Liabilities

Total Stockholders' Equity

Total Liabilities \& Stockholders' Equity

\begin{tabular}{|c|c|c|}
\hline $\begin{array}{c}20 \times 2 \\
\text { (unaudited) }\end{array}$ & $\begin{array}{c}20 \times 1 \\
\text { (audited) }\end{array}$ & $\begin{array}{c}20 \times 0 \\
\text { (audited) }\end{array}$ \\
\hline$\$ 7,359$ & 6,269 & 7,586 \\
\hline 59,364 & 58,086 & 59,488 \\
\hline 49,159 & 43,898 & 44,251 \\
\hline$\underline{\$ 163,731}$ & $\underline{\$ 162,678}$ & $\$ 163,489$ \\
\hline$\$ 29,448$ & $\$ 28,423$ & $\$ 29,587$ \\
\hline 5,618 & 5,714 & 6,014 \\
\hline 53,489 & 53,031 & 54,047 \\
\hline 110,242 & 109,647 & 109,442 \\
\hline$\underline{\$ 163,731}$ & $\underline{\$ 162,678}$ & $\$ 163,489$ \\
\hline
\end{tabular}




\section{Revenue Recognition Issue}

As the in-charge on the Tintype audit you are expected to complete a two part task to assess the revenue recognition policy put in place by management regarding the Safeco Eye Laser. In some instances during the audit, a subject matter expert may be utilized by engagement teams for complex tasks such as revenue recognition. As this revenue recognition issue was identified during the planning phase of the audit, the engagement partner has elected to contact an internal firm revenue recognition subject matter expert for assistance. The engagement partner would like for you to assess management's position of the amount of revenue recognized as of year-end prior to receiving advice from the internal firm revenue recognition subject matter expert.

Planning materiality has been set at $\$ 594,000$. Please note that the audit manager has assessed a budget of no more than 35 minutes in total to complete this task and this sub-part task is allotted 20 of those 35 minutes. You are able to go over budget, however, as with typical engagements you are expected to meet the budget provided.

\section{Safeco Eye Laser}

Within the Medical business unit, Tintype has begun manufacturing and selling a new product that falls under ophthalmic equipment. This product is called the Safeco Eye Laser and allows for detection of various eye diseases via special imaging and provides a variety of treatment methods all through the use of cutting edge technology. This is the first product that Tintype has produced that also has an embedded software component also developed by Tintype. Tintype enters into contractual arrangements to sell its ophthalmic equipment with large hospitals and universities throughout the United States. Management has stated that there are three components associated with the Safeco Eye Laser.

1. The Safeco Eye Laser hardware. The laser hardware is delivered to the customer's specified site and is installed for the customer without an extra charge. Tintype has never sold, nor does it offer to sell, the Safeco Eye Laser as a stand-alone product without the embedded software. Tintype estimates that the stand-alone value per laser is $\$ 30,280$. In order to arrive at the estimated stand-alone value of the laser, management discussed its process and any judgments made with the audit team. Both parties agree with the standalone value of the laser as identified by management. Finally, there is no right of return for sales of the Safeco Eye Laser.

2. The software package that accompanies the Safeco Eye Laser hardware. A software package accompanies the Eye Laser hardware and consists of a cutting edge embedded software and software updates. The cutting edge software was developed by Tintype. The software is not licensed to the customer as each laser only works with the embedded 
software. There are no substitute software programs that can be used by the laser manufactured or sold by Tintype's competitors. There is no stand-alone value of the embedded software. As part of the package, Tintype also provides software updates for the laser when, and if, new treatment applications are available. In order to ensure customers are receiving the newest updates for the software, Tintype pushes monthly updates to customers. Twenty-four months of updates are included as part of the initial software package when the laser is purchased. Additional months of updates can be purchased subsequent to the end of the two year period. The software package is not sold separately, but Tintype estimates its value per laser as $\$ 11,760$. In order to arrive at the estimated value of the software package, management discussed its process and any judgments made with the audit team. Both parties agree with the value of software package as identified by management.

3. The maintenance plan. Tintype's contractual arrangements for the Safeco Eye Laser also offer an initial option to purchase a two-year separately priced maintenance agreement for the equipment. This maintenance plan includes telephone support, repair or replacement of nonconforming parts, software updates, and bug fixes for the software. The maintenance plan sells for $\$ 10,500$ and can only be applied to a particular laser. The Tintype maintenance agreement is only available to purchasers of the Safeco Eye Laser and has never been sold separately.

During the fiscal year ending 20x2, Tintype sold 261 units of the Safeco Eye Laser and each purchaser opted to also purchase the related maintenance plan. As these lasers are sold to large universities and hospitals they were purchased on July 1, 20x2 due to the budget year of the customers. The lasers and related software have been delivered to the customers prior to December 31, 20x2.

\section{The Accounting Issue}

Given the facts provided, there are three important related accounting decisions to consider:

1. Given that the Safeco Eye Laser includes software, what revenue recognition guidance is applicable?

2. Are there multiple deliverables?

3. If so, what is the appropriate revenue recognition for each deliverable?

The applicable guidance related to revenue recognition for multiple elements and software revenue recognition is summarized below. Refer to the related tabs for more detailed inclusion of the applicable guidance.

\section{ASC 605-25, Revenue Recognition: Multiple-Element Arrangements}


This guidance addresses some aspects of the accounting by a company for arrangements under which it will perform multiple revenue-generating activities. Specifically, this guidance addresses how to determine whether an arrangement involving multiple deliverables contains more than one unit of accounting, and how arrangement consideration shall be measured and allocated to the separate units of accounting in the arrangement.

\section{ASC 985-605 Software: Revenue Recognition}

This guidance provides guidance on when revenue should be recognized and in what amounts for licensing, selling, leasing, or otherwise marketing computer software.

\section{Management's Position}

Management has recognized $\$ 15,017,940$ as revenue during 20x2. Refer to the table below for details.

\begin{tabular}{|l|c|c|c|c|}
\hline & $\begin{array}{c}\text { Safeco Eye } \\
\text { Laser }\end{array}$ & $\begin{array}{c}\text { Safeco Eye Laser } \\
\text { Software } \\
\text { Package }\end{array}$ & $\begin{array}{c}\text { Safeco Eye } \\
\text { Laser } \\
\text { Maintenance } \\
\text { Plan }\end{array}$ & Total \\
\hline $\begin{array}{l}\text { Total number sold } \\
\text { on July 1, 20x2 }\end{array}$ & 261 & 261 & 261 & \\
\hline Value per unit & $\$ 35,280$ & $\$ 11,760$ & $\$ 10,500$ & \\
\hline $\begin{array}{l}\text { Total revenue } \\
\text { recognized as of } \\
\text { December 31, 20x2 }\end{array}$ & $\$ 9,208,080$ & $\$ 3,069,360$ & $\$ 2,740,500$ & $\$ 15,017,940$ \\
\hline
\end{tabular}

Management's response to the three related accounting decisions are as follows:

1. Management believes the relevant guidance that applies to the sale of the Safeco Eye Laser is ASC 605 Revenue Recognition and specifically ASC 605-25 Revenue Recognition: Multiple-Element Arrangements, due to there being multiple revenue generating activities related to the sales of the Safeco Eye Laser.

2. Management identifies the following separate units of accounting:

a. The laser hardware with the software package and

b. The related maintenance plan.

3. Management believes that the revenue related to the laser and the software package, as well as the maintenance plan should be recognized immediately.

Management's detailed discussion related to these accounting decisions can be found below.

\section{Applicable Revenue Recognition Guidance}

Management states that the software package is a key component of the product and therefore the revenue should not be accounted for differently from the laser hardware. Management cites 
that the laser cannot be used without the embedded software and that under ASC 985-605-154(e), ASC 985-605 does not apply if "software components of tangible products that are sold, licensed, or leased with tangible products when the software components and nonsoftware components of the tangible product function together to deliver the tangible product's essential functionality."

In order to account for the revenue to be recognized for the sales of the Safeco Eye Laser, management believes that ASC 605-25 Revenue Recognition: Multiple-Element Arrangements should be applied as there are multiple revenue generating activities related to the sales of the Safeco Eye Laser (i.e. the laser hardware including the software package and the related maintenance plan). The multiple elements meets the scope requirements required by ASC $605-25$ as stated per ASC 605-25-15-2, which management believes allows them to apply this guidance.

\section{Identification of Separate Units of Accounting}

Management notes that the laser with the software package and the related maintenance plan are each separate units of accounting. Although management is able to separately value both the laser and the software package, they believe that as the software is embedded it would not be considered separate from the laser. As the maintenance plan is separately priced and customers have the option of purchasing these plans, they should be treated as a separate unit of accounting from the laser and software package. Management points to ASC 605-25-5, that states: "In an arrangement with multiple deliverables, the delivered item or items shall be considered a separate unit of accounting if the delivered item or items have value to the customer on a standalone basis," in order to justify their defined units of accounting.

\section{Revenue Recognition}

Management cites that upon delivery of the laser and software, their obligations are met and the revenue can be recognized, which is in agreement with ASC 605-25-1. Management further notes that as the majority of work related to the maintenance plan deals with initial set-up of the laser, the revenue from the maintenance plan can be recognized immediately. Any maintenance work remaining would deal with the software, which management considers minimal at best. In addition, management cites that although they offer monthly updates they cannot value future software updates and cannot assume at this time that any updates would be important enough to consider recognizing revenue related to the software in the future as opposed to immediately. Management believes that they are applying guidance set forth in ASC 605-25-1, which states that "revenue is not recognized until earned," and that "revenues are considered to have been earned when the entity has substantially accomplished what it must do to be entitled to the benefits represented by the revenues," in order to appropriately recognize revenue related to the sales of the Safeco Eye Laser and maintenance plans. 


\section{Your Task}

As a reminder, management has recognized revenue in the amount of $\$ 15,017,940$ as of December 31, 20x2 for the sale of the Safeco Eye Laser and related maintenance plans. Based on the information given, and the applicable guidance provided, please provide your assessment of management's position by entering how much revenue should be recognized for the sales of the Safeco Eye Laser and the related components prior to receiving information from your internal firm revenue recognition expert.

I believe that the following amount of revenue should be recognized as of December 31, 20x 2 by Tintype for the sales of its Safeco Eye Lasers and the related components.

\section{$\$$}

Tintype, Inc.

Reference: w/p 3000-2

\section{Safeco Eye Lasers Revenue Recognition Assessment For the Year Ended December 31, 20x2}

Please document how you arrived at your assessment of management's position and how much revenue Tintype should recognize for the sales of the Safeco Eye Laser and the related components. 
Please respond to the following questions.

1) I think my revenue recognition estimate is accurate.

$\begin{array}{ll}\text { 1---1 fully } & \text { I fully } \\ \text { disagree } & \text { agree }\end{array}$

2) I am very certain about the accuracy of my revenue recognition judgment.

\begin{tabular}{|c|}
\hline $\begin{array}{l}\text { I fully } \\
\text { disagree }\end{array}$ \\
\hline
\end{tabular}

3) I am sure I am performing well on this revenue recognition task.

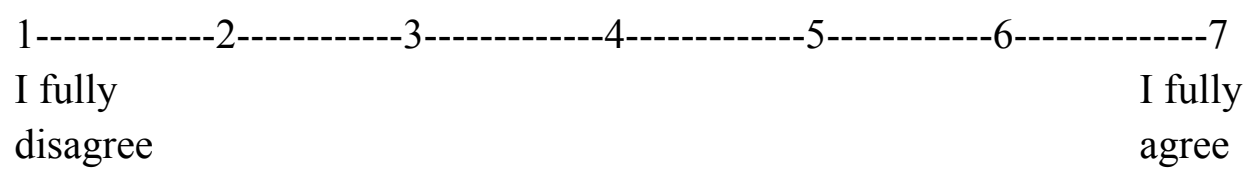

4) I felt that I had adequate time to complete the required task.

1-------------2------------3-------------4-------------5-----------'6--------------7

$\begin{array}{ll}\text { I fully } & \text { I fully } \\ \text { disagree } & \text { agree }\end{array}$

5) Based on the case information provided, are you going to receive any recommendations from a revenue recognition subject matter expert regarding the revenue currently recognized by Tintype?

Yes $\quad$ No 
6) Recall that subject matter experts will be utilized for complex issues such as revenue recognition. How likely would you use a revenue recognition subject matter expert's advice to assist in the previous task?

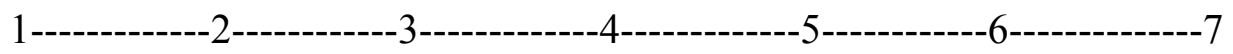

Not likely

Very likely

Please scroll to the next page to perform the second revenue recognition task. 


\section{Revenue Recognition Issue - Continued}

As previously noted, due to the complexity of the issue your engagement partner has decided to engage an internal firm revenue recognition subject matter expert to provide assistance to the team. You provided the subject matter expert the same information you previously read concerning the revenue recognition issue and management's position.

As per AU-C 300 Planning and Supervision, when subject matter experts provide assistance to an engagement team they are treated as part of the engagement team. AU-C 300 requires the review of their work to be the same as the supervisory and review standards for other engagement team members. Therefore, as you are part of the core audit team, you have the responsibility to ensure that the information provided by the subject matter expert is appropriate and includes all the relevant facts of the issue at hand as you understand them. As such, professional standards require that you assess the recommendation provided by the subject matter expert. You should utilize your own judgment based on all the information provided to make your assessment regarding the revenue recognition issue.

The memo received from the subject matter expert regarding the Safeco Eye Laser revenue recognition is provided below.

As a reminder, planning materiality has been set at $\$ 594,000$. Please note that the audit manager has assessed a budget of no more than 35 minutes in total to complete this task and this sub-part task is allotted 15 of those 35 minutes. You are able to go over budget, however as with typical engagements you are expected to meet the budget provided.

\section{MEMO}

To: Tintype, Inc Engagement Team

From: Chris Moore, Revenue Recognition Subject Matter Expert Team manager

Subject: Safeco Eye Laser and related maintenance plans revenue recognition Date: February 20, 20x3

This memo is to respond to the request made by the Tintype, Inc engagement team to review management's revenue recognition policies regarding the Safeco Eye Laser and related maintenance plans. It is the audit team's responsibility to assess our understanding of management's facts and position. Based on our discussions with the Tintype, Inc. engagement team we understand management's facts and position on the following:

- There are three components related to the Safeco Eye Laser. These components include (1) the Safeco Eye Laser hardware, (2) the software package, and (3) the separately sold 
maintenance plan. Specifically related to each component identified by management we noted:

- The laser hardware is delivered to the customer's specified site and is installed for the customer. The laser hardware is not sold as a stand-alone product without the embedded software. The stand-alone value per laser is $\$ 35,280$. There is no right of return for sales of the Safeco Eye Laser.

○ The software package was developed by Tintype and there are no substitute software programs that can be used by the laser manufactured or sold by competitors. Software updates are provided for the laser when and if new treatment applications are available. In order to ensure customers are receiving the newest updates for the software, Tintype pushes monthly updates to customers. Twenty-four months of updates are included as part of the initial software package when the laser is purchased. Additional months of updates can be purchased subsequent to the end of the two year period. The software is not licensed to the customer as each laser only works with the embedded software. There is no stand-alone value of the embedded software. The software package is not sold separately. The value of the software package is assessed at $\$ 11,760$.

$\circ$ A two-year separately priced maintenance agreement can also be purchased for the equipment. This plan includes telephone support, repair or replacement of nonconforming parts, software updates, and bug fixes for the software. The maintenance plan sells for $\$ 10,500$ and can only be applied to a particular laser and has never been sold separately.

- Management believes that ASC 605-25 Revenue Recognition: Multiple-Element Arrangements applies to the Safeco Eye Laser sales transactions, due to there being multiple revenue generating activities related to the sales of the Safeco Eye Laser.

- As required by ASC 605-25, management identifies the following separate units of accounting:

- The laser hardware with the software package and

○ The related maintenance plan.

- Management believes that the revenue related to the laser and the software package, as well as the maintenance plan should be recognized immediately. This has resulted in management recognizing $\$ 15,017,940$ of revenue for the sales of the Safeco Eye Laser as of December 31, 20x2.

\section{Analysis}

\section{7) Value of the Elements}

Based on our understanding management and the engagement team had previously come to an agreement on the stand-alone values of the laser hardware, the software package, and the 
maintenance plan. We will be utilizing the values as provided by management and outlined above.

\section{8) Revenue Recognition Guidance To Be Applied}

It is apparent to us that the embedded software does function together with the laser to provide the essential functionality of the laser. This assessment is due to:

e. Tintype has never sold, nor does it offer to sell, the Safeco Eye Laser without the embedded software and

f. The non-software components of the Safeco Eye Laser substantially contributes to the functionality of the product.

As per ASC 985-605-15-4A, guidance in ASC 985-605 does not apply to the following transactions and activities:

c. Arrangements for products or services containing software that is incidental to the products or services as a whole

e. Software components of tangible products that are sold, licensed, or leased with tangible products when the software components and non-software components of the tangible product function together to deliver the tangible product's essential functionality

Based on the guidance, sales of the Safeco Eye Laser would not fall under ASC 985-605. Instead, the revenue recognition for the product sales and related maintenance plan falls under ASC 605-25, Revenue Recognition: Multiple-Element Arrangements. We agree with management's assessment in regards to the applicable guidance.

\section{9) Specified Units of Accounting}

Per ASC 605-25-2, "revenue arrangements with multiple deliverables shall be divided into separate units of accounting if the deliverables in the arrangement meet the criteria in paragraph 605-25-25-5." ASC 605-25-25-5 states:

"In an arrangement with multiple deliverables, the delivered item or items shall be considered a separate unit of accounting if both the following criteria are met:

e. The delivered item or items have value to the customer on a stand-alone basis.

f. If the arrangement includes a general right of return relative to the delivered item, delivery or performance of the undelivered item or items is considered probable and substantially in control of the vendor."

It is our position that, the delivered items have

(1) Value to the customer on a stand-alone basis and

(2) The performance of the undelivered items are considered probable and in control of Tintype, Inc. 
Therefore, the criterion to divide deliverables into separate units of accounting has been met. Furthermore, it is our position that the software package is considered a separate unit of accounting from the laser hardware due to the ability of Tintype to assess a stand-alone value as well as the customers having the option to purchase additional months of updates. As such, the software package is considered to meet ASC 605-25-25-5 (a) as previously stated.

Based on the information, the units of accounting are:

(6) The laser hardware,

(7) The software package, including the updates that are provided on a monthly basis, and

(8) The maintenance support provided by the maintenance agreement.

In this regard, we disagree with management's position on the separate units of accounting. We advise that the revenue from each unit should be recognized separately based on what that unit of accounting is and when the revenue from that unit is earned.

\section{Revenue Recognition}

Based on this analysis, the transaction price in the arrangement would be allocated to each deliverable based on its relative stand-alone selling price, as per ASC 605-25, and recognized in accordance with the applicable guidance within ASC 605-25-1, which states that "revenue is not recognized until earned."

The portion of the transaction price allocated to the Safeco Eye Laser hardware should be recognized upon delivery to the customer. The portion of the transaction price allocated to the software package and maintenance should be recognized when the services are provided to the customer. As the embedded software has no value, the software package value relates to the updates that are provided over a two-year period. In this instance, we disagree with management's position that the maintenance plan revenue should be recognized immediately.

Based on the information provided by the Tintype engagement team we believe a total of $\$ 10,660,545$ revenue should be recognized as of December 31,20x2 for the sales of the Safeco Eye Laser, software package, and the related maintenance plans. Refer to the schedule below for calculations. 


\begin{tabular}{|l|c|c|c|c|}
\hline & $\begin{array}{c}\text { Safeco Eye } \\
\text { Laser }\end{array}$ & $\begin{array}{c}\text { Safeco Eye } \\
\text { Laser Software } \\
\text { Package }\end{array}$ & $\begin{array}{c}\text { Safeco Eye } \\
\text { Laser } \\
\text { Maintenance } \\
\text { Plan }\end{array}$ & Total \\
\hline $\begin{array}{l}\text { Total number } \\
\text { sold on July 1, } \\
\text { 20x2 }\end{array}$ & 261 & 261 & 261 & \\
\hline Value per unit & $\$ 35,280$ & $\$ 11,760$ & $\$ 10,500$ & \\
\hline $\begin{array}{l}\text { Number of } \\
\text { months service } \\
\text { is provided }\end{array}$ & $\mathrm{n} / \mathrm{a}$ & 24 & 24 & \\
\hline $\begin{array}{l}\text { Revenue per } \\
\text { unit sold to be } \\
\text { recognized per } \\
\text { month }\end{array}$ & $\mathrm{n} / \mathrm{a}$ & $\$ 490.00$ & $\$ 437.50$ & \\
\hline $\begin{array}{l}\text { Number of } \\
\text { months service } \\
\text { was used during } \\
\text { 20x2 }\end{array}$ & $\mathrm{n} / \mathrm{a}$ & 6 & 6 & \\
\hline $\begin{array}{l}\text { Total revenue } \\
\text { recognized as of } \\
\text { December 31, } \\
\text { 20x2 }\end{array}$ & $\$ 9,208,080$ & $\$ 767,340$ & $\$ 685,125$ & $\$ 10,660,545$ \\
\hline
\end{tabular}

As a reminder, management has recognized revenue in the amount of $\$ 15,017,940$ as of December 31, 20x2 for the sale of the Safeco Eye Laser and related components.

Prior to receiving the memo from the internal firm revenue recognition subject matter expert group you stated that $\$$ of revenue should be recognized as of December 31, 20x2 by Tintype for the sales of its Safeco Eye Lasers and the related components.

Based on the information given, the applicable guidance provided, and the memo received from the internal firm revenue recognition subject matter expert, please provide the recommendation that you would give to your audit team of how much revenue Tintype should recognize for the sales of the Safeco Eye Laser and the related components. 
I believe that the following amount of revenue should be recognized as of December 31, 20x2 by Tintype for the sales of its Safeco Eye Lasers and the related components.

\section{$\$$}

Please document below how you arrived at your recommendation of how much revenue Tintype should recognize for the sales of the Safeco Eye Laser and the related components. Please also indicate how/if you used the advice provided by the internal firm revenue recognition subject matter expert team.

Reference: w/p 3000-3

Tintype, Inc.

Safeco Eye Lasers Revenue Recognition Assessment

For the Year Ended December 31, 20x2

Please scroll to the next page. 
Please respond to the following questions.

1) If you had the opportunity, what information would you like to provide (either as new information or updated information) to the subject matter expert?

2) If you had the opportunity, what follow-up questions would you ask the subject matter expert?

3) Do you believe that the subject matter expert had a clear understanding of the client specific facts related to the revenue recognition issue?

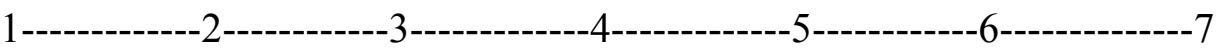

Not a very clear

Clearly understood

understanding all client facts

4) Based on the information you received earlier, I believe that the subject matter expert used all the necessary client specific facts to arrive at their recommendation.

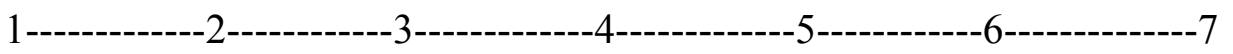

I fully I fully

disagree agree

5) I believe that seeking advice during an engagement suggests a lack of technical expertise.

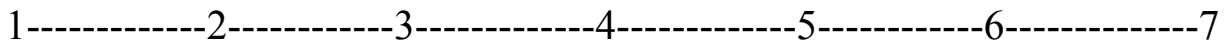

I fully

I fully

disagree

agree 
6) I believe that seeking advice conveys a lack of confidence?

\begin{tabular}{|c|}
\hline $\begin{array}{l}\text { I fully } \\
\text { disagree }\end{array}$ \\
\hline
\end{tabular}

7) I believe that seeking advice negatively affects performance evaluations at the end of the audit engagement.

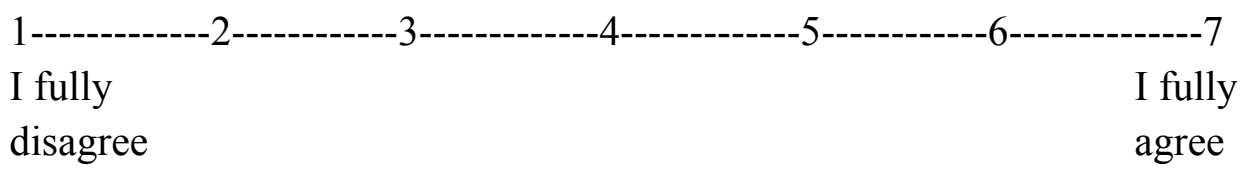


1) Please provide the name of your current employer

2) Please provide your current job title (e.g., senior, manager, etc.)

3) How long have you worked as an auditor?

_ Years _ Months

4) What is your gender?

Female

5) How often do you deal with assessing revenue recognition policies employed by clients?

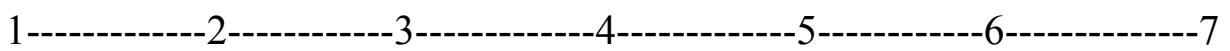

Never All the time

6) How many of your audit engagements have employed the use of internal firm subject matter experts during the most recent financial statement audit?
a. None
b. One
c. Two
d. Three or more
e. If more than three, please specify how many

7) When auditing a company similar to the company in the case study, would an auditor at your rank be responsible to evaluate the advice provided by the subject matter expert to assess if all the appropriate client specific facts were utilized?

Yes

No 


\title{
APPENDIX C
}

\section{IRB Approval Letter}

\author{
girginiaTech \\ MEMORANDUM \\ Office of Research Compliance \\ Institutational Review Board \\ North End Center, Suite 4120, Virginia Tech \\ 300 Turner Street NW \\ Blacksburg. Virginia 24061 \\ 540/231-4606 Fax 540/231-0950 \\ email irb@vtedu \\ website http://www.irb.vt.edu \\ DATE: \\ July 17, 2013 \\ TO: \\ Sudip Bhattacharjee, Nicole S Wright \\ FROM: \\ Virginia Tech Institutional Review Board (FWA00000572, expires April 25, 2018) \\ PROTOCOL TITLE: Auditors' Use of Formal Advice from Internal Firm Subject Matter Experts: The \\ Impact of Advice Quaity and Advice Awareness \\ IRB NUMBER: 13-606 \\ Effective July 17, 2013, the Virginia Tech Institution Review Board (IRB) Chair, David M Moore, \\ approved the New Application request for the above-mentioned research protocol. \\ This approval provides permission to begin the human subject activities outlined in the IRB-approved \\ protocol and supporting documents. \\ Plans to deviate from the approved protocol and/or supporting documents must be submitted to the \\ IRB as an amendment request and approved by the IRB prior to the implementation of any changes, \\ regardless of how minor, except where necessary to eliminate apparent immediate hazards to the \\ events involving risks or harms to human research subjects or others. \\ All investigators (listed above) are required to comply with the researcher requirements outlined at: \\ http://www.irb.vt.edu/pages/responsibilities.htm \\ (Please review responsibilities before the commencement of your research.) \\ PROTOCOL INFORMATION: \\ Approved As: \\ Protocol Approval Date: \\ Protocol Expiration Date: \\ Exempt, under 45 CFR 46.110 category(ies) 2 \\ Continuing Review Due Date ${ }^{\star}$. N/A \\ *Date a Continuing Review application is due to the IRB office if human subject activities covered \\ under this protocol, including data analysis, are to continue beyond the Protocol Expiration Date.

\section{FEDERALLY FUNDED RESEARCH REQUIREMENTS:} \\ Per federal regulations, 45 CFR 46.103(f), the IRB is required to compare all federally funded grant \\ proposals/work statements to the IRB protocol(s) which cover the human research activities included \\ in the proposal / work statement before funds are released. Note that this requirement does not apply \\ to Exempt and Interim IRB protocols, or grants for which VT is not the primary awardee. \\ The table on the following page indicates whether grant proposals are related to this IRB protocol, and \\ which of the listed proposals, if any, have been compared to this IRB protocol, if required. \\ Invent the Future \\ YIRGINIA POLYTECHNIC INSTITUTE AND STATE UNIVERSITY \\ An equal opportunity, affirmative action institution
}

